Leandro Zerbinatti

Extração de Conhecimento de Laudos de Radiologia Torácica Utilizando Técnicas de Processamento Estatístico de Linguagem Natural

São Paulo 
Leandro Zerbinatti

\section{Extração de Conhecimento de Laudos de Radiologia Torácica Utilizando Técnicas de Processamento Estatístico de Linguagem Natural}

Tese apresentada à Escola Politécnica da Universidade de São Paulo para obtenção de título de Doutor em Engenharia.

Área de Concentração: Sistemas Eletrônicos Orientador: Prof. Dr. Lincoln de Assis Moura Jr. 


\section{FICHA CATALOGRÁFICA}

Este exemplar foi revisado e alterado em relação à versão original, sob responsabilidade única do autor e com a anuência de seu orientador.

São Paulo, 11 de maio de 2010.

Assinatura do autor

Assinatura do orientador

Zerbinatti, Leandro

Extração de conhecimento de laudos de radiologia torácica utilizando técnicas de processamento estatísticos de linguagem natural / L. Zerbinatti. -- ed.rev. -- São Paulo, 2010.

$160 \mathrm{p}$.

Tese (Doutorado) - Escola Politécnica da Universidade de São Paulo. Departamento de Engenharia de Telecomunicações e Controle.

1. Informática médica 2. Linguagem natural (Processamento) 3. Representação de conhecimento I.Universidade de São Paulo. Escola Politécnica. Departamento de Engenharia de Telecomunicações e Controle II. t. 


\section{DEDICAÇÃO}

Dedico este trabalho à minha esposa Vivian e ao meu filho Théo, que com amor me oferecem a luz a cada amanhecer, a ternura que me acompanha nas tardes da vida e o conforto das noites em nosso lar. 


\section{AGRADECIMENTOS}

Agradeço eternamente ao Prof. Dr. Lincoln de Assis Moura Jr. pela orientação na elaboração deste estudo e pelos tantos caminhos abertos na minha mente, na vida acadêmica e na carreira profissional.

Agradeço ao pessoal do InCor, especialmente ao Dr. André Castilla e à Dra. Alice Bacic, que além de me fornecer os dados necessários para a realização dessa pesquisa, também me ofereceram valiosas informações sobre o contexto dos dados.

Agradeço ao pessoal da Atech, em especial aos colegas Alberto Yussuke Tateishi e à Leila Mara Faccioli, pela compreensão e força na elaboração deste estudo.

Agradeço a todos os professores que tive, pela paciência e dedicação e que sem eles, eu não seria capaz de chegar a esse momento.

Agradeço ainda os maiores professores de minha vida, meus pais João e Glória, que me ensinaram os valores que carrego comigo até os dias de hoje.

Enfim, agradeço a todos os amigos que sempre estiveram do meu lado e me incentivaram. 


\section{RESUMO}

Este trabalho promove um estudo em informática em saúde no qual se analisam laudos de radiologia torácica através de métodos de processamento estatístico de linguagem natural com o intuito de subsidiar a interoperabilidade entre sistemas de saúde.

Foram utilizados 2000 laudos de radiologia do tórax para a extração de conhecimento identificando-se as palavras, n-gramas e frases que os compõem.

Foi calculado o índice de Zipf e verificou-se que poucas palavras compõem a maioria dos laudos e que a maioria das palavras não tem representatividade estatística

A partir dos termos identificados foi realizada a tradução e a comparação da existência desses em um vocabulário médico padronizado com terminologia internacional, o SNOMEDCT. Os termos que tinham uma relação completa e direta com os termos traduzidos foram incorporados nos termos de referência juntamente com a classe à qual o termo pertence e seu identificador.

Foram selecionados outros 200 laudos de radiologia de tórax para realizar o experimento de rotulação dos termos em relação à referência. A eficiência obtida neste estágio, que é o percentual de rotulação dos laudos, foi de $45,55 \%$.

A partir de então foram incorporados aos termos de referência, sob a classe de conceito de ligação, artigos, preposições e pronomes. É importante ressaltar que esses termos não adicionam conhecimento de saúde ao texto. A eficiência obtida foi de 73,23\%, aumentando significativamente a eficiência obtida anteriormente.

Finalizamos o trabalho com algumas formas de aplicação dos laudos rotulados para a interoperabilidade de sistemas, utilizando para isto ontologias, o HL7 CDA (Clinical Documents Architecture) e o modelo de arquétipos da Fundação OpenEHR.

Palavras-chave: Informática em Saúde, Processamento estatístico de linguagem natural, Representação do conhecimento em saúde 


\begin{abstract}
This work promotes a study in health informatics technology which analyses reports of chest X-ray through statistical natural language processing methods for the purpose of supporting the interoperability between health systems.

Two thousand radiology reports were used for the extraction of knowledge by identifying the words, n-grams and phrases of reports.

Zipf's constant was studied and it was determined that few words make up the majority of the reports and that most of the words do not have statistical significance.

The translation and comparison with exisiting standardized medical vocabulary with international terminology, called SNOMED-CT, was done based on the terms identified. The terms that had a complete and direct correlation with the translated terms were incorporated into the reference terms along with its class and the word identifier.

Another 200 reports of chest x-rays were selected to perform the terms tagging experiment of with respect to the reference. The efficiency obtained, which is the percentage of labeling of the reports, was $45.55 \%$.

Subsequentely, articles, prepositions and pronouns were incorporated into the terms of reference under the linkage concept of class. It is important to note that these terms do not carry health knowledge to the text. Thus, the efficiency ratio was $73.23 \%$, significantly increasing the efficiency obtained previously.

The study was concluded with some forms of application of the reports tagged for system interoperability, using different ontologies, the HL7 CDA (Clinical Documents Architecture) and the archetypes at OpenEHR Fondation.
\end{abstract}

Keywords: Health Informatics, Statistical natural language processing, Health knowledge representation 


\section{LISTA DE TABELAS}

TABELA 1 - QUANTIDADE DE LAUDOS DE RADIOLOGIA TORACICA 61

TABELA 2 - QUANTIDADE DE TOKENS NOS EXPERIMENTOS 70

TABELA 3 - QUANTIDADE DE OCORRÊNCIAS DISTINTAS DO CONJUNTO EXPERIMENTAL

TABELA 4 - AS OCORRÊNCIAS MAIS MAIS FREQUENTES NOS EXPERIMENTOS

TABELA 5 - QUANTIDADE TOTAL DE TOKENS NOS EXPERIMENTOS SEM ARTIGOS, PREPOSIÇÕES E PONTUAÇÕES

TABELA 6 - QUANTIDADE TOTAL DE PALAVRAS NOS EXPERIMENTOS SEM ARTIGOS, PREPOSIÇÕES E PONTUAÇÕES

TABELA 7 - AS 10 PALAVRAS MAIS FREQUENTES NOS EXPERIMENTOS, EXCLUÍNDO-SE ARTIGOS, PREPOSIÇÕES E PONTUAÇÕES

TABELA 8 - QUANTIDADE DE 2-GRAMAS DO CONJUNTO EXPERIMENTAL 80

TABELA 9 - EXEMPLO DA REDUÇÃO DA QUANTIDADE DE N-GRAMAS QUANTO MAIOR O N

TABELA 10 - OS N-GRAMAS MAIS FREQUENTES NO CONJUNTO EXPERIMENTAL

TABELA 11 - QUANTIDADE DE N-GRAMAS FINAL

TABELA 12 - AS DEZ FRASES MAIS FREQUENTES DO CONJUNTO EXPERIMENTAL

TABELA 13 - OS TERMOS REFERENCIADOS PELO SNOMED-CT

TABELA 14 - PERCENTUAL DE TERMOS REFERENCIADOS PELO SNOMED-CT 88 TABELA 15 - MÉDIA DE PALAVRAS POR LAUDO, PALAVRAS ROTULADAS E NÃO ROTULADAS 90

TABELA 16 - EFICÁCIA DE ROTULAÇÃO DE LAUDOS 90

TABELA 17 - MÉDIA DE PALAVRAS POR LAUDO, PALAVRAS ROTULADAS E

NÃO ROTULADAS COM ARTIGOS E PREPOSIÇÕES

TABELA 18 - EFICÁCIA DE ROTULAÇÃO DE LAUDOS COM ARTIGOS E PREPOSIÇÕES 


\section{LISTA DE FIGURAS}

FIGURA 1 - TIPOS DE ESTRUTURAÇÃO DE DOCUMENTOS (ADAPTADO DE CHANG, 2006)

FIGURA 2 - COMPLEXIDADE DOS SISTEMAS

FIGURA 3 - PAÍSES QUE FALAM A LINGUA PORTUGUESA.

FIGURA 4 - REPRESENTAÇÃO DO PARADIGMA SIMBÓLICO E CONEXIONISTA (ADAPTADO DE MINSKY,2006)

FIGURA 5 - EXEMPLO DE REDE SEMÂNTICA 22

FIGURA 6 - O PROBLEMA DA USABILIDADE E REUSABILIDADE 28

FIGURA 7 - IMAGEM DIGITALIZADA DA PRIMEIRA RADIOGRAFIA DA HISTÓRIA, A MÃO DA MULHER DE ROËNTGEN

FIGURA 8 - EQUIPAMENTO DE RAIO X DA GE, MODELO MPX 32

FIGURA 9 - PROCESSO DE TOKENIZAÇÃO DE FRASES 38

FIGURA 10 - PROCESSO DE COMPOSIÇÃO DE N-GRAMAS 42

FIGURA 11 - AS ÁREAS DO CONSELHO EXECUTIVO DE INFORMÁTICA EM

SAÚDE NA ISO/TC 215

FIGURA 12 - AS ÁREAS DE ABRANGÊNCIA DOS ARQUÉTIPOS DO OPEN EHR 52 FIGURA 13 - A ÁRVORE DOS ARQUÉTIPOS DO OPEN EHR 53

FIGURA 14 - OS MÉTODOS ADOTADOS NA SOLUÇÃO DO TRABALHO 65

FIGURA 15 - FREQUÊNCIA DE OCORRÊNCIA DOS TOKENS DA PRIMEIRA SEQUENCIA DE EXPERIMENTOS

FIGURA 16 - FREQUÊNCIA DE OCORRÊNCIA DOS TOKENS DA SEGUNDA SEQUENCIA DE EXPERIMENTOS

FIGURA 17 - FREQUENCIA DE OCORRENCIA DE TOKENS NOS DOIS MIL LAUDOS

FIGURA 18 - DISTRIBUIÇÃO DO ÍNDICE DE ZIPF NO PRIMEIRO CONJUNTO EXPERIMENTAL

FIGURA 19 - DISTRIBUIÇÃO DO ÍNDICE DA LEI DE ZIPF NO SEGUNDO CONJUNTO EXPERIMENTAL

FIGURA 20 - O ÍNDICE DE ZIPF NOS 2000 LAUDOS 80

FIGURA 21 - FREQUÊNCIA DAS FRASES

FIGURA 22 - EFICÁCIA NA ROTULAÇÃO DE LAUDOS 90

FIGURA 23 - EFICÁCIA NA ROTULAÇÃO DE LAUDOS COM REFERENCIAS COM ARTIGOS E PREPOSIÇÕES

FIGURA 24 - ONTOLOGIA BASEADA NO SNOMED-CT E REPRESENTADA NO PROTĖGÈ

FIGURA 25 - ONTOLOGIA BASEADA NO SNOMED-CT E REPRESENTADA NO PROTĖGÉ 
FIGURA 26 - REPRESENTAÇÃO DAS INSTÂNCIAS DAS CLASSES DO LAUDO EXEMPLO 


\section{SUMÁRIO}

1. INTRODUÇÃO 13

1.1 Organização do Trabalho 18

2. REVISÃO DA LITERATURA 19

2.1 Conhecimento e representação do conhecimento 19

2.1.1 Ontologias 24

2.2 A Radiologia 30

2.2.1 Os componentes do aparelho do raio $X \quad 31$

2.2.2 O processo de geração de laudos de radiologia 33

2.3 Processamento Estatístico de Linguagem Natural 35

2.3.1 Corpus 36

2.3.2 Tokens e Palavras 38

2.3.3 N-gramas 41

2.3.4 A semântica das sentenças 42

3. PADRÕES DA INFORMÁTICA EM SAÚDE 44

3.1.1 SNOMED-CT 46

3.1.2 - Arquitetura de Documentos Clínicos 49

3.1.3 Arquétipos $\quad 51$

4. UMA VISÃO HISTÓRICA DA REVISÃO DA LITERATURA 54

5. OBJETIVOS DESTE TRABALHO 60

5.1 Contribuição da pesquisa $\quad 60$

6. MATERIAIS E MÉTODOS 61

$\begin{array}{ll}6.1 \text { Materiais } & 61\end{array}$

6.1.1 Os Laudos de Radiologia Torácica 61

6.1.2 Ferramentas 63

6.2 Métodos 64

6.2.1 Processamento Estatístico de Linguagem Natural 65

6.2.2 Geração de Vocabulário em Português 68

6.2.3 Rotulador de Laudos 68

6.2.4 Cálculo de Precisão e Recuperação 69

7. RESULTADOS 70

7.1 A Extração do Conhecimento 70

$\begin{array}{ll}7.1 .1 \text { Os tokens e as palavras } & 70\end{array}$

$\begin{array}{ll}7.1 .2 & \mathrm{O} \text { Índice de Zipf } \\ 7 & 78\end{array}$

$\begin{array}{ll}7.1 .3 \text { Os n-gramas } & 80\end{array}$

7.1.4 As Frases $\quad 84$

7.2 Geração de vocabulário padrão em Português 86

7.3 Rotulador de Laudos $\quad 88$ 
8. O USO DOS LAUDOS EM VOCABULÁRIO PADRÃO NA INTEROPERABILIDADE DE SISTEMAS. 94

8.1 Seleção do Modelo para Interoperabilidade semântica 94

8.1.1 Ontologias 96

8.1.2 HL7 / Clinical Document Architecture 98

8.1.3 Arquétipos $\quad 99$

9. DISCUSSÃO E ANÁLISE DOS RESULTADOS 100

10. CONCLUSÃO 104

11. REFERÊNCIAS BIBLIOGRÁFICAS 108

APÊNDICE A - PALAVRAS 115

APÊNDICE B - NGRAMAS $\quad 124$

APÊNDICE C - FRASES $\quad 130$

APÊNDICE D - TERMOS EM PORTUGUÊS COM CLASSES SNOMED E IDENTIFICADORES 


\section{INTRODUÇÃO}

Conhecimento é definido pelo dicionário Oxford de diversas formas. Entre elas estão: (i) competências e as competências adquiridas por uma pessoa através da experiência ou educação, o conhecimento teórico ou prático de um tema, (ii) o que é conhecido em uma determinada área (iii) a consciência ou familiaridade adquirida pela experiência de um fato ou situação.

Conhecimento envolve processos complexos como a percepção, aprendizagem, comunicação, associação e raciocínio.

O conhecimento na área da saúde não poderia ser diferente. Ele é formado de práticas educacionais e é influenciado pela experiência prática da função. Como exemplo, podemos citar o conhecimento de um profissional da saúde que ao observar a imagem de um determinado órgão nela reconhece alguma anomalia. Este conhecimento depende de experiência e prática.

Representar conhecimento é necessário para possibilitar seu armazenamento, recuperação e compartilhamento. Pode-se definir a representação do conhecimento como "um conjunto de convenções sintáticas e semânticas que fazem com que seja possível descrever coisas". (Bench-Capon, 1990)

De forma ampla, a representação do conhecimento apresenta de maneira correta o domínio do conhecimento e as tarefas para que este conhecimento possa ser utilizado, por humanos ou equipamentos.

Os profissionais da área da saúde, quando elaboram laudos, normalmente representam este conhecimento em linguagem natural, seja em papel ou utilizando equipamentos eletrônicos computacionais para este registro, que deve ser inteligível e recuperável.

Tradicionalmente os registros na área de saúde são efetuados em papel, porém, no Brasil, uma ação da Sociedade Brasileira de Informática em Saúde - SBIS e o Conselho Federal de Medicina - CFM, tem buscado promover um processo de certificação para o uso de sistema de registro eletrônico de saúde, com a possibilidade de abandono dos registros em papel.

Uma vez regulamentados, os registros que hoje se encontram no papel poderão ser legalmente incorporados em sistemas eletrônicos, prescindindo do registro em papel. 
O registro das informações de saúde é freqüentemente realizado utilizando texto livre, já que não há um amplo uso de sistemas capazes de coletar a informação clínica de maneira estruturada, apesar do esforço realizado pela comunidade internacional de informática em saúde ao investir no desenvolvimento de padrões, modelos e sistemas que façam tal captura de forma estruturada, no ponto de cuidado.

Profissionais e organizações de saúde com freqüência usam diferentes termos para representar o mesmo conceito. Por exemplo, termos como "tumor hepático" e "hepatoma" podem ou não representar a mesma entidade nosológica, porém o texto que os descreve é diferente para cada conceito, do ponto de vista de um sistema computacional.

Os textos podem apresentar níveis de estruturação ou podem ser totalmente livres de estruturação. Uma forma de identificar o nível de estruturação é analisar a forma pela qual a informação é apresentada dentro do texto. (Honorato, 2008)

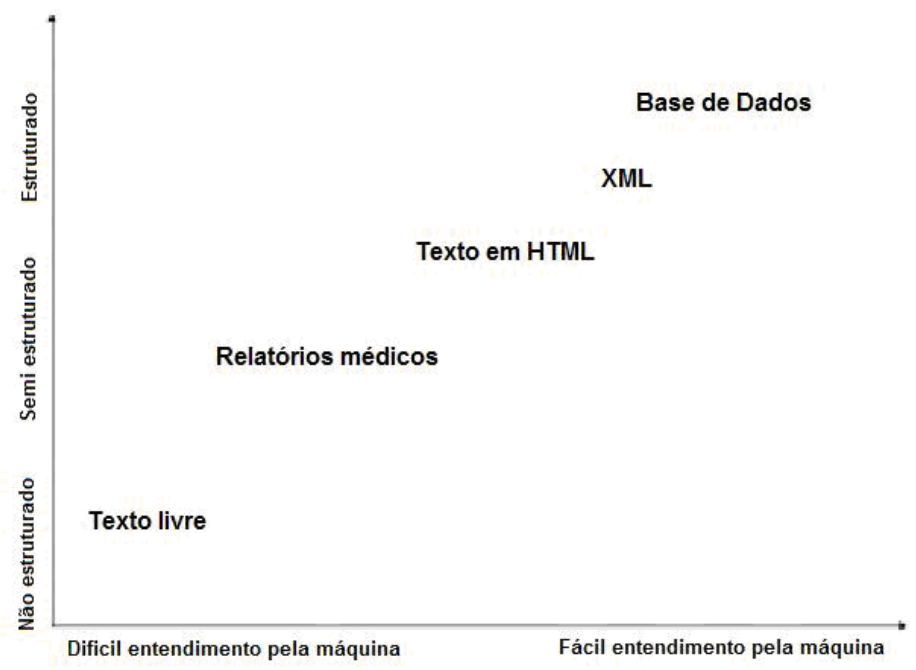

FIGURA 1 - TIPOS DE ESTRUTURAÇÃO DE DOCUMENTOS (ADAPTADO DE CHANG, 2006)

Como observado na figura 1, alguns documentos apresentam níveis de estruturação e isto influi diretamente na facilidade de sua incorporação em sistemas computacionais.

Quanto mais desestruturados são os documentos, mais difícil de transformá-los em artefatos passíveis de processamento computacional. (Chang, et al. 2006)

Para editar os laudos médicos, a ferramenta normalmente utilizada para a escrita são os processadores de texto, através da qual o profissional da saúde indica as técnicas, achados, observações e avaliação ou conclusão sobre um determinado procedimento clínico. É 
importante mencionar que podem existir "frases feitas" e lembrar que existem sistemas de prontuário eletrônico ou registro eletrônico de saúde que buscam captar a informação clínica de forma estruturada. Entretanto em muitas situações prevalece o texto livre.

A identificação de padrões implícitos nos registros realizados em texto livre e a extração de conhecimento semântico podem beneficiar a tomada de decisão médica auxiliando o profissional da saúde na extração de conhecimentos escritos nos laudos.

As transformações de informações médicas apresentam alguns desafios como a disponibilidade de laudos e a confidencialidade dos registros, a expressividade, formatos heterogêneos, abreviações de textos, eventos raros, erros de ortografia e falta de um conjunto de padronização de domínio. (Honorato, 2008)

Existe também a necessidade essencial de intercâmbio de informação clínica de forma consistente entre os diferentes usuários da informação, em benefício do paciente e do sistema de saúde. Por exemplo, profissionais da saúde, operadoras de planos de saúde, pesquisadores e outros usuários autorizados podem e devem ter acesso à informação. A habilidade de trocar informação sem perda de significado é chamada de interoperabilidade semântica de sistemas.

Caso requisitos de interoperabilidade semântica não sejam atendidos, cada um dos diferentes usuários das informações de saúde elabora e implanta seus sistemas, não promovendo troca de informações. Com isto criam-se nichos de coleta de dados que simplesmente não podem ser reutilizados por ausência de significado.

A interoperabilidade semântica compreende o âmbito do conhecimento, das informações ou dados. Sem a troca de informações, pode haver redundância de soluções ou lacunas de dados que os sistemas não contemplem e que são estritamente necessários, seja para fins clínicos, financeiros ou administrativos.

$\mathrm{Na}$ troca de conhecimento uma semântica que possa ser utilizada por vários usuários é necessária para que, mesmo que os clínicos descrevam de maneira diferente o mesmo conhecimento, este seja traduzido para um conhecimento comum e compartilhado entre os sistemas conectados.

Para que isso seja possível, é necessário que haja a padronização em diversos pontos de coleta e armazenamento de dados das redes de atendimento dos serviços de saúde.

Padrões terminológicos devem ser adotados em várias fases do desenvolvimento de sistemas de informação em saúde, partindo da captura dos dados do processo de atendimento clínico, à descrição do caso através de linguagem médica, à padronização que 
utiliza os conceitos sistêmicos e padrões como o SNOMED, à classificação utilizando a CID10 e à possibilidade de utilização de classificações estatísticas padronizadas e, finalmente, à classificação do registro do atendimento ao paciente, possibilitando o uso secundário das informações geradas.

Notoriamente, os sistemas para atendimento à área de saúde são críticos. Um sistema para ser classificado como crítico é tal que uma falha pode resultar em morte ou em lesões graves à pessoas, perda ou danos graves ao equipamento ou, ainda, dano ambiental.

A engenharia de software para atender aos sistemas críticos é particularmente difícil e alguns aspectos devem ser analisados para atender a este tipo de sistema. Estes aspectos incluem a engenharia de processos e a gestão, as ferramentas e o ambiente para o desenvolvimento e a adoção dos requisitos legais dos órgãos reguladores. A figura 2 representa esquematicamente a classificação de sistemas baseada na complexidade técnica e gerencial.

No quadrante composto por sistemas de alta complexidade técnica e alta complexidade gerencial estão localizados os sistemas para organizações de larga escala, que tipicamente identificam os sistemas para a área da saúde pública.

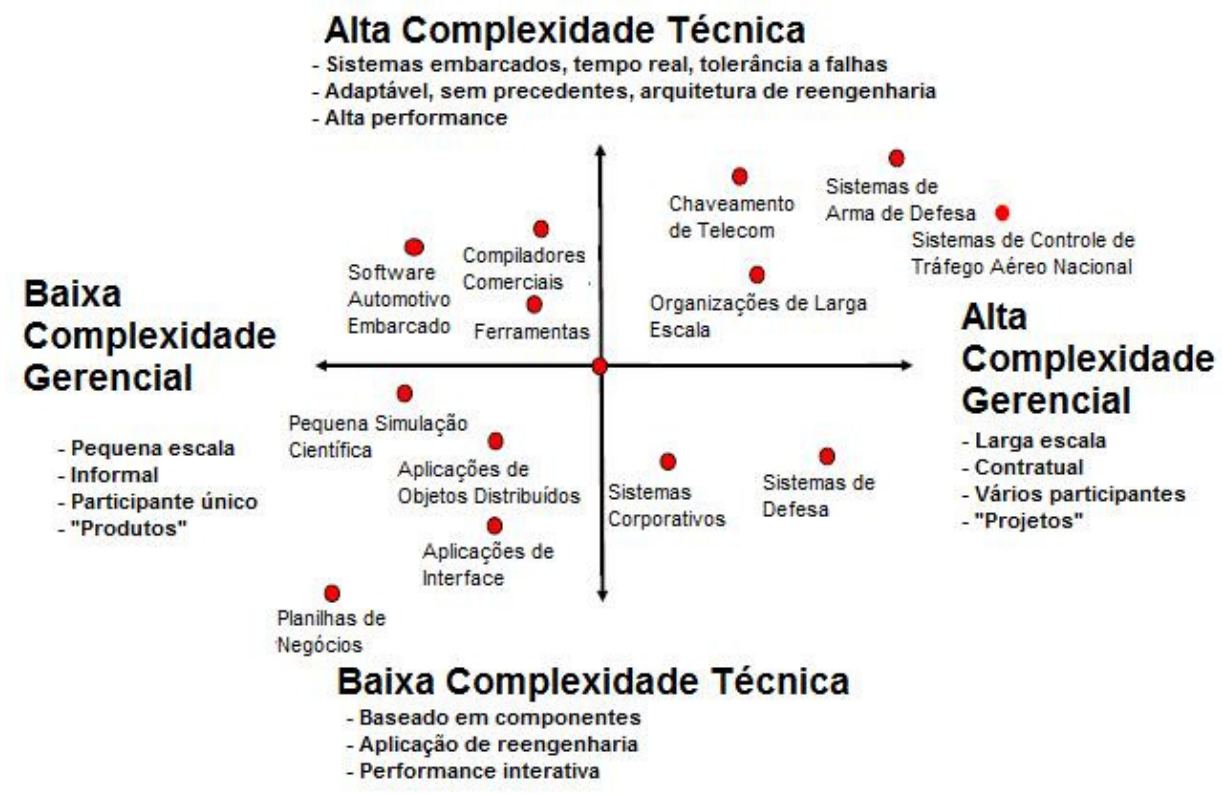

FIGURA 2 - COMPLEXIDADE DOS SISTEMAS 
Outro aspecto importante nesse estudo é a linguagem natural utilizada para a representação do conhecimento. Existem várias línguas faladas no mundo. Este fato decorre das explorações de terras, imigrações dos povos e relações comerciais entre os países.

Em números absolutos, o inglês não é a língua mais falada no mundo, mas aquela mais usada comercialmente.

Em números de falantes nativos, o ranking das línguas segundo o livro "The Etnologue languages of the world", de 2005 é: (Raymond, et al., 2005)

$1^{\circ}$ - Chinês $(1.213 .000,00)$;

$2^{\circ}$ - Espanhol (329.000.000);

$3^{\circ}$ - Inglês (328.000.000);

4ํㅡ - Árabe (221.000.000);

$5^{\circ}$ - Hindi (182.000.000);

6ำ - Bengali (181.000.000);

$7^{0}$ - Português (178.000.000).

Segundo informações da Organização Mundial de Saúde em seu projeto denominado ePORTUGUESe, que tem a função de "fortalecer a colaboração entre países de língua portuguesa na área da informação e capacitação da saúde" a língua portuguesa é a sexta língua mais falada no mundo. "O português tem mais de duzentos e cinqüenta milhões de pessoas distribuídas por oito países em quatro continentes" conforme demonstrado na Figura 3.

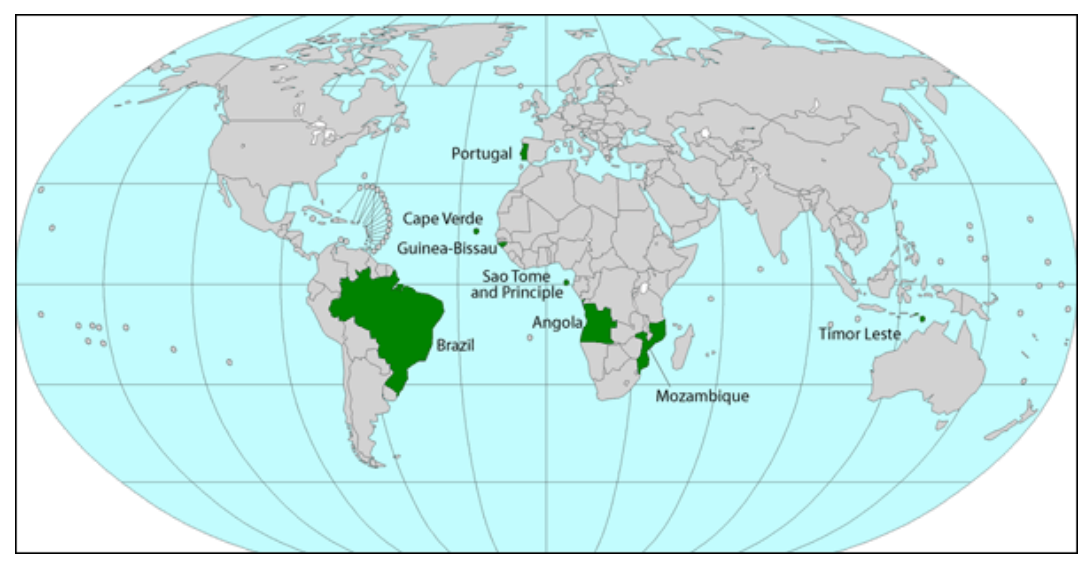

FIGURA 3 - PAÍSES QUE FALAM A LINGUA PORTUGUESA. 
A Figura 3 e o projeto ePORTUGUESe evidenciam que o português é a lingua mais falada ao sul do equador.

Portanto o estudo de métodos de processamento de linguagem natural em língua portuguesa é uma área de aplicação que merece ser explorada e desenvolvida, para dar suporte às aplicações de sistemas de informação em saúde em nossa língua.

\subsection{Organização do Trabalho}

Este trabalho é organizado em capítulos, distribuídos da seguinte forma.

- Capítulo 2: Revisão da Literatura abordando o conhecimento e representação do conhecimento, a radiologia o processamento estatístico de linguagem natural e os padrões na área de informática na saúde.

- Capítulo 3: Os Padrões da Informática em Saúde.

-Capítulo 4 - Uma Visão Histórica da Revisão da Literatura

-Capítulo 5 - O objetivo do trabalho.

- Capítulo 6: Os Materiais e Métodos utilizados abrangendo o processamento estatístico de linguagem natural, o classificador SNOMED-CT, o classificador de laudos, e o classificador de modelo para interoperabilidade semântica.

- Capítulo 7: Resultados obtidos nos experimentos.

- Capítulo 8: O uso dos vocabulários padrão na interoperabilidade dos sistemas

- Capítulo 9: As discussões sobre os resultados obtidos e sobre o trabalho

- Capítulo 10: As conclusões e a continuidade do trabalho.

- Capítulo 11: Referências bibliográficas 


\section{REVISÃO DA LITERATURA}

Apresentamos, na revisão da literatura, um levantamento dos temas relacionados ao conhecimento e a representação do conhecimento, radiologia, processamento estatístico de linguagem natural, padrões de interoperabilidade e um estudo histórico relacionando estes assuntos

\subsection{Conhecimento e representação do conhecimento}

Todo o tempo, nós seres humanos podemos imaginar coisas e situações. Ouvimos palavras e frases dentro de nossas mentes. Visualizamos situações que ainda não existem e exploraramos imagens prevendo os efeitos de possíveis ações. Muito da nossa capacidade humana vem da possibilidade de manipularmos representações mentais de objetos, eventos e conceitos (Minsky, 2006). Com essa capacidade, podemos utilizar objetos físicos para representar conhecimento. Isto ocorre, por exemplo, quando utilizamos um mapa para nos guiar em uma cidade ou, ainda, quando utilizamos palavras para descrever o caminho entre as ruas e os sentidos a percorrer nesse mapa, ou também, quando identificamos características ao olhar e analisar uma imagem radiográfica.

Para responder questões sobre um evento passado, usamos aquilo que chamamos de memória. A memória é um registro realizado no momento de ocorrência de um evento prévio. Não é possível armazenar o evento em si, nós somente podemos fazer registros sobre alguns objetos, idéias e relações do evento (Minsky, 2006).

Quando o médico elabora um laudo de radiologia torácica, ele reconhece alguns padrões de imagens, presentes em uma imagem radiográfica. Estes padrões são recordados ou inferidos através de conhecimentos obtidos por meio da formação acadêmica formal, ou experiencial, que é baseado na sua atuação profissional. Em outras palavras o clínico reconhece um padrão em grande parte por já o haver experenciado antes.

Utilizamos vários mecanismos para representar um evento, como, por exemplo, a descrição verbal sobre ele, um estímulo visual sobre uma cena, analogias com eventos semelhantes, e predições sobre eventos ocorridos no passado, entre outros (Minsky, 2006).

Profissionais da saúde normalmente registram os laudos de radiologia para que outro profissional avalie o resultado do procedimento radiológico e tome as decisões necessárias. 
$\mathrm{Na}$ troca de experiências entre profissionais da saúde ou ainda a passagem de conhecimento entre professores e alunos nas universidade utiliza-se, frequentemente, a descrição verbal para explanar sobre um evento.

Os livros são referências que homogenizam os conhecimentos de experiências adquiridas nas residências ou práticas médicas e estes são em grande maioria registrados utilizando imagens e linguagem natural.

Nós utilizamos diferentes formas de pensar sobre o mesmo evento. Utilizamos explicações verbais, manipulando diagramas mentais, visualizando as expressões faciais e gestos das pessoas envolvidas. Experiências práticas são importantes para consolidar essas várias formas de informação que nos embasa a tomada de decisões (Minsky, 2006).

Os seres humanos são os únicos animais capazes de tratar idéias como se fossem coisas, ou conceituar (Minsky, 2006).

Temos a capacidade de inventar novos conceitos e os colocar em uso. Representamos novas idéias em formas estruturais que instalamos em redes do nosso cérebro. Um pequeno fragmento de conhecimento não tem sentido, a menos que faça parte de uma estrutura mais vasta e que tenha ligações com outras partes de nossa rede de conhecimentos, não importando a forma através da qual estes links estão conectados (Minsky, 2006).

Essa é uma das bases deste estudo. Se analisarmos somente uma palavra dispersa em um documento, ela possui um conhecimento restrito à sua semântica. Quando ela é interligada com outras, em locuções ou frases, então um conhecimento mais amplo se estabelece. Ou ainda, quando uma parte do conhecimento é representado em um arquétipo, ele somente faz sentido se interligado na totalidade do conhecimento sobre a saúde de um indivíduo.

A linguagem é um dos principais meios de manifestação da inteligência humana. É através dela que expressamos necessidades básicas, aspirações, técnicas e tantas outras formas de inteligência (Bird, et al., 2005).

A linguagem é uma das formas mais naturais para representar formalmente o conhecimento. Para isto utilizamos os símbolos alfa-numéricos compondo palavras e sentenças de forma a expressar, de forma livre, o conhecimento sobre determinada área de domínio.

Um dos componentes centrais de uma base de conhecimento é um conjunto de sentenças, expressas em uma linguagem, chamada de linguagem de representação do conhecimento e e que representa algum relato sobre o mundo (Russel, et al., 2004). 
Essas sentenças são expressas de acordo com a sintaxe da linguagem de representação, a semântica da linguagem, que define o significado das sentenças.

Dentre algumas linguagens de representação de conhecimento utilizando a lógica tradicional, podemos citar a lógica proposicional, a lógica de primeira ordem, teoria da probabilidade e lógica Fuzzy (Russel, et al., 2004).

Pode parecer óbvio que os seres humanos manipulem símbolos, mas até por volta de 1990, pesquisadores da linha conexionista questionavam se a manipulação de símbolos tinha qualquer função explicativa real em modelos detalhados de cognição. Essa pergunta permanece sem uma resposta definitiva, mas a visão atual é que as abordagens conexionista e simbólica são complementares, não concorrentes (Russel, et al., 2004).

Sistemas conexionistas têm muitas aplicações práticas, pois eles podem ser desenvolvidos para aprender a reconhecer tipos diversos de padrões, sem a necessidade de uma pessoa para programá-los (Minsky, 2006). Porém um dos problemas claros da representação conexionista é a dificuldade para seres humanos visualizarem a semântica que carregam os nós e os símbolos numéricos e a quantificação destes valores, ou seja, de forma geral, não é possível explicar o raciocínio incorporado em uma rede conexionista. Em uma representação simbólica, a semântica parece mais natural e abrangeria um número maior de indivíduos, se o objetivo fosse repassar este conhecimento a outros grupos.

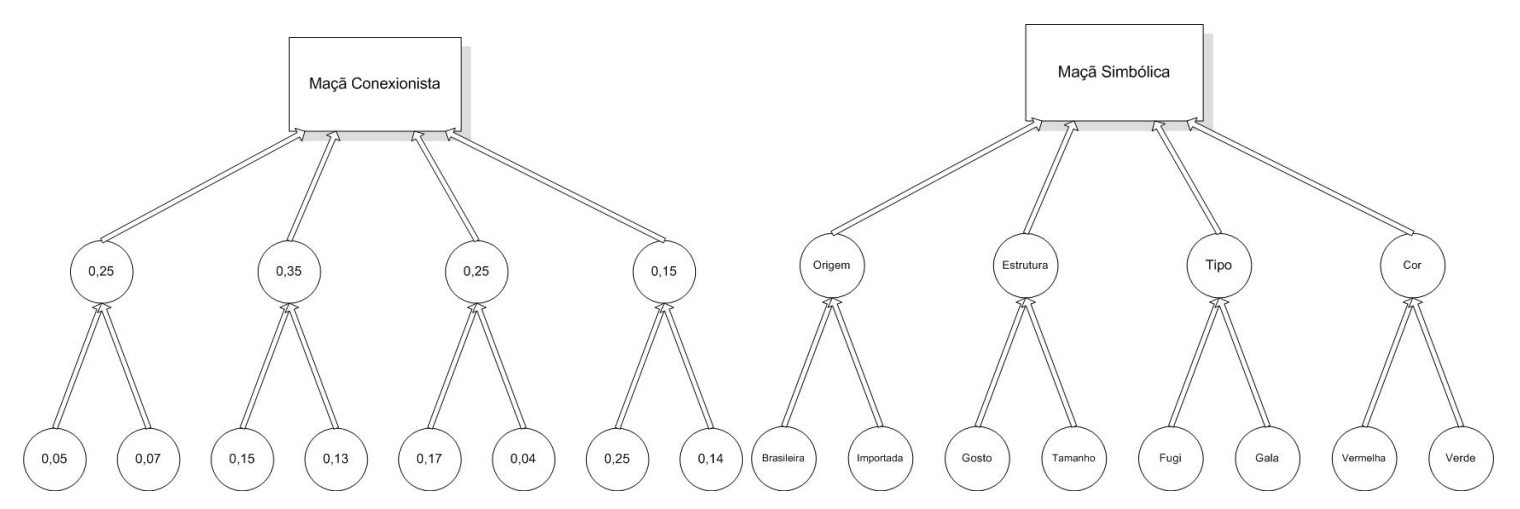

FIGURA 4 - REPRESENTAÇÃO DO PARADIGMA SIMBÓLICO E CONEXIONISTA (ADAPTADO DE MINSKY,2006) 
A Figura 4 representa uma maçã em um mapa de forma conexionista e na forma simbólica. Note que, na representação conexionista, o conhecimento fica disperso em valores que ponderam a influência de cada nó, mas não fica intuitivo o significado de cada nó. Já na abordagem simbólica, existem nós de interligação entre esses nós. Cada elemento dessa rede recebe conceitos representados através de palavras.

Utilizando o paradigma de representação simbólica podemos utilizar outras formas, como por exemplo, as redes semânticas, as representações ontológicas, e as representações lógicas.

Existem muitas variantes de representação de redes semânticas, mas todas têm a capacidade de representar objetos individuais, categorias de objetos e relações entre objetos. Uma notação gráfica típica exibe nomes de objetos ou categorias em elipses ou retângulos e os conecta por meio de arcos rotulados (Russel, et al., 2004).

Exemplificamos uma rede semântica na Figura 5.

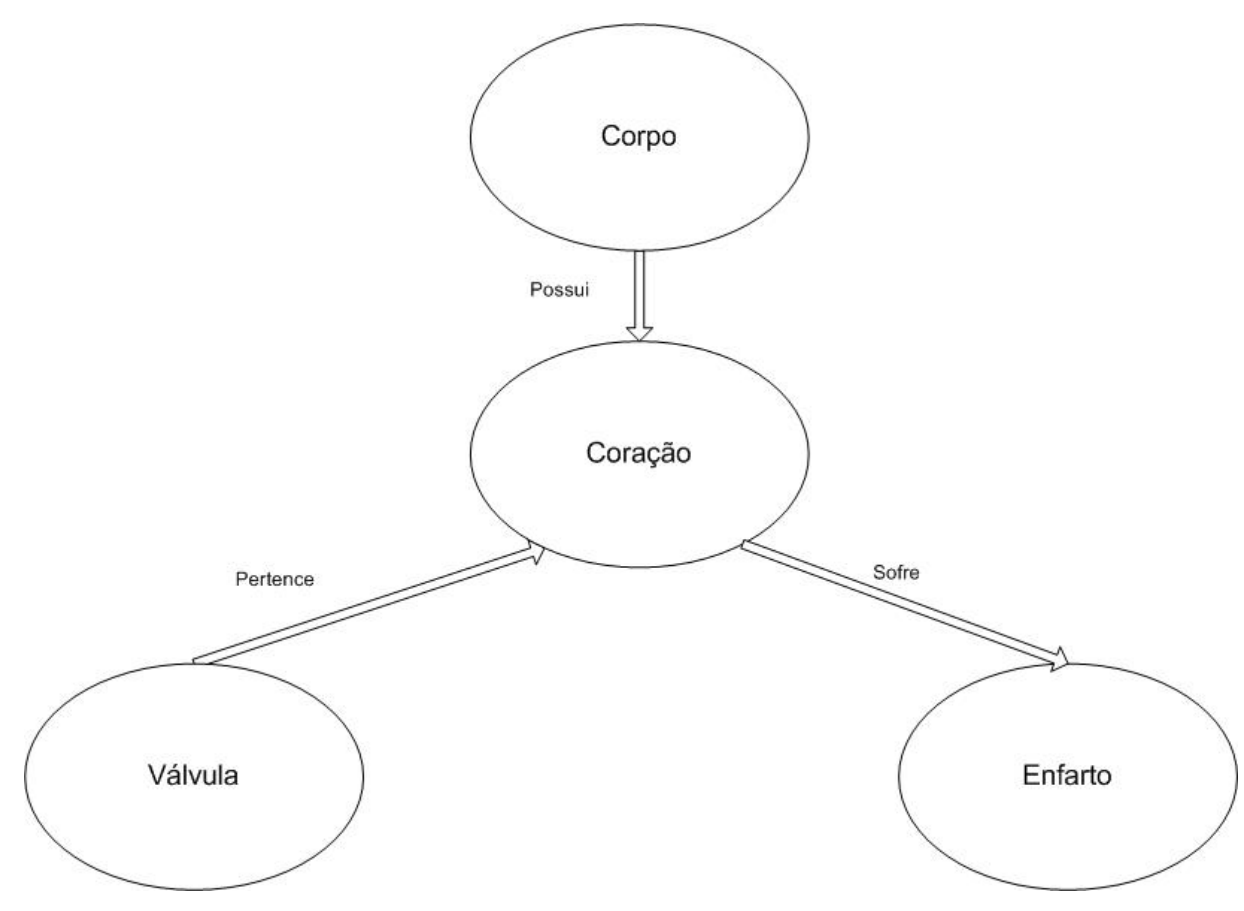

FIGURA 5 - EXEMPLO DE REDE SEMÂNTICA 
As redes semânticas têm raízes no esforço de desenvolvimento de sistemas para entendimento de linguagem natural, como entendimento de simples histórias, e foram usadas para representar, de alguma forma, o entendimento humano (Bench-Capon, 1990).

O estudo da lingüística tenta solucionar problemas relacionados à sintaxe e a semântica.

A sintaxe é a combinação de símbolos da linguagem utilizada.

A semântica é o estudo do significado destes símbolos e o entendimento da intenção do uso destes símbolos.

O estudo da semântica se preocupa com o significado das palavras e as redes semânticas fornecem uma descrição relacionando os símbolos em uma rede de conceitos (BenchCapon, 1990).

A principal idéia por trás das redes semânticas é que o significado de um conceito vem do modo como ele é conectado a outros conceitos. Em uma rede semântica, as informações são representadas como um conjunto de nós conectados entre si através de um conjunto de arcos marcados, que representam relações entre os nós (Rich, et al., 1993).

Outra explicação da rede semântica é que ela é um grafo com nós interligados por arcos, onde tanto os nós quanto os arcos recebem uma descrição. Nos nós são descritos os conceitos, denotados através de palavras na língua corrente utilizada, e nos arcos o relacionamento entre estes conceitos (Bench-Capon, 1990).

A representação Ontológica tem a ontologia como sua unidade principal. O termo Ontologia tem origem no grego "ontos", ser, e "logos", palavras. O termo original é a palavra aristotélica "categoria" que pode ser utilizada para classificar algo. Aristóteles propôs categorias para classificar entidades e introduziu o termo "differentia" para distinguir espécies diferentes da mesma categoria (Almeida, et al., 2003).

O termo Ontologia foi utilizado em 1613 por Rudolf Gockel e Jacob Lorhard, aparentemente de maneira independente. De acordo com o Oxford English Dictionary, o primeiro registro do uso em inglês desta palavra data do ano de 1721 (Welty, et al., 2001).

O termo Ontologia ganhou expressão nas áreas de Inteligência Artificial, Computação Lingüística e Teoria de Banco de Dados, em áreas de pesquisa de Engenharia do Conhecimento, Representação do Conhecimento, Análise Orientada a Objetos e Desenho de Sistemas Baseados em Agentes (Casare, 2005).

Guarino e Giaretta propuseram que a palavra Ontologia se refira aos sentidos de Filosofia e Engenharia do Conhecimento (Gómez-Pérez, et al., 2005). 
Elaborar ontologias é definir categorias para os objetos e conceitos que existem em um mesmo domínio. Ontologia é um "catálogo de tipos de coisas" em que se supõe existir um domínio, na perspectiva de uma pessoa que usa uma determinada linguagem (Almeida, et al., 2003).

A conceitualização consiste em definir os axiomas que restringem e limitam a interpretação de uma entidade, além de descrever entidades em linguagem natural. Dessa forma, uma ontologia associa o nome de uma entidade com uma descrição em linguagem natural do significado desse nome, restringindo e limitando essa definição por meio de axiomas formais, resultando em uma sentença de uma teoria lógica (Casare, 2005).

Uma lógica é caracterizada por seus compromissos epistemológicos que são os estados possíveis do conhecimento permitidos em cada declaração. Uma declaração pode ter apenas três estados: verdadeiro, falso ou desconhecido, no caso de lógicas proposicionais e lógicas de primeira ordem. Em sistemas que utilizam a teoria da probabilidade podem ter graus de crença que variam de zero (0), significando a descrença total, até um (1) (um), crença total (Russel, et al., 2004).

Outras lógicas formais são capazes de lidar com inconsistências e mesmo paraconsistências, quando uma mesma declaração é considerada verdadeira e falsa ao mesmo tempo com distintos graus de credibilidade ou crença (Schroeder, 2009).

No contexto da saúde o conhecimento médico, expresso em grande parte em relações e associações entre variáveis explicativas e certos efeitos de natureza clínica, está armazenado em bases de conhecimento, que podem assumir a forma tradicional de livros textos e periódicos especializados, ou alguma forma de armazenamento eletrônico (Massad, et al., 2003).

Minsky (2006) sugere uma representação hierárquica das várias estruturas que podem ser utilizadas para representar o conhecimento. Esta hierarquia se inicia nas estórias narrativas, que é utilizada pela linguagem natural, passando pelos frames e redes semânticas, dos quais a ontologia herda vários conceitos de representação, passando pelas redes conexionistas com apoio das teorias de probabilidades e redes neurais.

\subsubsection{Ontologias}

Ontologia é uma disciplina da Filosofia que define o Ser, as coisas e estruturas dos objetos, propriedades e outros aspectos da realidade (Welty, et al., 2001). 
Existe uma série de definições e conceitos para Ontologia, das quais as mais relevantes são apresentadas a seguir.

Borst (1997) apresenta uma definição simples e completa: "Uma ontologia é uma especificação formal e explícita de uma conceitualização compartilhada", onde "formal" significa legível para computadores; "especificação explícita" significa os conceitos, propriedades, relações, funções, restrições, axiomas; "compartilhado" quer dizer conhecimento consensual; e "conceitualização" diz respeito a um modelo abstrato de algum fenômeno do mundo real.

Neches e seus colegas definiram a ontologia em 1991 da seguinte forma: "Uma ontologia define os termos básicos e relações de vocabulário de uma área, bem como as regras para combinar termos e relações que definem a extensão de um vocabulário" (Gómez-Pérez, et al., 2005).

Nardon define "O conceito de ontologia está intimamente relacionado ao conceito de conceitualização. A conceitualização é uma forma de representar os objetos, conceitos e outras entidades que existem em um domínio de interesse e os relacionamentos semânticos entre estes objetos, conceitos e entidades." (Nardon, 2003).

Guarino e Giaretta propuseram a ontologia como "Um grupo de axiomas lógicos designados para computar o significado intencionado de um vocabulário." (Gómez-Pérez, et al., 2005).

Bernaras e seus colegas definiram no framework do KACTUS, em 1996 como: "Ela (a ontologia) provê o significado para uma descrição explícita da conceitualização por trás da representação do conhecimento em uma base de conhecimento." (Gómez-Pérez, et al., 2005).

Outro conceito adotado por Swartout et all, 1997, na estratégia para construção de ontologias para reuso, como o projeto SENSUS com mais de 70.000 nós, é definido por: "Uma ontologia é uma estrutura hierárquica que contém um grupo de termos utilizados para descrever o domínio que será utilizado como estrutura de fundamentos para uma base de conhecimento" (Gómez-Pérez, et al., 2005).

Já para Uschold e Jasper, 1999, "Uma Ontologia pode possuir uma variedade de formas, mas será necessário incluir um vocabulário de termos e algumas especificações sobre seu significado. Este inclui definições e uma indicação de como os conceitos são interrelacionados e impõem coletivamente uma estrutura no domínio e restrições de interpretações possíveis para os termos" (Gómez-Pérez, et al., 2005). 
Os termos Ontologia e Modelo Conceitual às vezes são empregados para indicar o mesmo tipo de representação do mundo, porém alguns fatores diferenciam-lhes.

Entre eles, conforme sugere Welty e Guarino (2001) o modelo conceitual é uma implementação de uma determinada ontologia, implementação essa que satisfaz os requisitos da Engenharia da Aplicação. Já um projeto de ontologia é independente das considerações técnicas da aplicação, e tem como único objetivo especificar a conceitualização do mundo da aplicação.

Nessa revisão bibliográfica faremos uma exploração de algumas características de uma ontologia. Dentre as mais relevantes, escolhemos escrever sobre os componentes, aspectos de usabilidade e reusabilidade, e sobre as linguagens para construção das ontologias.

\subsubsection{Componentes de uma Ontologia}

Existem diferentes técnicas e modelos que podem ser utilizados para modelar e representar ontologias como frames, lógica de primeira ordem, lógicas descritivas, técnicas de engenharia de software ou tecnologias de base de dados (Malucelli, 2006). Entretanto cada uma destas técnicas pode representar o mesmo conhecimento com diferentes graus de formalismo e granularidade, e devem conter os mesmos componentes básicos:

- Classes: Utilizado para modelar os conceitos do domínio ou tarefa. Eles são normalmente organizados em taxonomias e propriedades. A taxonomia de classes é representada em uma estrutura de árvore. Ela pode assumir várias propriedades permitindo que uma classe possa ter uma super classe. Classes podem ser concretas ou abstratas. Ao contrário das classes abstratas, as classes concretas têm instâncias diretas (Malucelli, 2006).

- Atributos: Representam as características dos conceitos. Atributos são também chamados de slots e às vezes de papéis ou propriedades. Eles são distinguidos das relações porque seus valores possíveis correspondem a um tipo de dado (string, number, e boolean, entre outros).

- Relações: Modelam os tipos de associações entre os conceitos. As relações binárias são também utilizadas para expressar atributos dos conceitos. A escala de uma relação é um conceito (Malucelli, 2006). 
- Instâncias: Representam elementos especiais. Eles são especializações de uma determinada classe. Novas instâncias podem ser criadas e valores podem ser designados em atributos e relações (Malucelli, 2006).

- Funções: Representam casos especiais de relações na qual o enésimo elemento de uma relação é único para os $m$-1 elementos precedentes. (Malucelli, 2006)

- Axiomas: Modelam sentenças que são geralmente verdadeiras. Axiomas são utilizados para verificar a consistência de uma ontologia ou a consistência de um conhecimento armazenado. (Malucelli, 2006)

\subsubsection{Usabilidade e Reusabilidade de Ontologias}

O problema da usabilidade e reusabilidade aplicados no campo da ontologia sugere que quanto mais reutilizável uma ontologia for, menos utilizável ela se torna, e vice versa. $A$ distribuição do tipo de ontologia, em relação ao seu reuso está descrito na Figura 6. Ontologias de alto nível são normalmente generalistas e as ontologias de domínio de aplicação são capturadas para a solução de um problema.

Todos os tipos de ontologias podem ser encontrados em um ou mais repositórios de ontologias e podem ser combinadas para desenvolver outra ontologia. 


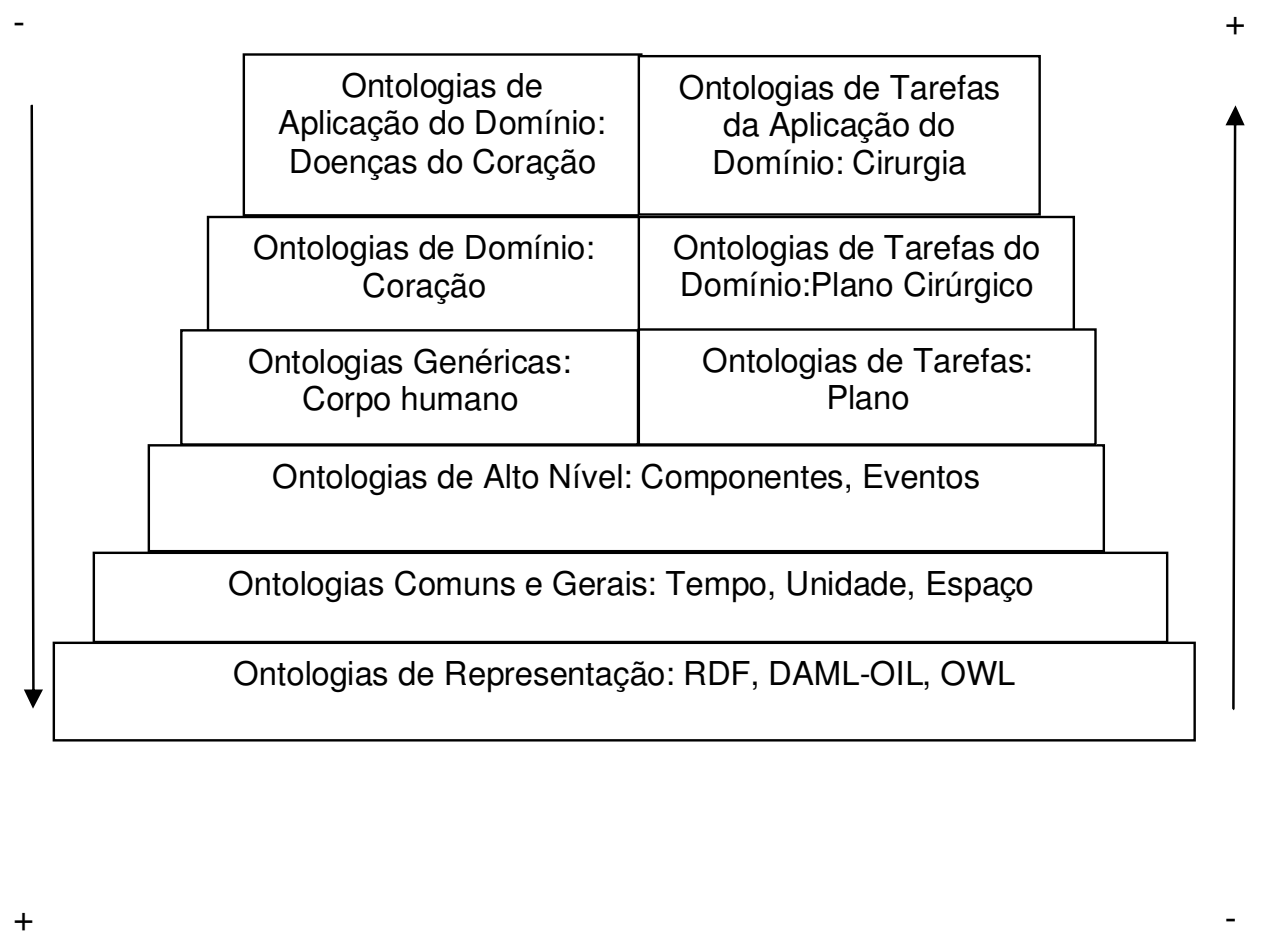

FIGURA 6 - O PROBLEMA DA USABILIDADE E REUSABILIDADE

Gruber, 1993, propôs um conjunto de princípios elementares para projetar ontologias. Ele identificou os seguintes princípios:

Clareza: A ontologia deve comunicar efetivamente a sua principal intenção na definição de termos; estas definições devem ser objetivas. Quando a motivação para definir conceitos vem de situações sociais ou requisitos computacionais, a definição deve ser independente do contexto computacional ou social.

Coerência: A ontologia deve ser coerente. A ontologia deve possibilitar uma inferência que seja consistente com suas definições. A coerência deve ser aplicada também aos conceitos informalmente definidos. Se uma sentença inferida dos axiomas contradiz uma definição ou exemplo, então a ontologia é incoerente.

Extensibidade: As ontologias devem ser designadas para antecipar o uso de vocabulários compartilhados. Deve ser possível definir novos termos para usos especiais baseados em um vocabulário consistente, e ela não deve requerer uma revisão de definições pré-existentes. 
Mínima influência da codificação: A conceitualização deve ser especializada com um nível de conhecimento independente de uma codificação particular. A polarização da codificação deve ser mínima, pois agentes de compartilhamento de conhecimento pode ser implementado em diversos sistemas e utilizar diferentes estilos de representação.

Compromisso ontológico mínimo: Uma ontologia deve requerer um mínimo de compromisso ontológico para fornecer atividades de compartilhamento do conhecimento.

\subsubsection{Linguagens de Ontologias}

Uma ontologia para a representação do conhecimento possui um modelo primitivo utilizado para formalizar o conhecimento no paradigma de representação do conhecimento.

A ontologia de representação do conhecimento de uso mais generalizado é o Frame Ontology, desenvolvido por Gruber, em 1993, para capturar as convenções de representação do conhecimento sob uma abordagem baseada em frames do Ontolingua.

Mais recentemente, linguagens de ontologias estão sendo criadas com um contexto da Web Semântica como o RDF, RDF Schema, OIL, DAML-OIL e OWL. Todas essas linguagens também correspondem com ontologias de representação do conhecimento.

O OWL é resultado de um trabalho do W3C Web Ontology (WebOnt) Work Group, que foi formado em novembro de 2001. Esta linguagem deriva do DAML+OIL, portanto, contém várias funções e nominações de suas primitivas. Também como sua antecessora, esta linguagem tem a intenção de compartilhas ontologias na Web.

O OWL é dividido em três camadas; OWL Lite, OWL DL e OWL Full. 


\subsection{A Radiologia}

O diagnóstico por imagens é uma área da medicina que tem evoluído incessantemente. Esta área apóia os profissionais da área da saúde em enxergar, através de imagens que caracterizam a anatomia ou a funcionalidade de determinado órgão ou, ainda, alguma área do corpo humano.

São diversas tecnologias adotadas para a geração de imagens e, considerando apenas as mais conhecidas, podemos citar a Radiografica, a Tomografia Computadorizada e a Medicina Nuclear.

Todas elas têm como característica a radiação, que é uma das formas de energia existentes. Esta energia não se armazena. Quando esta energia alcança o corpo de um paciente ela pode provocar ou não algum dano biológico. Esse dano depende da quantidade de energia a qual o corpo será exposto.

Em todos os equipamentos de geração de imagens médicas através de radiologia é possível calibrar a quantidade de energia da radiação que será aplicada ao corpo do paciente.

Em um aparelho de raios X, quando aumentamos ou diminuímos o "kV", aumentamos ou diminuímos a energia dos raios $X$.

Em 1896, o físico francês Henri Becquerel descobriu a radioatividade. Nas suas pesquisas com urânio, descobriu que esse material emitia radiações. A radioatividade está associada a uma instabilidade nuclear. Existem átomos que possuem um excesso de energia no seu núcleo e esses átomos emitirão radiações até que ele se estabilize.

Em 1895, o físico holandês Wilhen Conrad Roëntgen, estudava os fenômenos gerados pela alta tensão em um tubo de raios catódicos quando descobriu o raio-X. De forma casual, em um dos seus experimentos existia uma caixa revestida com uma substância fluorescente. Ele percebeu que no aumento da tensão, uma luz era emitida da caixa. Analisando durante vários dias este descobrimento, e não identificando a sua origem, ele deu o nome da incógnita X. Por essa descoberta Roëntgen foi o primeiro físico a receber o prêmio Nobel em 1901.

No mesmo ano da descoberta ele produziu a primeira radiografia da história, a mão da sua esposa, apresentada na Figura 7. 


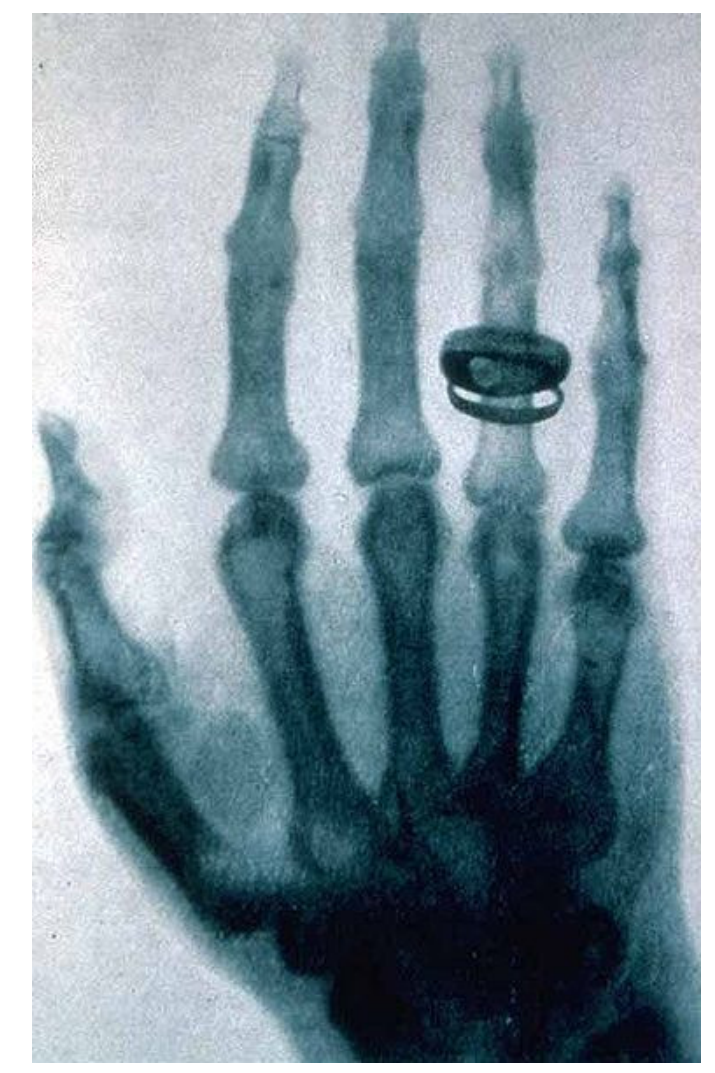

FIGURA 7 - IMAGEM DIGITALIZADA DA PRIMEIRA RADIOGRAFIA DA HISTÓRIA, A MÃO DA MULHER DE ROËNTGEN

\subsubsection{Os componentes do aparelho do raio $X$}

Descreveremos brevemente os componentes de um aparelho de raio $\mathrm{X}$. Cada componente do aparelho tem uma função na produção de uma imagem. Um tipo de aparelho de raio $X$ é identificado na Figura 8.

O tubo de raio $X$ tem a função de blindar os raios $X$ emitidos nas direções fora da janela. Para isto uma carcaça de material denso e de chumbo reveste a ampola de raios $X$ ligada aos circuitos eletrônicos de retificação de corrente elétrica e de alta tensão, além do sistema de arrefecimento (Castro Jr., 2008).

Acoplados ao tubo encontram-se o colimador e o comando de movimentação. O colimador tem a função de mostrar por intermédio de um foco de luz a região que será exposta aos raios $\mathrm{X}$ para a formação da imagem. $\mathrm{O}$ comando de movimentação é realizado por botões que realizam os movimentos do tubo ao longo da mesa. 
O bucky mural é uma estrutura destinada à obtenção de imagens compostas por uma gaveta para o chassi, a grade antidifusora e uma placa alvo. Ela também possui um sistema de movimentação vertical para auxiliar no melhor posicionamento do paciente.

O console é o componente do equipamento no qual são selecionados os parâmetros técnicos do disparo, que determinam o foco, a quantidade e a energia dos fótons de raio $X$. O console de operação deve ficar em um local blindado da radiação, para que o profissional não se exponha desnecessariamente.

A grade antidifusora está presente tanto no bucky mural quanto no da mesa. Sua função é absorver os fótons espalhados para que não cheguem no filme. Sem a grade antidifusora, a imagem perde resolução e diminui o contraste.

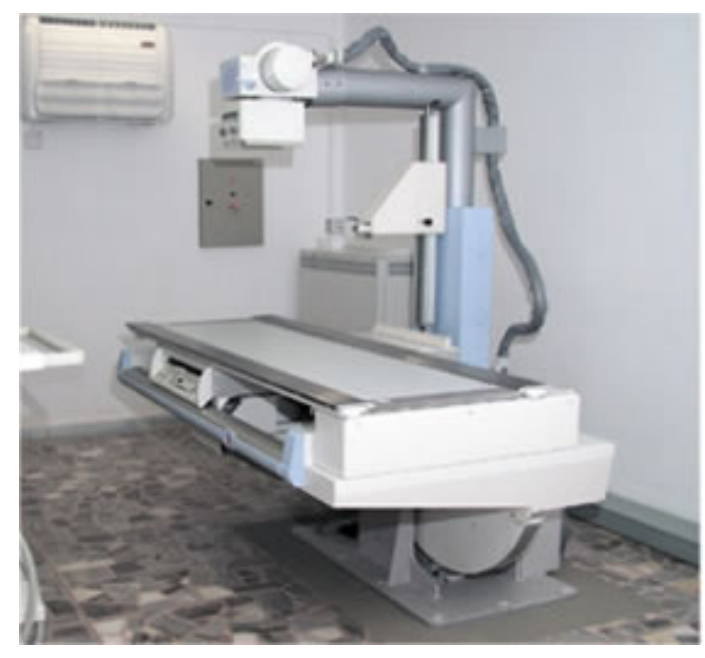

FIGURA 8 - EQUIPAMENTO DE RAIO X DA GE, MODELO MPX

O chassi é o compartimento onde é acoplado o filme e o écran. Os tamanhos são definidos em função do filme.

O écran é a tela que absorve os raio $X$ e os tranforma em luz. Esse fenômeno é chamado de fluorescência. Basicamente existem as que emitem luz azul e as que emitem luz verde. Um outro fator importante para o uso do écran é a redução de exposição à radiação. Para fótons de raios $X$ incidente na tela haverá uma quantidade muito maior de fotons de luz produzidos, de tal forma que a utilização das telas exige uma dose de raios $X$ no paciente muito menor do que quando somente utilizava-se o filme. 
O filme radiológico é composto por uma película plástica, chamada de base, revestida por uma substância chamada emulsão e por uma camada protetora. Quando a luz incide sobre o filme ocorre uma tranferência de energia do fóton para o filme, provocado por uma mudança de características químicas. Nesse momento o filme apresenta uma imagem latente, que necessita ser revelada para ser visível a olho nu (Castro Jr., 2008).

Atualmente os equipamentos de radiologia incorporam meios de sensibilização de matrizes digitais reutilizáveis, substituindo o processo de sensibilização e revelação do filme radiológico.

A formação da imagem radiológica depende do dispositivo que emite a radiação, do paciente e do conjunto grade, tela e filme.

Quando a radiação é emitida do aparelho e direcionada para determinada estrutura do corpo do paciente, ela irá ter maior ou menor dificuldade de atravessar os tecidos, dependendo de sua densidade e tamanho. Esta propriedade é chamada de atenuação dos raios $\mathrm{X}$ no corpo, que é o princípio para o entendimento da formação da imagem no filme (Castro Jr., 2008).

Os tecidos mais densos, como os ósseos, atenuam mais os raios $\mathrm{X}$ ocasionando a menor radiação captada pela tela, produzindo menos luz, que por sua vez impressionará menos o filme. O resultado após a revelação será uma região mais clara na imagem. Já num tecido menos denso, como a gordura ou músculo, a atenuação é menor, e a imagem resultante ficará mais escura (Castro Jr., 2008).

\subsubsection{0 processo de geração de laudos de radiologia}

Para a geração, conferência, impressão, assinatura e disponibilização dos laudos radiológicos, as instituições de saúde adotam processos que visam sistematizar as tais atividades, para melhor atender aos pacientes.

No XI Congresso Brasileiro de Informática em Saúde, foi apresentado um trabalho que descreveu um modelo de referência para o processo de radiologia baseado em três (3) instituições de saúde (Ebisawa, et al., 2008).

No processo apresentado, o médico insere o filme radiológico no negatoscópio, descreve por escrito as alterações do pré-laudo e o envia para o digitador. O digitador datilografa o laudo no sistema, seleciona o médico, imprime o laudo e o entrega para a assinatura do médico. O médico, por sua vez, confere o laudo, em caso de concordância, o assina e retorna novamente para o digitador. Este recebe o laudo, insere o laudo e o filme radiológico 
no envelope, coloca a etiqueta identificando o paciente e disponibiliza o envelope para a entrega.

O laudo é processado de forma a obter uma aprovação do médico. Não existe, no entanto, qualquer padronização de termos clínicos utilizados. Esta falta de padronização terminológica na geração do laudo dificulta a sua classificação e a busca por casos similares.

Na próxima seção apresentaremos a revisão da literatura do processamento estatístico de linguagem natural. 


\subsection{Processamento Estatístico de Linguagem Natural}

Entre os anos de 1960 e 1985 muitos estudos relacionados à lingüística, psicologia, inteligência artificial e processamento de linguagem natural foram dominados por uma abordagem racional, ou seja, caracterizada por acreditar que o conhecimento na mente humana não é derivado do senso e sim derivada de herança genética (Manning, et al., 1999).

Chomsky sugere na abordagem racionalista que as partes principais da linguagem são inatas, ou seja, são escritas no cérebro ao nascer, fazendo parte da herança genética humana (Manning, et al., 1999).

A capacidade da língua é um dos componentes da moderna teoria da evolução. A capacidade humana para imaginação criativa, linguagem e outros modelos de simbolismos, matemáticos, interpretação e armazenamento de fenômenos naturais, práticas sociais entre outros, é uma capacidade cristalizada nos 50.000 anos de existência humana e que nos difere de qualquer outro animal, inclusive outros hominídeos (Chomsky, 2006).

Este é um dos famosos desentendimentos entre dois dos fundadores da Teoria da Evolução das Espécies. Alfred Russel Wallace afirmava, ao contrário de Darwin, que a evolução desta capacidade não ocorreu de acordo com a variação da seleção natural somente, mas requereu "alguma outra influência, lei, ou agência", como a teoria gravitacional, coesão, e outras forças sem as quais o universo não existiria (Chomsky, 2006).

Vários cientistas concordam com o paleoantropólogo lan Tattersall que afirma ser quase certo que a invenção da linguagem foi um acontecimento súbito e serviu de estímulo para libertar a capacidade humana para registrar sua evolução proporcionando um salto evolutivo (Chomsky, 2006).

O biólogo evolucionário Jared Diamond descreveu este processo como o resultado de algum evento genético que permitiu ao cérebro originar a linguagem humana com uma rica sintaxe, de forma a permitir uma multiplicidade de modos de manifestação, sendo uma condição essencial para o desenvolvimento social. Isto propiciou mudanças bruscas de comportamento que são revelados por arquivos arqueológicos (Chomsky, 2006).

Esta mudança proporciou uma evolução do conhecimento humano, que foi aumentado com a capacidade de representar o conhecimento de forma escrita.

Os conhecimentos humanos evoluíram em diversas áreas e normalmente é utilizada a forma escrita da linguagem natural como forma de registro e compartilhamento de conhecimento. 
Um dos objetivos da ciência linguística é caracterizar e explicar as múliplas observações linguísticas em torno da conversação, escrita ou através de outras mídias. Parte deste conhecimento se encontra na cognição de como o homem adquire, produz e entende a linguagem, e outra parte se encontra no entendimento da relação da língua através da palavra, e uma outra parte ainda se demonstra em entender a estrutura da língua que utilizamos para nos comunicar (Manning, et al., 1999).

A análise da linguagem escrita pode ser dividida nas abordagens morfológicas, sintática e semântica (Charniak, 1993).

A análise morfológica estuda a estrutura das palavras, a estrutura das sentenças, o significado das sentenças individuais e como as sentenças se relacionam entre si.

$\mathrm{Na}$ análise sintática determina-se o significado de uma frase que contribui para a determinação do significado do todo.

A análise da semântica da linguagem pode ser abordada por alguns aspectos. Um deles é a análise a partir do núcleo mínimo, ou seja, o significado dos elementos, incluindo os mais simples deles, e em segundo os princípios que permitem combinações de símbolos, organizados hierarquicamente, que fornecerão os meios para a utilização da língua nos seus múltiplos aspectos (Chomsky, 2006).

Existe ainda uma abordagem empírica que foi dominante nas principais pesquisas entre 1920 e 1960 e agora está ressurgindo.

A definição de empírico está associada a um conceito frequêncial de probabilidade que é determinada com base na proporção de vezes que um evento " $A$ " ocorre em certo número de observações. Em outras palavras, a probabilidade é determinada pela frequência relativa: quanto maior o número de observações, mais o valor calculado tenderá ao valor real da probabilidade.

Estes métodos empíricos estão fornecendo novas abordagens explicativas aos problemas de processamento da linguagem, fornecendo abordagens para a compreensão, aquisição, e inferência da linguagem, mantendo a sofisticação dos modelos simbólicos (Chater, et al., 2006).

\subsubsection{Corpus}

Corpus é uma coletânea de textos representativos de uma língua, dialeto ou outro subconjunto de uma língua, para fins de análise lingüística (Mokva, et al., 2004). 
A utilização do computador para os estudos com base em corpus é extremamente importante, pois o computador busca, recupera, seleciona e calcula rapidamente, dando ao lingüista a possibilidade de compreender e explicar o que compreendeu de maneira fundamentada e bastante segura (Mokva, et al., 2004).

A construção de um corpus extenso a abrangente deve envolver uma cuidadosa preparação e a entradas de informações de muitas pessoas durante um extenso período. Dados de boa qualidade devem ser coletados, processados, documentados e armazenados de forma sistematizada. Várias camadas de anotações devem ser aplicadas, o que requer um conhecimento especializado na morfologia e na sintaxe da linguagem (Bird, et al., 2009).

O sucesso da criação de um corpus depende da criação de um fluxo de trabalho eficiente e que envolva ferramentas apropriadas e conversores de formatos. $O$ controle de qualidade deve verificar inconsistência nas anotações e garantir o mais alto possível nível de qualidade (Bird, et al., 2009).

Visto que esta tarefa é complexa e árdua, grandes corpora demoram anos para serem preparados e envolve dezenas ou centenas de pessoas trabalhando.

Existem basicamente três tipos de corpus.

Em um primeiro tipo de corpus, o projeto se desenvolve ao longo do curso da exploração do criador.

Este é o padrão típico do tradicional campo lingüístico. O corpus resultante é utilizado durante anos subseqüentes de pesquisa e pode servir como um recurso de arquivo por tempo indeterminado. A expansão da computação promoveu um grande avanço em trabalhos deste tipo (Bird, et al., 2009).

Outro tipo de corpus é a criação de um cenário típico de pesquisa experimental em que o corpo do material é cuidadosamente projetado e coletado de uma variedade de seres humanos, então analisados para avaliar uma hipótese ou desenvolver uma tecnologia. Este tipo de corpus é comum para a criação de base de dados a serem compartilhadas ou reutilizadas (Bird, et al., 2009).

Um terceiro tipo vem do esforço de se criar um corpus que seja a referência para uma linguagem em particular, como o American National Corpus (ANC) ou o British National Corpus (BNC). Aqui o objetivo é produzir um registro abrangente de muitas formas, estilos e usos da linguagem (Bird, et al., 2009).

Nosso trabalho está classificado no segundo tipo de corpus apresentado, tendo para a sua criação um conjunto de laudos criados por médicos e digitadores e que abrange o 
conhecimento médico do corpo clínico dos profissionais responsáveis pela geração de laudos de radiologia torácica.

\subsubsection{Tokens e Palavras}

Podemos definir token como uma ocorrência particular de uma palavra em um corpus. Naturalmente muitas destas palavras se repetem, portanto que existem milhares de tokens e somente alguns tipos de palavras em um corpus (Charniak, 1993).

Em processamento de linguagem também podemos definir token como a ocorrência individual de algum símbolo ou conjunto de símbolos (Manning, et al., 1999).

Tokens são blocos de caracteres normalmente associados a cada palavra, ou ítem léxico que compõem um texto. (Carvalheira, 2007)

Um dos primeiros passos em uma aplicação de processamento de linguagem natural é a extração de tokens, ou tokenização. Os símbolos que fazem parte de um texto são divididos em tokens, que são as menores unidades indivisíveis de um texto (Banerjee, et al., 2002).

Exemplificando, na Figura 9 definimos a extração de tokens a partir de uma sentença.

\begin{tabular}{|c|c|c|c|c|c|c|c|c|}
\hline \multicolumn{1}{|c|}{ Osteofitose dorsal, escoliose de convexidade à direita } \\
\hline Osteofitose & dorsal &, & escoliose & de & Convexidade & a & Direita &. \\
\hline Token 1 & 2 & 3 & 4 & 5 & 6 & 7 & 8 & 9 \\
\hline
\end{tabular}

FIGURA 9 - PROCESSO DE TOKENIZAÇÃO DE FRASES

Após a extração dos tokens, pode-se identificar as palavras que se repetem ao longo do corpus.

Palavras podem ser definidas como uma seqüência ordenada de símbolos de tamanho finito. Ao conjunto de símbolos é dado o nome de alfabeto. Em alguns casos o alfabeto utilizado representa literalmente o alfabeto a, b, c, d, e, e. z. Em outras circunstâncias, o alfabeto também é composto de outros caracteres como números e símbolos $(0,1,2 \ldots 9,+,-$ , ${ }^{*}, !$, ?) (Gough, 1988). 
Um importante conceito é que um símbolo é atômico, ou seja, um símbolo é uma unidade indivisível a partir da qual uma palavra é construída (Gough, 1988).

Representamos 0 alfabeto grego com 0 símbolo $\Sigma$, e o conjunto de todas as palavras formadas por uma seqüência de símbolos de $\Sigma$ chamaremos de $\Sigma^{+}$. Note-se que o conjunto $\Sigma$ é finito, mas o conjunto $\Sigma^{+}$é infinito (Gough, 1988).

Para incluir todos os caracteres, incluindo os símbolos, por exemplo, o espaço, utilizaremos o símbolo $\varepsilon$, que denota um carácter sem símbolo. Esta falta de símbolo não é um elemento de $\Sigma$ ou de $\Sigma^{+}+$, mas um novo conjunto $\varepsilon$. $\Sigma^{*}$ é definido como a união entre o conjunto $\Sigma^{+}$e $o$ conjunto $\varepsilon$. (Gough, 1988)

Em símbolos $\Sigma^{*}=\Sigma^{+} \cup\{\varepsilon\}$ (equação 1)

Portanto $\Sigma^{*}$ pode ser definido como o conjunto de palavras compostas por símbolos de tamanho zero (espaço) ou maior (Gough, 1988).

Para a formulação de uma semântica não é necessário o uso de todas as palavras constantes em $\Sigma^{*}$, mas somente aquelas que têm sentido em um contexto particular, o que está relacionado com o significado das palavras (Gough, 1988).

Palavras como artigos, preposições, ou pronomes freqüentemente não possuem um sentido particular isoladamente, mas são fundamentais como ligação entre sentidos de outras palavras.

Com o uso de técnicas estatísticas pode-se identificar quantas vezes uma palavra ocorre no corpus e a distribuição de frequência de palavras no corpus.

A aplicação da estatística ao processamento de linguagem natural tem evidenciado que as palavras ocorrem em uma distribuição desigual em qualquer corpus. Algumas palavras são muito comuns, ocorrendo mais de $1 \%$ do total de ocorrências de palavras em um corpus. Tipicamente, as 100 palavras mais comuns ocorrem um pouco mais da metade das vezes que outras palavras em um corpus (Manning, et al., 1999).

Entretanto algumas palavras ocorrem raramente. Mais de $90 \%$ das palavras ocorrem menos de 10 vezes. Algumas palavras raras perfazem uma proporção considerável de corpus. Normalmente $12 \%$ das palavras em um corpus ocorrem menos de 3 vezes (Manning, et al., 1999).

Este fato pode ser explicado através dos estudos de George K. Zipf.

Em 1949 George K. Zipf, em seu livro Human Behavior and the Principle of Least Effort: An Introduction to Human Ecology, discorreu sobre o princípio do mínimo esforço, que 
discrimina a essência da condição humana. Basicamente, o princípio identifica que as pessoas agem de forma a minimizar o seu trabalho. Os elementos de prova desta teoria empírica estão revelados através da distribuição estatística de linguagem (Manning, et al., 1999).

A teoria de Zipf nos informa que se contarmos a freqüência de uma palavra que ocorre na linguagem escrita de um corpus, e então relacionarmos as palavras em ordem de freqüência de ocorrência, podemos explorar a relação entre a freqüência de uma palavra $f$ e a sua posição na lista, chamada rank $r$

Este índice $\mathrm{k}$ descrevemos como: $k=f . r$ (equação 2)

Aplicando este índice, Zipf conseguiu demonstrar que, na freqüência de distribuição de palavras na língua humana, existem algumas palavras muito comuns, um número médio de palavras com freqüência media de ocorrência e muitas palavras de baixa freqüência de ocorrência.

De acordo com sua teoria, tanto o indivíduo que está falando, quanto aquele que está ouvindo, estão tentando minimizar o esforço de comunicação. O esforço tende a diminuir quando ele tenta utilizar o menor vocabulário possível, utilizando palavras que acredite ser de conhecimento comum entre ele e o ouvinte, e o esforço do ouvinte diminui pois não precisa conhecer um vasto vocabulário de palavras individualmente raras.

Sobre o número de significados de uma palavra, Zipf argumenta que, para o emissor conservar seu esforço, ele prefere utilizar somente uma palavra que contenha todos os significados enquanto para o esforço do ouvinte preferirá que cada significado seja expresso com uma palavra diferente. Assumindo que estas forças sejam igualmente fortes, identificase que quanto maior o rank de cada palavra maior o número de significados que ela assume (Manning, et al., 1999).

Nesta tese as palavras que descrevem alguma patologia específica tendem a ter um único significado. Com isto as palavras que compõem o domínio deste trabalho tendem a não se repetir. As palavras que mais ocorrem são as de uso geral.

Tomemos como exemplo as palavras "alta" e "epicárdio".

"Alta" pode significar elevação, ordem médica que se dá pelo término de um tratamento ou internação hospitalar, elite social, é adjetivo quantificador de substantivos, entre outras.

Já a palavra epicárdio é um substantivo restrito para descrever "o folheto visceral do pericárdio, que recobre diretamente o miocárdio". Esta restrição de significado leva a uma menor ocorrência de "epicárdio" em um corpus. 


\subsubsection{N-gramas}

As palavras são a base da formulação de sentenças.

Sentenças são formadas por uma sequência de palavras capazes de exprimir uma semântica.

Para o processamento estatístico de linguagem natural, as sentenças são formadas de ngramas.

Tipicamente os n-gramas são formados por tokens contínuos (Banerjee, et al., 2002).

Chamamos de n-gramas a representação de seqüência de palavras que ocorrem em um corpus.

Para uma seqüência de palavras de comprimento $n$ para um $n$ fixo, podemos atribuir como probabilidade a expressão $P\left(X_{n}=x_{n}\right)$, para todas as possíveis seqüências de $x_{n}$ (Charniak, 1993).

Aqui, $X_{n}$ é a seqüência de variáveis randômicas onde $n$ representa $X_{1}, X_{2}, \ldots X_{n}$ e cada uma delas tem um valor atribuído a uma palavra da língua e $x_{n}$ é uma seqüência particular de palavras obtidas, atribuindo a elas um valor para a variável randômica. (Charniak, 1993).

A probabilidade de ocorrer uma seqüência de palavras na língua se dá pela fórmula:

$P\left(x_{1}, x_{2}, x_{3}, \ldots x_{n}\right)=P\left(x_{1}\right) P\left(x_{2} \mid x_{1}\right), P\left(x_{3} \mid x_{1}, x_{2}\right) \ldots P\left(x_{n} \mid x_{1}, \ldots ., x_{n-1}\right)$, (equação 3)

Desta forma, atribuímos a probabilidade de ocorrência da próxima palavra de um texto.

De forma similar, esta probabilidade pode ser descrita como $P\left(w_{n} \mid w_{1}, \ldots ., w_{n-1}\right)$ (Manning, et al., 1999).

Ou seja, um modelo probabilístico de n-gramas pode ser utilizado para predizer a probabilidade de ocorrência da próxima palavra, como uma função $P$. Assim a última palavra de um n-grama é utilizada para predizer a próxima palavra.

O número $n$ representa a quantidade de palavras encadeadas nesta seqüência, assumindo valores inteiros. Como exemplo a seqüência "nível alto" é um n-grama de $n=2$. Na Figura 10 ilustramos a composição dos n-gramas a partir dos tokens.

Algumas palavras relacionadas ao contexto de laudos de radiologia torácica têm pouca incidência, porém a sua semântica pode ser significativa, pois denota uma particularidade técnica da análise desse laudo. Essa constatação nos leva à conclusão de que alguns n- 
gramas, apesar de baixa probabilidade de ocorrência, não devem ser descartados em face de sua importância semântica.

\begin{tabular}{|c|c|c|c|c|c|c|c|c|c|c|}
\hline Tokens & 1 & 2 & 3 & 4 & 5 & 6 & 7 & 8 & 9 & 10 \\
\hline \multicolumn{11}{|l|}{ 2-grama } \\
\hline \multicolumn{11}{|l|}{ 3-grama } \\
\hline \multicolumn{11}{|l|}{ 4-grama } \\
\hline \multicolumn{11}{|l|}{ 5-grama } \\
\hline \multicolumn{11}{|l|}{ 6-grama } \\
\hline \multicolumn{11}{|l|}{ 7-grama } \\
\hline 8-grama & & & & & & & & & & \\
\hline
\end{tabular}

FIGURA 10 - PROCESSO DE COMPOSIÇÃO DE N-GRAMAS

\subsubsection{A semântica das sentenças}

Duas características devem ser considerados como origem da capacidade da linguagem humana. Primeiro, o núcleo semântico do mínimo significado entre os elementos, considerando os mais simples. Segundo, os princípios que permitem uma combinação infinita de símbolos, hierarquicamente organizados, o que fornecerá meios para a utilização da língua em múltiplos aspectos (Chomsky, 2006).

Muito se tem estudado sobre como capturar o conteúdo semântico de um corpus. Muitos modelos de representação de textos assumem que as palavras podem aparecer aleatoriamente no texto, independentes uma das outras, seguindo um padrão de distribuição governado pela progressão textual dos tópicos discutidos e convenções comunicativas (Arcoverde, 2007).

Atualmente, a capacidade de automatizar o entendimento do texto, ou capturar a sua semântica é limitada (Arcoverde, 2007).

As estratégias adotadas para representação de consulta a documentos podem se dividir naquelas que utilizam modelos de n-gramas e as que utilizam a dependência de termos. 
A literatura revela um número crescente de trabalhos que adotam modelos com dependência de termos (Arcoverde, 2007).

Os modelos de dependência de termos podem ser fundamentados por um conjunto de relacionamentos estatísticos entre termos, regidos através da probabilidade de coocorrência de n-gramas.

Apesar do significado elementar relacionar o significado de uma sentença às palavras, o contexto no qual essa palavra está inserida, leva à desambiguação do significado e está diretamente ligado aos termos que estão associados a essa palavra. 


\section{PADRÕES DA INFORMÁTICA EM SAÚDE}

Dentre tantas utilidades da padronização em informática em saúde, uma das principais é a interoperabilidade entre sistemas.

O IEEE define interoperabilidade como a "habilidade de dois ou mais componentes de trocar informações e utilizar as informações que foram trocadas". A interoperabilidade pode ter três níveis.

A interoperabilidade sintática provê uma estrutura de informação ou conhecimento para que seja inteligível por um sistema clínico. A interoperabilidade semântica atua na representação de dados.

A interoperabilidade estrutural e interpretação semântica são aquelas nas quais a semântica da informação ou conhecimento pode ser analisada por especialistas do domínio (médicos). Ele envolve conceitos de representação em saúde.

A interoperabilidade semântica requer que o sistema de informação entenda a semântica da informação e as fontes das informações (Garde, et al., 2007).

Para a interoperabilidade deve-se considerar, também, a existência de um legado de sistemas, de plataformas de hardware e software instalados. O conceito de interoperabilidade parte de princípios que tratam da diversidade de componentes, com a utilização de produtos diversos de fornecedores distintos. Tem por meta a consideração de todos os fatores para que os sistemas possam atuar cooperativamente, fixando as normas, as políticas e os padrões necessários para consecução desses objetivos.

A norma ISO/TR 16056-1:2004 - Health Informatics - Interoperability of telehealth systems and networks trata da padronização no campo da Informática na Saúde e da tecnologia das comunicações, garantindo a compatibilidade e interoperabilidade de arquivos entre sistemas independentes. Também garante a compatibilidade de dados para propósitos de comparação estatística, no intuito de reduzir a duplicação de esforços e redundâncias.

Alguns temas que essa norma abrange são: estrutura de dados, intercâmbio de dados, contexto semântico, segurança, farmácia, equipamentos, requisitos de negócio para o registro eletrônico em saúde e a harmonização das normas e modelos. A figura 11 apresenta a divisão temática dos grupos de trabalho do Comitê ISO/TC 215. A discussão da norma ISO/TR 16056-1:2004, que se encontra em revisão, é liderada pelo WG 2, mas envolve o WG 1 e o WG 8. 


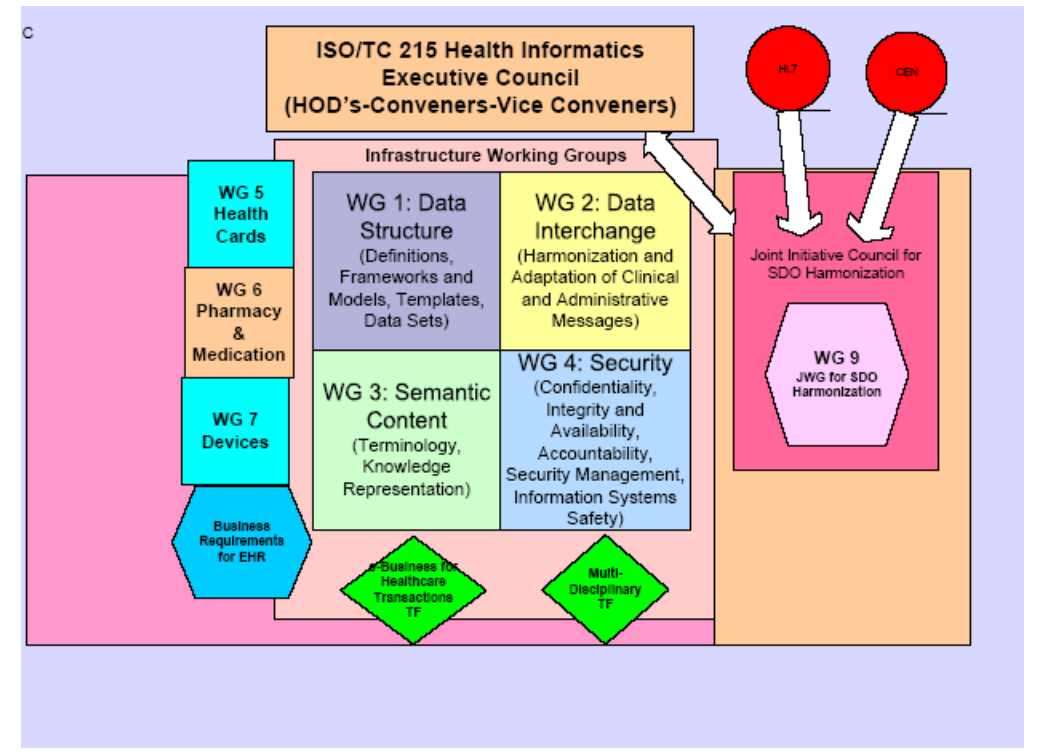

FIGURA 11 - AS ÁREAS DO CONSELHO EXECUTIVO DE INFORMÁTICA EM SAÚDE NA ISO/TC 215

Trocar informações de saúde entre profissionais de saúde ou sistemas de informações clínicas é um processo crítico para o setor de atendimento em saúde. Algumas características como a sensibilidade de dados médicos, a ética e as restrições legais são fatores que impõem requisitos de segurança e rigoroso controle de acesso à informação.

Em muitas organizações de saúde, a construção de sistemas de informação em saúde, não incorpora mecanismos para a padronização de conteúdos e de sua semântica, que permitam a unificação dos dados. Em geral, estes são distribuídos de forma fragmentada entre os sistemas internos e externos à organizaçcão impedindo a interconexão, integração e a construção de um repositório de dados que seja reutilizável.

Uma maneira de resolver este problema é desenvolver um novo e integrado sistema de informação para toda a organização que pode representar um grande custo econômico, uma traumática atualização dos sistemas existentes e a necessidade de adaptação de todos os usuários ao novo sistema. Outra solução é o uso de uma estratégia de sistema de informação federalizada, contendo uma ligação entre as fontes de dados heterogêneas e oferecendo uma visão unificada e um repositório virtual centralizado (Moner, et al., 2006). 
Desta maneira é possível o desenvolvimento de um sistema de informação clínica que contenha uma definição semântica abrangente, tornando possível a interoperabilidade semântica entre os sistemas.

Uma das tecnologias amplamente utilizadas para prover a interoperabilidade entre sistemas é o XML.

O eXtensible Markup Language (XML) é um padrão criado pelo W3 Consortium para representação de documentos. Na área de saúde, o XML tem sido amplamente utilizado, visto que um prontuário médico é formado por diversos documentos e que, para um uso adequado, estes devem estar estruturados. O XML pode ser usado para estruturar os documentos e facilitar o seu entendimento por computadores, tornando-os capazes de armazenar dados extrair informações das mesmas. Além disso, o XML é muito utilizado para o intercâmbio de informações entre sistemas, sendo que, para tanto, torna-se necessário o desenvolvimento das Document Type Definitions (DTDs) para cada conjunto de dados a ser trocado (Costa, 2001).

Dessa forma, para a troca de informações clínicas, por exemplo, deve haver uma DTD que especifique o arquivo XML com tais informações (Sokolowski e Dudeck, 1999). Alguns padrões já consagrados, como o HL7, por exemplo, tem adotado o XML como sintaxe em suas mensagens. O DATASUS do Ministério da Saúde também tem utilizado extensamente o XML na definição das mensagens entre os sistemas do Cartão Nacional de Saúde bem como o comitê Padronização do Registro Clínico (PRC) especificou uma DTD para o seu conjunto de dados (Costa, 2001).

\subsubsection{SNOMED-CT}

O ponto histórico inicial da representação do conhecimento na informática em saúde são as terminologias. Alguns léxicos de termos foram utilizados para a classificação de humanos, como a CID - Classificação Internacional de Doenças, e foram evoluindo em redes de estruturas semânticas codificadas e com classificações internas, como o SNOMED-CT. As terminologias são utilizadas principalmente para o uso computacional, para o suporte à decisão e como guias de processamento.

O SNOMED-CT - Systematized Nomenclature of Medicine - Clinical Terms tem sido utilizado por vários autores para aplicar os princípios de aplicação de ontologias formais baseados em terminologias. Com o uso de padrões terminológicos para a construção de ontologias evitam-se a duplicação e a redundância de representação de conhecimentos (Spackman, et al., 2002). 
O SNOMED - CT tem a intenção de ser uma terminologia global para ser utilizada em cenários heterogêneos. Ele é um modelo conceitual documentado habilitando os usuários ao uso de métodos formais para o desenvolvimento de extensões locais ou contribuir efetivamente para um refinamento colaborativo da terminologia (Spackman, et al., 2002).

O SNOMED-CT é um dos trabalhos mais utilizados de desenvolvimento de terminologias construídas e distribuidas pelo College of American Pathologists (CAP) com o propósito de codificar, armazenar e recuperar informações de saúde. Os trabalhos foram iniciados com o SNOP - Systematized Nomenclature of Pathology em 1965 e foi expandido até o SNOMED - Systematized Nomenclature of Medicine em 1976 e subsequente as suas novas edições.

Entre 1979 e 1993 o CAP focou no desenvolvimento de uma terminologia prática e compreensiva que poderia ser utilizado em manuais de códigos para ser utilizado por sistemas de informação computadorizada. Iniciando nos idos de 1990 o CAP embarcou em uma reengenharia do SNOMED, adaptando-o para o uso em sistemas eletrônicos sofisticados no atendimento em saúde e saúde pública.

Como consequência desta reengenharia houve um substancial retrabalho em cooperação do projeto CMT - Convergent Medical Terminology e o CAP publicou o SNOMED Reference Terminology - RT em 2000. Em uma grande transformação com mais do dobro de tamanho e a expansão do modelo de conceitos e outras funções ocorreu o agrupamento entre o SNOMED-CT, com o UK National Health Services (NHS) com o Clinical Terms versão 3, resultando na primeira release do SNOMED Clinical Terms - CT, em janeiro de 2002.

Em 2003, o governo dos Estados Unidos licenciou o SNOMED - CT e o National Committee on Vital and Health Statistics (NCVHS) o recomendou como uma terminologia geral para o registro de informações clínicas do paciente, naquele país. No Reino Unido, o SNOMED-CT passou a ser um padrão nacional e elemento chave do programa nacional do NHS para a tecnologia da informação (Spackman, et al., 1997).

Resumidamente, o SNOMED é uma terminologia clínica, sistematizada, hierarquizada, composta de conceitos, descrições e correlações cujo objetivo é representar de forma precisa informações no escopo da área de saúde.

O SNOMED foi concebido para a utilização em registros eletrônicos de saúde e facilita a estruturação e a interoperabilidade entre sistemas de informação, uma vez que permite a codificação, o armazenamento, a troca e a agregação de dados clínicos.

A versão de janeiro de 2008 do SNOMED-CT apresenta aproximadamente 311.000 conceitos ativos, 800.000 descrições e 1.360 .000 correlações. 
É uma integração sistemática de vários vocabulários, mapeado com as classificações mais relevantes (ex: CID-9, CID-10) e alinhado com os padrões para troca de mensagens (ex: HL7, XML, DICOM)

Alguns marcos históricos do SNOMED - CT são: SNOP(1965), SNOMED(1974), SNOMED II(1979), SNOMED versão 3(1993), Códigos LOINC integrados ao SNOMED (1997), SNOMED 3.5 (1998), SNOMED RT(2000), SNOMED-CT(2002), SNOMED espanhol (2002), SNOMED alemão (2003) (ANS, 2008).

Em abril de 2007, o gerenciamento do SNOMED-CT foi transferido para o IHTSDO International Health Terminology Standards Development Organization, com a responsabilidade pela manutenção, desenvolvimento e distribuição do SNOMED-CT.

O IHTSDO é uma organização sem fins lucrativos estabelecida em Copenhagen, Dinamarca (ANS, 2008).

O conteúdo do SNOMED-CT é dividido nas seguintes hierarquias: achados clínicos, procedimentos, entidades de observação, estrutura corpórea, organismo, substância, produto farmacêutico / biológico, espécime, conceito especial, objeto físico, força física, evento, ambiente / localidade geográfica, contexto social, situação com um contexto expecífico, estágios e escalas, conceito de ligação, valor qualificador, artefato de armazenamento.

As aplicações de software para o atendimento em saúde são focados em conjunto de dados clínicos, a ligação a bases de conhecimento clínico, recuperação de informação, e uma boa conexão de dados. As informações podem estar armazenadas de tipos diferentes, em diferentes tempos e em locais de atendimentos distintos.

As informações padronizadas melhoram a análise de dados, informações e conhecimento. O SNOMED-CT provê um padrão para informações clínicas. As aplicações de software podem utilizar os conceitos, hierarquias e relacionamentos de um ponto de referência comum para a análise de dados (IHTSDO, 2008).

O padrão terminológico pode prover benefícios aos médicos, pacientes, administradores, e desenvolvedores de software, entre outros. Uma terminologia clínica pode ajudar a fornecer soluções de saúde de maneira mais acessível e com a informações completas durante todo o ciclo de atendimento, envolvendo o histórico médico, os tratamentos os resultados laboratoriais e os laudos de alta (IHTSDO, 2008). 
Portanto, o SNOMED e o SNOMED-CT não são um exercício teórico acadêmico mas o inicio de um desenvolvimento com uma séria expectativa de atender a demanda prática de usabilidade.

\subsection{2- Arquitetura de Documentos Clínicos}

O Health Level 7 (HL7) é uma organização desenvolvedora de padrões que é certificada pela American National Standards Institute (ANSI). É uma organização focada no desenvolvimento de protocolos de comunicação utilizada nos Estados Unidos e com reconhecimento internacional sob suas implementações.

A sua principal missão é prover padrões para a troca, gerenciamento e integração de dados para o atendimento clínico do paciente

O HL7 também desenvolve padrões para a representação de documentos clínicos. Estes documentos têm o nome de Arquitetura de Documentos Clínicos ou Clinical Document Architecture (CDA) (Dolin, et al., 2001).

O HL7 elaborou um modelo de referência de informação no qual é possível identificar a representação das informações mais relevantes a serem utilizadas em sistemas de informação em saúde, chamado de HL7 Reference Information Model - RIM.

Baseado no RIM, foi desenvolvida uma Arquitetura de Documentos Clínicos (CDA) contendo informações estruturadas e não estruturadas para ser utilizada como padronização na interoperabilidade de sistemas.

O documento CDA contém observações clínicas e serviços, e reúne características de:

- Persistência: ele continua a existir em um mesmo estado, por um período de tempo definido por requisitos locais reguladores.

- Legibilidade Humana: garante que um receptor de um documento CDA possa exibir o conteúdo clínico em um navegador Web padrão.

- Potencial para autenticação: constitui em um conjunto de informações que se destina ser legalmente autenticados como uma única entidade.

- Contexto: estabelece o contexto padrão para o seu conteúdo.

- Totalidade: a autenticação de um documento clínico se aplica a um todo e não se aplica às partes do documento sem o contexto completo do documento. 
- Administração: mantido por uma organização responsável pela sua guarda e uso.

O documento CDA é um objeto completo de informações que pode incluir texto, imagens, som e outros tipos de mídia.

O documento CDA possui um cabeçalho e um corpo. O cabeçalho contém o contexto no qual o documento foi criado e o corpo possui as informações e as declarações que compõem o conteúdo real do documento.

O propósito do cabeçalho é possibilitar que o documento clínico trafegue entre instituições sem perdas, facilitando a gestão do documento clínico e a compilação de um documento clínico único e individual do paciente durante o ciclo de vida do registro eletrônico em saúde.

O cabeçalho possui quatro componentes lógicos:

- Informação que identifica o documento, define sua confidencialidade e descreve o seu relacionamento com outros documentos.

- O encontro descreve o cenário nas quais os dados foram coletados.

- Agentes de serviço incluem aqueles que autenticam o documento, que se destinam a receber uma cópia do documento, autores do documento e prestadores de serviços de saúde que participaram do serviço documentado.

- Envolvidos no serviço incluem o paciente e outros participantes significativos como os membros da família.

O corpo do CDA possui seções, parágrafos, listas e tabelas. Estes componentes estruturais possuem características dos dados, descrição dos dados multimídia e codificações oriundas do padrão terminológico.

Toda a estrutura do CDA tem um significado do contexto e possui atributos de confidencialidade, origem e de linguagem humana.

Os documentos inseridos no CDA incluem entradas codificadas <coded_entry>, um invólucro recursivo <content>, um mecanismo de referência genérica <link> e de multimídia $<$ observation_media>.

As entradas codificadas são utilizadas simplesmente para inserir um código no documento CDA, referenciando o texto original com base em terminologias padronizadas ou servem para referenciar a origem do texto.

O elemento recursivo permite envolver uma seqüência de texto simples. As entradas codificadas de referência podem referenciar o texto original. 
O mecanismo de referência genérica é semelhante a um hiperlink utilizada em HTML e o elemento multimídia representa a mídia na qual o documento é armazenado, fora do documento, e incorporado para garantir referência.

\subsubsection{Arquétipos}

O nome arquétipo é utilizado para designar um modelo de definição de um conceito de domínio e utiliza restrições sobre as estruturas de um modelo de referência.

Arquétipos são pedaços de conhecimento que indicam como representar conceitos ou informações. Um arquétipo de algum elemento clínico pode definir, por exemplo, que este conceito é formado por uma quantidade, tamanho, e data, entre outros conceitos.

A proposta da Fundação OpenEHR é criar um padrão que permita representar formalmente arquétipos, possibilitando assim que as especificações de conceitos clínicos criadas com o formalismo necessário sejam compartilhadas e resultem na construção de sistemas de informação em saúde fundamentados em conceitos sólidos e interoperáveis (Nardon, et al., 2008).

Arquétipos são descritos como um modelo formal e reutilizável de um conceito do domínio.

Outras características dos arquétipos são que cada conceito é descrito de forma autocontida e na forma de conhecimento volátil.

Um arquétipo é composto por três partes. Uma seção de cabeçalho, uma seção de definição e uma seção de ontologias (Kilic, et al., 2006).

O cabeçalho possui basicamente metadados sobre o arquétipo como o identificador ou informações de autorização (Moner, et al., 2006).

A seção de definição é onde os conceitos clínicos representados nos arquétipos são descritos. Uma árvore estrutural é criada a partir de um modelo de referência. Esta descrição é desenvolvida para conter as seguintes informações:

a) Contém o intervalo dos atributos e os tipos primitivos.

b) A existência de atributos e os valores obrigatórios atribuídos.

c) Contém a cardinalidade entre os atributos e a característica se o atributo é multivalorado.

d) Contém a ocorrência de um objeto indicando quantas vezes um dado de uma instância de classe ocorre. 
e) Contém os objetos complexos em que seus atributos possam ser reutilizados em outro arquétipo ou fragmento de arquétipo.

Finalmente a seção de ontologias contém os códigos que representam o significado dos nós com os termos ou textos baseados no SNOMED ou LOINC e várias outras ontologias, que são parte da seção de ontologia de um arquétipo (Kilic, et al., 2006).

Os arquétipos da Fundação OpenEHR são divididos em conjuntos do conhecimento organizados hierarquicamente em observação, avaliação, instrução, ação, administração, composição, seção, estrutura e agrupamento. Na Figura 12 identificamos a abrangência hierárquica dos arquétipos do OpenEHR.

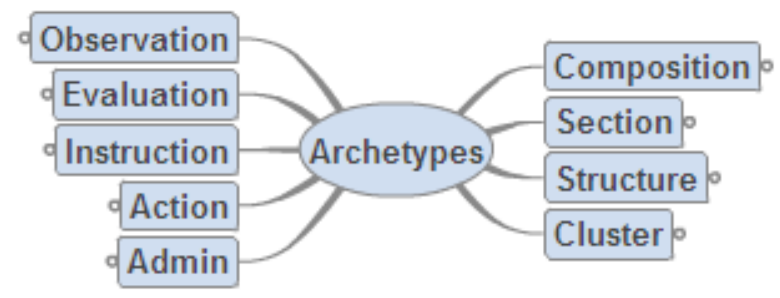

FIGURA 12 - AS ÁREAS DE ABRANGÊNCIA DOS ARQUÉTIPOS DO OPEN EHR

A Figura 13 demonstra os arquétipos que fazem parte da hierarquia de avaliação. Cada um dos arquétipos são pedaços de conhecimento auto contidos. 


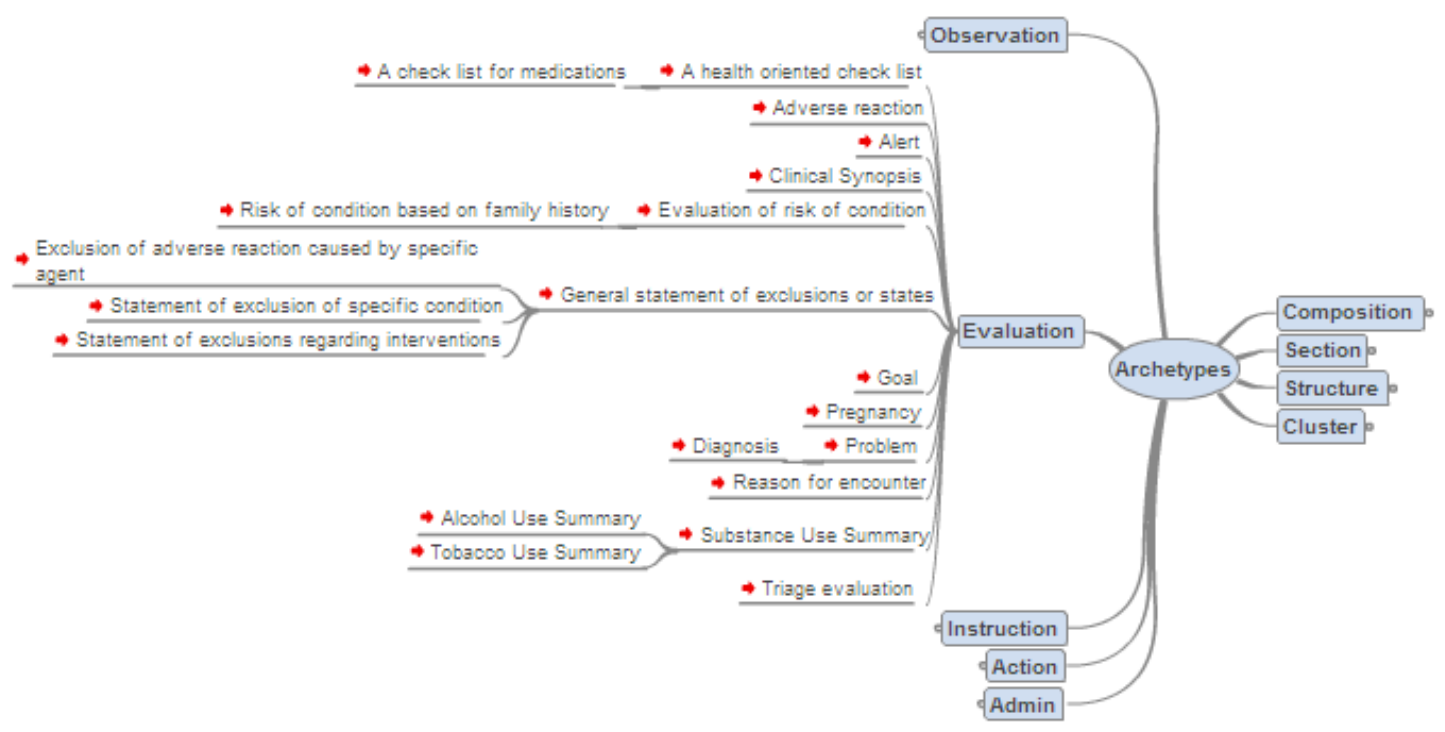

FIGURA 13 - A ÁRVORE DOS ARQUÉTIPOS DO OPEN EHR

Os arquétipos são definidos em uma linguagem computável chamada ADL (Archetype Definition Language), que pode ser tranformada em XML. Diferentes arquétipos podem ser agrupados em um template.

Um template é usado para definir uma ficha clínica, ou um formulário que será preenchido.

A partir de um template é possível definir uma interface, que pode ser utilizada por uma aplicação de entrada de dados, com base nos conceitos e definições contidas nos diversos arquétipos.

Quando as informações descritas pelos templates são informadas, dá se origem a um documento chamado composition que contém efetivamente os dados clínicos que formam as diversas fichas clínicas.

O padrão que define um composition é baseado em XML, e, com isto, é possível exportar informações para o formato de composition, mesmo que a aplicação original que coletou as informações não tenha sido baseada em arquétipos e templates. 


\section{UMA VISÃO HISTÓRICA DA REVISÃO DA LITERATURA}

Quando estudamos o processamento da linguagem natural, no domínio do conhecimento de radiologia uma das principais pesquisadoras que emerge da literatura é a Dra Carol Friedman.

Em 1994 Friedman estudou as informações clínicas registradas em relatórios e mapeou esta informação em uma representação estruturada de termos clínicos. O estudo abrangeu a aplicação de parsing, a estrutura de textos identificando o padrão semântico, a padronização de termos e, por último, uma análise mapeando os termos em um vocabulário controlado. Para este estudo foram analisados 230 laudos de radiologia (Friedman, et al., 1994).

Um estudo foi apresentado em 1996 cuja caracteristica era mostrar uma revisão do problema demonstrado pelas ferramentas de processamento de linguagem natural ao fornecer um conhecimento linguistico conveniente no domínio médico. A abordagem sintática resolveria um grande número de problemas de situações típicas, porém era insuficiente para uma qualidade no tratamento da linguagem natural. Por outro lado uma abordagem conceitual necessitava de uma modelagem do domínio e um processo abrangente na área médica estava longe de ocorrer (Baud, et al. 1996).

Em 1999 Friedman apresentou uma visão geral sobre sistemas de extração de linguagem natural. Ela descreveu brevemente os objetivos deste tipo de estudo, como desenvolver os tipos de conhecimento requeridos e o estágio do desenvolvimento até aquele momento, discutindo, também, o futuro do processamento de linguagem natural na área de saúde. Ela discorreu sobre como os modelos de domínio devem ter suas terminologias classificadas em hierarquia de conceitos através de relações bem definidas (Friedman, et al., 1999).

Ainda em 1999, Taira apresentou um estudo sobre o processamento estatístico de linguagem natural utilizando como domínio 94 laudos de radiologia aos quais aplicou métodos de aquisição do conhecimento, parsing, interpretação e avaliação semântica. Em sua conclusão faltava uma representação de saída com uma terminologia de referência. (Taira, et al., 1999)

Em 2000, foi publicado um estudo em que o objetivo era definir uma técnica para associar métodos linguisticos de um domínio específico em ontologias. Foram analisados 2810 narrações clínicos contendo procedimentos radiológicos. Concluiu-se que as ontologias poderiam ser utilizadas para melhorar a representação do conhecimento na medicina, identificando os padrões semânticos utilizando métodos linguisticos, como o processamento 
de linguagem natural, e a representação do conhecimento como a ontologia (Amaral, et al., 2000).

Um estudo sobre a aplicação de processamento de linguagem natural em 889.921 laudos de radiografias foi publicado em 2002. Este trabalho apresentou o processamento de laudos acumulados em 10 anos de um centro médico urbano, comparado com 150 laudos classificados manualmente. Foram parametrizadas 24 condições clínicas entre doenças, anormalidades e estados clínicos para serem classificadas (Hripcsak, et al., 2002).

Em 2004 Friedman publicou um método baseado em processamento de linguagem natural para mapear automaticamente um conjunto de documentos. O MedLEE foi adaptado para procurar e gerar automaticamente um código específico. Foi analisada a precisão comparado também ao Unified Medical Language System (UMLS) e a análise de seis especialistas. (Friedman, et al., 2004)

Em 2004 Castilla apresentou um trabalho sobre extração automatizada de informações clinicas a partir de relatórios de radiografias de tórax em português, por um processador de linguagem natural desenvolvido em lingua inglesa. Para este estudo foi utilizado um tradutor para a lingua inglesa. (Castilla, et al., 2004). Este trabalho culminou na tese de doutorado de Castilla, em que apresentou uma ferramenta computacional de investigação clínicoepidemiológica aplicada a textos narrativos médicos, utilizando processamento de linguagem natural e tradução automática. O experimento abrangeu 12.869 relatórios de radiografias torácicas à procura de vinte e dois achados clínicos e radiológicos (Castilla, 2007).

Também em 2007, Bacic concluiu a sua tese de doutorado que abordou os relatórios de radiografias torácicas em um contexto de terminologias médicas padronizadas, envolvendo pesquisa de ontologias, extração de informações e processamento de linguagem natural. Foram analisados 589 laudos (Bacic, 2007).

Em 2007, foi apresentada em uma dissertação de mestrado na Universidade de São Paulo um método de criação semi-automática de ontologias a partir do uso de textos de do domínio de gestão de projetos, para a extração dos conceitos e relações presentes nesses textos, com base na comparação da frequência dos termos extraídos com escritos típicos da lingua e na extração de padrões linguisticos específicos. Este método identifica termos candidatos a conceitos e relações existentes entre eles e disponibiliza a ontologia utilizando a linguagem OWL (Carvalheira, 2007).

Também em 2007, apresentou-se na Internacional Conference on Artificial Intelligence um estudo compreendendo o problema de compartilhamento de conhecimento através de 
ontologias. Foi abordada a contrução de uma ontologia de domínio específico diretamente de um corpus utilizando técnicas de processamento estatístico de linguagem natural e interligação de conceitos, utilizando como base os mapas do UMLS - Unified Medical Language System (Sahay, et al., 2007).

Um trabalho descrevendo o uso do Protége e o uso de ontologias para o domínio do conhecimento de radiologia foi apresentado em 2007. O estudo descreve a importância de padrões terminológicos e ontológicos, como o RadLex, na estruturação de laudos, no aprendizado e na busca textual. As terminologias e as ontologias estão relacionadas. Se as terminologias são uma coleção de vocábulários para um domínio específico da atividade humana, as ontologias contém algum conhecimento sobre estes termos, associando alguns atributos e relações para descrever as entidades existentes em um dado domínio do conhecimento. O RadLex é um projeto criado para compreender a terminologia médica para uso com imagens médicas, visando capturar, indexar e recuperar uma variedade de informações sobre radiologia. O RadLex foi concebido para adquirir os termos relevantes de subdisciplinas da radiologia como abdominal, cardiovascular, musculatura, pediátrica, torácica e neuroradiologia. Estes termos estão apropriados em ontologias descritas na ferramenta Protégé (Rubin, et al., 2007).

Pyrros publicou em 2007 um estudo envolvendo relatórios de radiologia em formato de texto eletrônico não estruturado contendo a palavra "apendicite" à qual foi aplicada um algoritmo de extração de termos tendo como base um sistema PACS da General Electric em um hospital. Foram selecionados aleatóriamente 500 relatórios de multiplos radiologistas. Tais relatórios foram manualmente, categorizados e agrupados em dois arquivos de textos separados em 250 laudos com relatos positivos e 250 relatórios com relatos negativos de apendicite. Os dois arquivos foram submetidos a um sistema de classificação bayesiana que analisou os achados médicos para auxiliar e testar a assertividade das classificações dos relatórios relacionados a apendicite (Pyrros, et al., 2007).

Em 2008 foi apresentado no simpósio da AMIA - American Medical Informatics Association, um estudo sobre o desenvolvimento de um método para aquisição e descoberta de conhecimento médico embutido em relatórios clínicos narrativos. Neste estudo abordaramse metodos automáticos para detectar associações entre conceitos clínicos encontrados na literatura e em relatórios clinicos narrativos utilizando processamento de linguagem natural e métodos estatísticos (Wang, et al., 2008).

Ainda em 2008 foi apresentado um estudo cujo propósito foi descrever o uso do processamento de linguagem natural para avaliar os padrões nas recomendações, em relatórios não estruturados de radiologia baseados em características de imagens de 
pacientes, sua idade, referências físicas, sub-especialidade radiológica, modalidade, indicações, doencas e status do paciente. Este estudo avaliou um total de 4.279.179 laudos de radiologia criados em um período de 10 anos. Esta base de dados inclui laudos de tomografia computadorizada, imagens de ressonância magnética, fluoroscopia, medicina nuclear, ultrassonografias, radiografias, mamografias, angiografia, procedimentos especiais e testes de imagens não classificadas. O referido estudo não foi comparado com estudos de vocabulários padronizados nem tampouco a representação através de ontologias (Dang, et al., 2008).

Um trabalho sobre o uso de ontologias para melhorar a precisão da extração de termos em documentos foi publicado em 2008. Um método linguístico foi utilizado para extrair os padrões terminológicos de documentos. Posteriormente, foi medida e classificado através de uma ontologia de termos, a dependência semântica das palavras-padrão (Zhang, et al., 2008).

Um trabalho abrangente abordando os novos direcionamentos sobre o conhecimento foi apresentado em 2008. Baden elaborou um artigo com o propósito de orientar as pesquisas em engenharia do conhecimento e processamento de linguagem natural focando na análise de métodos sintáticos e semânticos. As pesquisas envolvendo o processamento de linguagem natural normalmente envolvem: a) entendimento de textos, utilizando modelos e ontologias para entendimento de textos; b) sumarização, indexação e correção de textos, para ser utilizados na correção que ocorrem nos textos; c) generalização de textos, para obter maior cobertura discretizando alterações particulares de textos e; d) máquinas de transcrição. Já as pesquisas envolvendo a engenharia do conhecimento normalmente envolvem a) a construção de uma base de conhecimento; b) a constução de ontologias;c) os agentes inteligentes; d) os trabalhos sobre o mundo virtual e; e) modelos de comparação e checagem (Baden, et al., 2008).

Um trabalho de pesquisadores japoneses foi elaborado no ano de $2008 \mathrm{com}$ o intuito de estudar a distribuição probabilística de termos médicos em japonês e desenvolver um algoritmo de análise de textos médicos naquela língua, tendo como base relatórios de tomografia computadorizada. Foram recuperados, através de probabilidades condicionais, os uni-gramas, bi-gramas e tri-gramas. Concluiu-se que a utilização de probabilidade condicional melhoraria a exatidão da análise computacional de termos médicos na lingua japonesa (Nishimoto, et al., 2008).

Em 2009 foi publicado um trabalho sobre o Linguateca, que foi um projeto político-científico financiado pelas autoridades na área de ciência e da tecnologia em Portugual para tratar do processamento computacional da língua portuguesa. Entre os pontos importantes para o 
processamento de linguagem natural na lingua portuguesa citadas no projeto estão a transparência, o desenvolvimento de aplicações relacionadas com o setor de informação, a ligação da investigação fundamental com as tecnologias, a dinamização dos métodos empíricos, os serviços de desenvolvimento de recursos e ferramentas partilháveis, a avaliação e controle de qualidade em relação ao português, e a disponibilização de recursos (Santos, 2009).

Também em 2009, Manine apresentou um trabalho sobre o modelamento de interações de textos genéricos com ontologias. As ontologias são identificadas como uma especificação normalizada de representação de textos. Em um sistema de extração de informação uma primeira ação é a extraição de instâncias através de processamento de linguagem natural. Depois aplica-se inferência dedutiva nas ontologias, criando-se novas instâncias e regras de inferências com algoritmos de lógicas de programação, utilizando as ontologias como hipóteses da linguagem e adotando como exemplo de linguagem um corpus anotado (Manine, et al., 2009).

Um estudo com caráter de aplicação prática foi apresentado no ano de 2009. O estudo informa que os planos para um sistema de informação clínica se iniciaram em 1988 em conjunto entre a Universidade Columbia e o Hospital Presbiteriano de Nova York. Foi necessário um sistema para codificar os dados adquiridos de múltiplas fontes, e armazenálos em um repositório de dados simples e coerente. As fontes de dados não utilizavam o mesmo padrão terminológico. Foi, então, criado um dicionário de entidades médicas com base de conhecimento terminológico que poderá ser utilizado como manutenção e auditorias. Esse ambiente provê um bom local para trabalhos de pesquisa em terminologia (Baorto, et al., 2009).

Em 2009 foi apresentado um outro trabalho no qual a principal motivação era a análise do grande volume de literatura que vem sendo produzido pelos experimentos em informática em saúde nos últimos anos. Um dos pontos de verificação deste grande repositório bibliográfico é o MEDLINE. O estudo focou no estudo de processamento estatístico de linguagem natural e métodos de aprendizagem de máquina para compor um indexador de textos médicos. Estes dois métodos foram avaliados de forma independente e combinada e obteve $48 \%$ de precisão e $30 \%$ de recuperação (Névéol, et al., 2009).

Alguns trabalhos recentes abordam o tema de aplicações de técnicas de processamento estatístico de linguagem natural e a apresentação da semântica juntamente com o CDA.

Meystre (2003) aplicaram um módulo denominado de NLU (Natural Language Understanding) para fazer a análise sintática de diversos tipos de laudos, inclusive de 
radiologia torácica e a geração de arquivos XML compatíveis com o CDA. (Meystre, et al., 2003)

Huang et al (2005) utilizaram um detector de limite de orações, um analisador estatístico de linguagem natural e um etiquetador no CDA. O trabalho foi comparado com um as descrições realizadas por autores médicos (Huang, et al., 2005).

Em um terceiro trabalho de referência foram descritas as lições aprendidas na tradução de conceitos complexos da área clínica e biomédica, escritos em linguagem natural, em formatos legíveis para o computador como CDA e padrões como o LOINC e o SNOMEDCT. Não foram utilizadas técnicas de processamento estatístico de linguagem natural (Huncher, et al., 2006).

No XI Congresso Brasileiro de Informática em Saúde, Nardon e colaboradores apresentaram um artigo em que foi discutida a construção de aplicações na área da saúde baseada na especificação de arquétipos, incluindo soluções e dificuldades para a adoção deste padrão (Nardon, et al., 2008).

Ainda neste congresso, Neira et al apresentaram um artigo que descreveu o processo de especificação e modelagem de conteúdo clínico em um sistema de informação hospitalar com o uso de arquétipos (Neira, et al., 2008). 


\section{OBJETIVOS DESTE TRABALHO}

Os principais objetivos deste estudo são:

a) a extração do conhecimento de laudos de radiologia torácica utilizando técnicas de processamento estatístico de linguagem natural;

b) a identificação de semânticas dos laudos de radiologia torácica, baseada em vocabulário de referência internacional,

c) a rotulação de laudos relacionando os termos na língua portuguesa com os termos de referência internacional; e

d) o entendimento dos dados obtidos para possibilitar a interoperabilidade semântica entre sistemas.

\subsection{Contribuição da pesquisa}

As contribuições dessa pesquisa são:

a) a identificação de todas as palavras, n-gramas e frases que compõem os laudos de radiologia torácida, baseada na amostra.

b) a identificação de lacunas de conhecimento da referência SNOMED-CT, tendo base na língua portuguesa.

c) a identificação da importância estatística do uso dos artigos, preposições e outros conceitos de ligação.

d) a conversão de texto livre em dados estruturados, possibilitando a interoperabilidade de sistemas baseado em três padrões internacionais. 


\section{MATERIAIS E MÉTODOS}

Apresentamos neste capítulo os materiais e métodos adotados nos experimentos deste estudo.

\subsection{Materiais}

\subsubsection{0s Laudos de Radiologia Torácica}

O principal material utilizado nos experimentos são os laudos de radiologia torácica referenciados no trabalho de pesquisa do Dr André Coutinho Castilla (Castilla, 2007) e da Drª Alice Shimada Bacic (Bacic, 2007).

Esses laudos não possuem qualquer identificação dos pacientes, nem tampouco dos profissionais que elaboraram os laudos. O uso deste conjunto de dados já havia sido analisado e aprovado pelo comitê de ética do InCor, quando ocorreram os estudos do Dr. André Coutinho Castilla e da Drª Alice Shimada Bacic.

Esses laudos são distribuídos em nove pastas de arquivos e a quantidade de laudos em cada uma destas pastas está distribuída conforme Tabela 1.

\begin{tabular}{|c|c|c|}
\hline Item & Pasta & Quantidade de laudos \\
\hline 1 & Txt & 14 \\
\hline 2 & Txta & 1554 \\
\hline 3 & Txtb & 1555 \\
\hline 4 & Txtc & 1555 \\
\hline 5 & Txtd & 1555 \\
\hline 6 & Txte & 1555 \\
\hline 7 & Txtf & 1555 \\
\hline 8 & Txtg & 1555 \\
\hline 9 & Txth & 1987 \\
\hline
\end{tabular}

TABELA 1 - QUANTIDADE DE LAUDOS DE RADIOLOGIA TORACICA 


\subsubsection{Limitações Conhecidas}

Os laudos disponíveis para este trabalho somam 12.886 laudos de radiologia torácica. elaborados diretamente pelos radiologistas do InCor - Instituto do Coração de São Paulo, a partir de um sistema para este fim. O InCor é um hospital público de cardiologia e executa em torno de 200 exames de raio X, 50 cateterismos e mais de 15 cirurgias cardíacas por dia.

Para a edição dos laudos de raio-X o operador, médico ou digitador, pode selecionar frases a partir de uma lista de frases previamente descritas.

Esse processo inicia-se pelo digitador (tipicamente um médico imagenologista), que seleciona a frase e edita o texto liberando-o para assinatura pelo médico. $O$ médico pode alterar a edição do texto até a liberação do laudo para o paciente ou para a equipe multiprofissional do InCor.

Os laudos disponibilizados para este estudo compreendem exames realizados entre os anos de 2006 e 2007. Os laudos recebidos pelos autores não possuíam qualquer dado de identificação do paciente.

No período compreendido por estes laudos existiam três médicos especialistas, quatro digitadores e quatro médicos residentes na equipe do InCor, sendo impossível identificar a distribuição de relatórios entre os médicos e os laudos.

O português é uma linguagem que utiliza com freqüência as marcas diacríticas, porém os laudos tais como recebidos para o nosso estudo, não possuem tais marcas o que é uma limitação do sistema no qual os laudos são gerados e armazenados. Esta característica pode gerar um grande problema em estudos amplos de lingüística, porém como as palavras se restringem a um campo específico do conhecimento, não existe dificuldade de estudo.

Tipicamente os laudos de radiologia torácica analisados possuem características que descrevem os tipos de equipamentos utilizados, os procedimentos realizados, o laudo e conclusão. Nem todos os laudos apresentam esta separação de forma clara, como pode ser identificado nas amostras abaixo.

tecnica:

exame realizado em equipamento de alta potencia, com tecnica de alta kilovoltagem, que fornece escala de contraste longa (baixo contraste).

laudo:

assimetria mamaria com irregularidades dos contornos.

osteopenia difusa.

artrose bilateralmente em ombros.

escoliose dorsal com achatamento de corpos vertebrais. 
pincamento de cupula diafragmatica esquerda e opacidades imprecisas.

vascularizacao pulmonar normal.

hilos de configuracao, topografia e dimensoes normais.

imagem cardiaca normal.

aorta alongada.

arco medio normal.

espessamento cisural a esquerda.

condensacao de limites imprecisos em apice de hemitorax esquerdo (pneumonite actinica sequelar?).

conclusao:

reestadiamento de neoplasia mamaria.

ac.

tecnica:

exame realizado em equipamento de alta potencia, com tecnica de alta kilovoltagem, que fornece escala de contraste longa (baixo contraste).

laudo:

suturas metalicas no esterno.

seios e cupulas diafragmaticas livres.

vascularizacao pulmonar normal.

hilos de configuracao, topografia e dimensoes normais.

imagem cardiaca normal.

aorta normal.

parenquima pulmonar de transparencia normal.

tecnica:

exame realizado em equipamento de alta potencia, com tecnica de alta kilovoltagem, que fornece escala de contraste longa (baixo contraste).

laudo:

estruturas osseas e tecidos moles da parede toracica, sem alteracoes.

seios e cupulas diafragmaticas livres.

vascularizacao pulmonar normal.

hilos de configuracao, topografia e dimensoes normais.

imagem cardiaca normal.

aorta normal.

arco medio normal.

parenquima pulmonar de transparencia normal.

\subsubsection{Ferramentas}

Nos experimentos foram utilizadas as seguintes ferramentas:

Equipamento: Microcomputador HP, Processador Intel Pentium D925, RAM 1GB, HD-250 GB

Sistema Operacional: Windows Vista

Ferramenta para Processamento de Linguagem Natural: NLTK - Natural Language Toolkit 0.9 .2

Linguagem de programação: Python 2.5.1

Ferramenta de geração de gráficos: Matlab 6.0 
Ferramenta de representação de Ontologias: Protégé 4.0

Ferramenta para consulta aos termos SNOMED-CT - CliniClue Browser

\subsection{Métodos}

O método aplicado no nosso trabalho está esquematizado na Figura 14.

Os processos utilizados foram:

- a seleção dos laudos de referência a partir do corpus. Foram primeiramente selecionados 1000 laudos e posteriormente o estudo foi repetido para outros 1000 laudos, totalizando portanto, 2000 laudos.

- a aplicação do processamento estatístico de linguagem natural, extraindo as palavras, ngramas e frases,

- a construção dos termos referenciados em português e;

- a aplicação do rotulador de laudos clínicos.

Os laudos clínicos devidamente rotulados com as referências de vocabulário são os documentos estruturados, necessários para a interoperabilidade entre sistemas com base nas ontologias descritas em OWL, no HL7 CDA e nos arquétipos. 


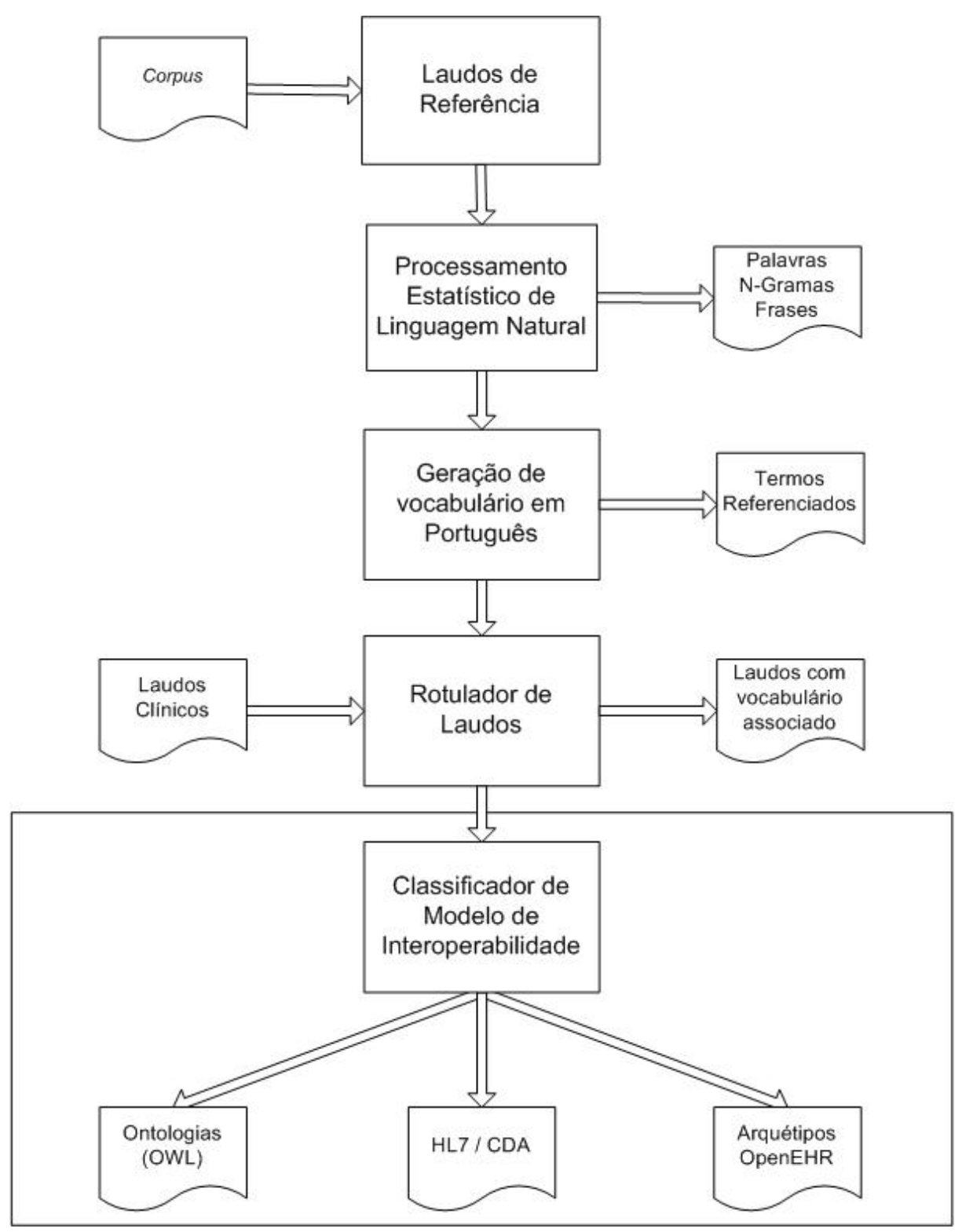

FIGURA 14 - OS MÉTODOS ADOTADOS NA SOLUÇÃO DO TRABALHO

\subsubsection{Processamento Estatístico de Linguagem Natural}

A aplicação dessa técnica busca identificar a freqüência de cada token do vocabulário no corpus. Essa distribuição permite verificar como o total de tokens é distribuído através do vocabulário do texto. 
Como já escrevemos, poucas palavras representam a maior parte das palavras existentes em um corpus.

Muitas palavras ocorrem somente uma vez no corpus, (chamadas hapaxes) mas não podem ser ignoradas face a sua semântica e sua representatividade clínica.

No nosso estudo procuramos resolver isto associando as palavras identificadas a um vocabulário padrão da área de informática em saúde, o SNOMED-CT, método que discutiremos na próxima sessão.

Inicialmente foi selecionado um conjunto de 1000 laudos.

Foi realizado o processo de tokenização, ou seja, a separação dos tokens existentes no conjunto de 1000 laudos.

Para o processo de tokenização foi utilizada a função do NLTK "nltk.tokenize.regexp.tokenize()" que retira do texto uma lista de expressões regulares. Como expressões regulares entenda como um ou mais caracteres de uma palavra.

Outro critério foi a retirada de pontos, espaços entre um ou mais caracteres.

Foi identificada a quantidade total de tokens presentes nesses laudos.

Esse procedimento foi realizado com amostragens de 10 laudos, 100 laudos, 200 laudos, 300 laudos, 400 laudos, 500 laudos, 600 laudos, 700 laudos, 800 laudos, 900 laudos e 1000 laudos.

Realizou-se um processo de análise de similaridade agrupando as palavras semelhantes e avaliando a freqüência da ocorrência destas palavras nos laudos.

Nesse processo foi utilizada a função "fd = nltk.FreqDist()" que conta o número de objetos que se apresentam de diversas formas na mesma estrutura abstrata, e resulta em um conjunto de itens e suas freqüência, chamada de distribuição de freqüência (fd frequency distribution).

Foi elaborado um ranking das palavras listando a freqüência de ocorrência dessas.

Da lista de ocorrências e do ranking foi calculado o índice de Zipf, com a finalidade de analisar a distribuição das palavras no corpus.

Para fins comparativos, foram retirados os artigos e preposições que ocorrem nos laudos. Estes artigos e preposições não oferecem conhecimento sobre a área domínio e tem uma ocorrência elevada.

Com os laudos íntegros, compostos de todas as palavras, inclusive artigos e preposições, foram separados os $n$-gramas com $n=2,3,4,5,6,7,8$, 9 e 10 . 
Para a separação dos $n$-gramas foram identificadas as palavras que se apresentavam de forma consecutiva, variando o $n$, incluindo as pontuações e outros símbolos que compõem o corpus. Foi implementada uma rotina em Phyton que realizou esse processo.

Foram separados para estudo os n-gramas que ocorrem mais de uma vez. Aqueles que ocorrem somente uma vez foram retirados da amostra, pois como ocorrem somente uma vez, não oferece representatividade estatística na composição do corpus. Não existe perda de informação visto que as palavras que compõem os n-gramas são analisadas

Foram retirados os n-gramas que continham símbolos distribuídos no conjunto, como pontuações, e também foram retirados aqueles que continham artigos e preposições no inicio ou término do n-grama. Este procedimento não interfere no conhecimento da sentença.

Em um processo manual, foram retirados os n-gramas que não faziam sentido na língua portuguesa.

Outro passo metodológico foi a consulta das frases que compõem os laudos. Foram identificadas todas as frases que compõem os 2000 laudos de radiologia torácica.

Para esse passo metodológico foi desenvolvido uma rotina em Phyton que identificou todas as sequencias de palavras que terminam em um ponto final (.).

$\mathrm{Na}$ língua inglesa, a palavra phrase significa locução, que é a junção de duas ou mais palavras que formam um conceito único. No nosso estudo frase é o conjunto de palavras que se encerra com um ponto final.

O significado de locução, em nosso estudo, está ligado ao conceito de n-gramas que são conjunto de palavras que fazem sentido em si.

Todos os passos desta metodologia foram repetidos na análise de outros 1000 (mil) diferentes laudos.

Abaixo a metodologia em passos sintéticos.

1. Selecionar os 1000 laudos de radiologia torácica.

2. Tokenizar os laudos.

3. Identificar a quantidade total de tokens

4. Identificar a quantidade de palavras diferentes

5. Calcular a freqüência das palavras.

6. Calcular o índice de Zipf 
7. Retirar as palavras (artigos, preposições, pronomes) e símbolos (pontuações)

8. Identificar a quantidade de palavras diferentes

9. Seleção dos n-gramas com $\mathrm{N}=2,3,4,5,6,7,8$, 9 e 10.

10. Realizar a separação de n-gramas que ocorrem mais de uma vez

11. Retirar os n-gramas que contém itens indesejáveis (pontuações)

12. Retirar os n-gramas que contém artigos iniciais ou finais

13. Retirar os n-gramas que não fazem sentido em si

14. Realizar os passos 1 a 14 para outros 1000 laudos de radiologia

15. Identificar a quantidade de frases diferentes

\subsubsection{Geração de Vocabulário em Português}

Com as palavras e os n-gramas representativos como saída do processamento estatístico de linguagem natural, realizamos a tradução manual de cada palavra ou n-grama para o inglês e a identificação da sua representação nas classes do SNOMED-CT bem como o seu identificador único.

Aquelas palavras e n-gramas para os quais foi identificada total semelhança com o termo traduzido, foi registrada a classe a qual pertencia e o identificador do conceito relacionado ao termo.

A saída deste módulo leva aos termos referenciados no SNOMED-CT em português, sejam eles palavras ou n-gramas.

\subsubsection{Rotulador de Laudos}

Um grupo de laudos de duzentos (200) laudos, diferentes do conjunto experimental de laudos, foi selecionado para ser utilizado na rotulação de acordo com termos de referência do SNOMED-CT.

Os 200 laudos, que correspondem ao número médio de laudos elaborados por dia no Incor, foram submetidos a uma comparação com a lista de referência de termos do SNOMED-CT em português. 
Foi elaborada uma rotina em Phyton que identifica a similaridade entre os termos do vocabulário de referência e os termos do conjunto experimental e rotula os termos do conjunto experimental de acordo com os termos do vocabulário de referência.

Aos termos encontrados, foram associados a classe pertencente ao SNOMED-CT, bem como o identificador do conceito.

Para o cálculo da eficácia do rotulador foi utilizada a fórmula de cobertura percentual de laudos classificados, em relação a aqueles não classificados.

$$
\text { Eficiácia }=\frac{\text { PalavrasClassificadasMédiaNoLaudo } * 100}{\text { TotaldePalavrasMédiaNoLaudo }} \text { (equação 4) }
$$

\subsubsection{Cálculo de Precisão e Recuperação}

Ao final do processo foram calculados os fatores de Precisão e Recuperação.

O fator de precisão pode ser entendido como a medida de exatidão ou fidelidade e o fator de recuperação como a medida de completude.

Precisão é definido como o número de palavras classificadas dividido pelo número total de palavras.

$$
\operatorname{Pr} \text { ecisão }=\frac{\text { PalavrasClassificadas }}{\text { TotaldePalavras }}(\text { equação 5) }
$$

Recuperação é definida como o número de palavras classificadas dividido pelo número de palavras classificadas somado ao número de palavras não classificadas.

Porém, o número de palavras não classificadas não é a diferença entre o número total de palavras e o número de palavras classificadas. Esse número se refere aos termos que deveriam ter sido classificados pelo método e não o foram.

Visto que essa conferência deveria ter sido realizada por profissional de saúde, mas não foi, esse fator não foi calculado.

$$
\text { Re cuperação }=\frac{\text { PalavrasClassificadas }}{\text { PalavrasClassificadas }+ \text { PalavrasNãoClassificadas }}(\text { equação 6) }
$$




\section{RESULTADOS}

Neste capítulo apresentamos os resultados obtidos nos experimentos, analisando os aspectos do processamento estatístico de linguagem natural, da geração do vocabulário em português e do rotulador de laudos.

\subsection{A Extração do Conhecimento}

A partir do processamento estatístico de linguagem natural extraímos o conhecimento incluso nos laudos de radiologia. Para que o conhecimento fosse explicitado avaliamos, conforme descrito na metodologia, a extração das palavras, n-gramas e frases mais representativas da amostra adotada para estudo, de forma a refletir estatisticamente o conhecimento constante dos laudos.

\subsubsection{0s tokens e as palavras}

Dos laudos que formam o corpus deste trabalho, foi realizado um processo de tokenização, ou seja, foram separados os tokens existentes nesses laudos. Deste processo foi possível identificar a quantidade total de tokens existentes em cada conjunto de experimentos. $\mathrm{Na}$ tabela 2 é demonstrada a quantidade de ambos os conjuntos de experimentos e a totalidade de tokens encontrados.

\begin{tabular}{|l|c|}
\hline & Quantidade \\
\hline Tokens do primeiro conjunto experimental & 77.729 \\
\hline Tokens do segundo conjunto experimental & 75.749 \\
\hline Total de Tokens & 153.896 \\
\hline
\end{tabular}

TABELA 2 - QUANTIDADE DE TOKENS NOS EXPERIMENTOS 
Identificamos que no primeiro experimento houve um número ligeiramente maior de tokens. Essa diferença não é representativa variando 2,54\%.

Visto que estes experimentos foram realizados com uma amostragem agrupada de 10 laudos, 100 laudos, 200 laudos, 300 laudos, 400 laudos, 500 laudos, 600 laudos, 700 laudos, 800 laudos, 900 laudos e 1000 laudos, foram listadas as ocorrências dos tokens em cada uma destas amostragens, e, nas Figuras 15, 16 e 17, apresentamos o resultado das duas seqüências de experimentos e da totalização desses.

Pode-se identificar as palavras em um corpus que possuem a maior quantidade de significados. Para isto é necessário contar a ocorrência das palavras no corpus e representá-la em uma distribuição ordenada crescente de freqüência de ocorrência.

Nesta técnica podemos identificar a freqüência de cada palavra do vocabulário utilizado no conjunto experimental.

Essa distribuição permite verificar como o total de palavras é distribuído através do vocabulário do texto.

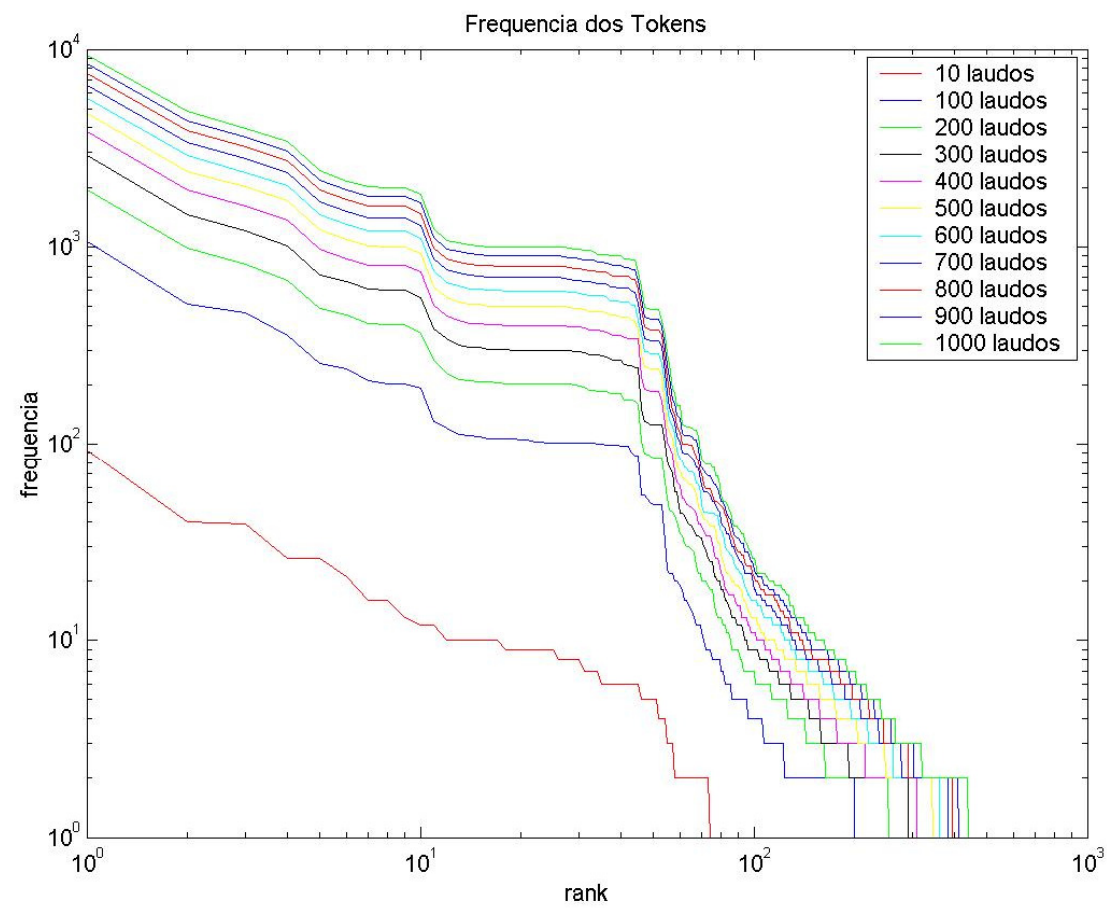

FIGURA 15 - FREQUÊNCIA DE OCORRÊNCIA DOS TOKENS DA PRIMEIRA SEQUENCIA DE EXPERIMENTOS 


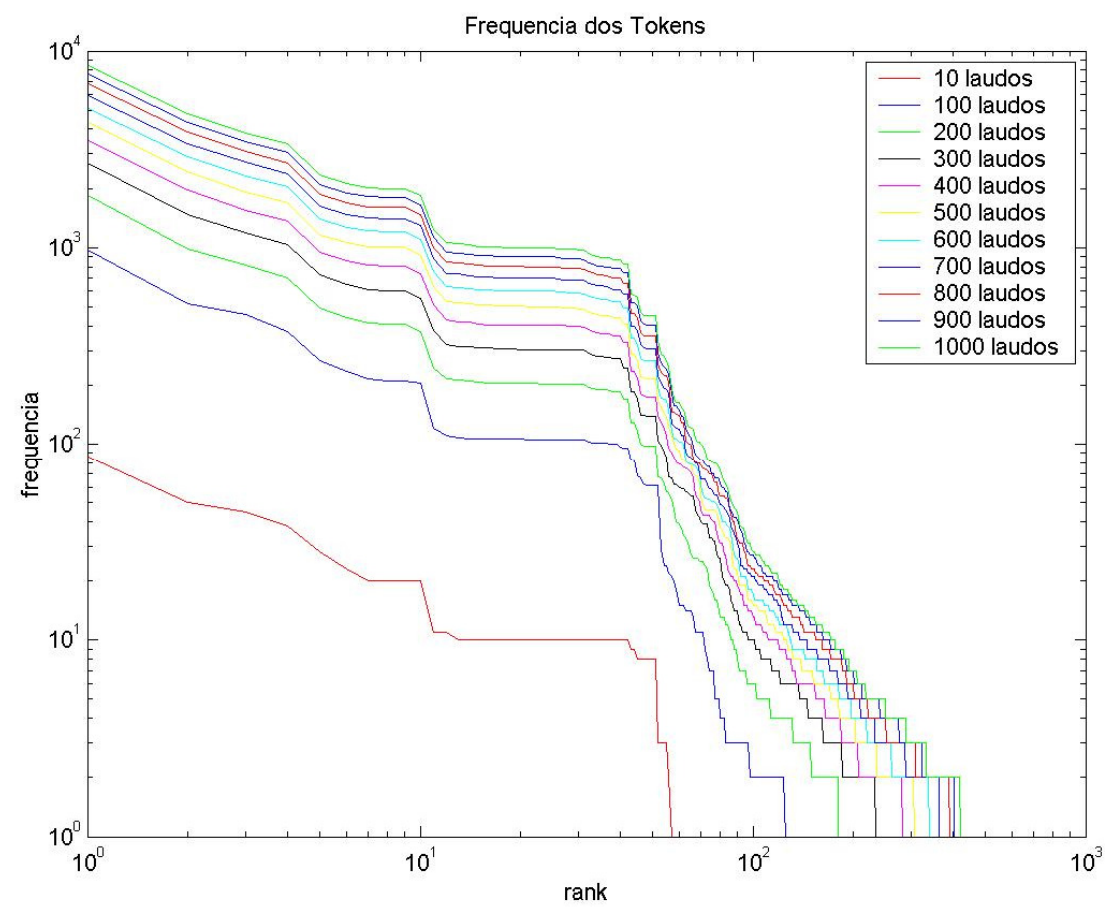

FIGURA 16 - FREQUÊNCIA DE OCORRÊNCIA DOS TOKENS DA SEGUNDA SEQUENCIA DE EXPERIMENTOS

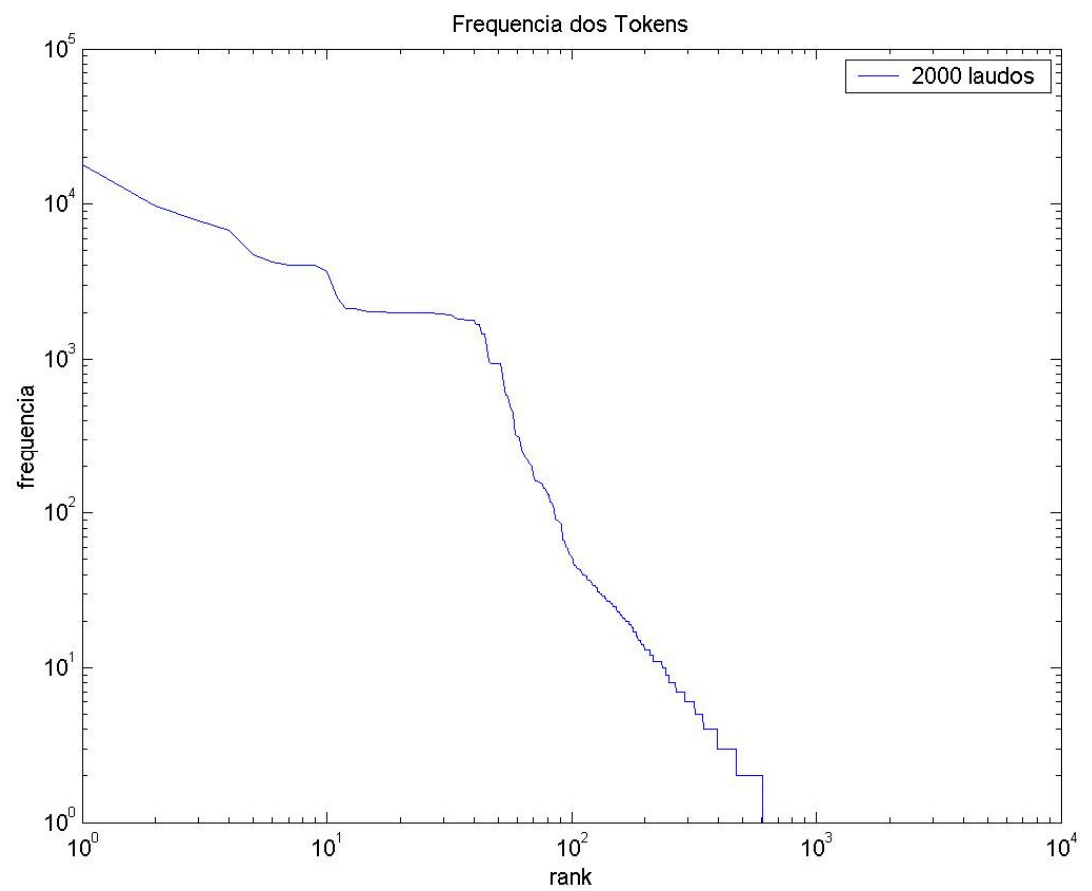

FIGURA 17 - FREQUENCIA DE OCORRENCIA DE TOKENS NOS DOIS MIL LAUDOS 
Vale ressaltar que a tendência da distribuição estatística já é notada na análise dos primeiros conjuntos de dados, ou seja, essa tendência já se verifica com a análise de 100 laudos.

Foi avaliada a freqüência de ocorrências distintas no conjunto experimental e seu valor está descritos na Tabela 3.

\begin{tabular}{|r|c|}
\hline & Quantidade \\
\hline $\begin{array}{l}\text { Ocorrências distintas do primeiro conjunto } \\
\text { experimental }\end{array}$ & 724 \\
\hline $\begin{array}{l}\text { Ocorrências distintas do segundo conjunto } \\
\text { experimental }\end{array}$ & 769 \\
\hline Total de Palavras & $\mathbf{1 . 0 6 7}$ \\
\hline
\end{tabular}

\section{TABELA 3 - QUANTIDADE DE OCORRÊNCIAS DISTINTAS DO CONJUNTO EXPERIMENTAL}

Analogamente à análise do total de tokens, houve uma pequena variação de ocorrência entre os valores do primeiro e segundo experimento, mas houve uma maior quantidade de palavras presentes nos segundos experimentos. A variação de presença foi de $5,85 \%$.

Listamos na Tabela 4 o ranking das 10 ocorrências mais freqüentes dos experimentos. 


\begin{tabular}{|c|c|c|c|c|c|c|}
\hline Rank & $\begin{array}{l}\text { Ocorrências do } \\
\text { primeiro } \\
\text { conjunto } \\
\text { experimental }\end{array}$ & $\begin{array}{l}\text { Quantidade } \\
\text { de ocorrência } \\
\text { do primeiro } \\
\text { conjunto } \\
\text { experimental }\end{array}$ & $\begin{array}{l}\text { Ocorrências } \\
\text { do segundo } \\
\text { conjunto } \\
\text { experimental }\end{array}$ & $\begin{array}{l}\text { Quantidade } \\
\text { de ocorrência } \\
\text { do segundo } \\
\text { conjunto } \\
\text { experimental }\end{array}$ & $\begin{array}{l}\text { Ocorrências } \\
\text { da totalidade } \\
\text { do conjunto } \\
\text { experimental }\end{array}$ & $\begin{array}{l}\text { Quantidade } \\
\text { de } \\
\text { ocorrência } \\
\text { total }\end{array}$ \\
\hline 1 & '.' & 9.420 & '.' & 8.476 & '.' & 17.896 \\
\hline 2 & 'de' & 4.810 & 'de' & 4.813 & 'de' & 9.623 \\
\hline 3 & 'normal' & 3.996 & 'normal' & 3.836 & 'normal' & 7.832 \\
\hline 4 & ',' & 3.378 & ',' & 3.372 & ',' & 6.750 \\
\hline 5 & 'e' & 2.414 & 'e' & 2.329 & 'e' & 4.743 \\
\hline 6 & ':' & 2.149 & ':' & 2.106 & ':' & 4.255 \\
\hline 7 & 'tecnica' & 1.995 & 'tecnica' & 2.011 & 'tecnica' & 4.006 \\
\hline 8 & 'alta' & 1.973 & 'alta' & 2.001 & 'alta' & 3.974 \\
\hline 9 & 'contraste' & 1.973 & 'contraste' & 2.000 & 'contraste' & 3.973 \\
\hline 10 & 'pulmonar' & 1.848 & 'pulmonar' & 1.837 & 'pulmonar' & 3.685 \\
\hline
\end{tabular}

\section{TABELA 4 - AS OCORRÊNCIAS MAIS MAIS FREQUENTES NOS EXPERIMENTOS}

Foram retirados dos laudos os símbolos, artigos e preposições. Estes artigos e preposições não oferecem conhecimento sobre a área domínio e tem uma elevada ocorrência no corpus. A retirada destes termos acarreta uma significativa diminuição no número de tokens do conjunto experimental. 


\begin{tabular}{|l|c|}
\hline & Quantidade \\
\hline $\begin{array}{l}\text { Tokens sem símbolos, artigos e preposições } \\
\text { do primeiro conjunto experimental }\end{array}$ & 49.056 \\
\hline $\begin{array}{l}\text { Tokens sem símbolos, artigos e preposições } \\
\text { do primeiro conjunto experimental }\end{array}$ & 47.742 \\
\hline $\begin{array}{l}\text { Total de tokens sem símbolos, artigos e } \\
\text { preposições do primeiro conjunto } \\
\text { experimental }\end{array}$ & 96.798 \\
\hline
\end{tabular}

\section{TABELA 5 - QUANTIDADE TOTAL DE TOKENS NOS EXPERIMENTOS SEM ARTIGOS, PREPOSIÇÕES E PONTUAÇÕES}

$\mathrm{Na}$ tabela 5 identificamos diminuição na quantidade de tokens, se compararmos aquelas nas quais os símbolos, preposições e artigos não foram retirados. Este fato ocorre visto que esse tipo de palavra ou símbolo ocorre muitas vezes, explicada pela lei de Zipf e que será demonstrada nos capítulos posteriores.

Com a retirada dos símbolos identificou-se uma pequena diminuição na quantidade de palavras, apresentada na Tabela 6.

Houve uma variação de 2,67\% na ocorrência de tokens entre o primeiro experimento e o segundo experimento. 


\begin{tabular}{|c|c|}
\hline & Quantidade \\
\hline $\begin{array}{l}\text { Palavras (sem artigos, preposições e } \\
\text { pontuações) do primeiro conjunto } \\
\text { experimental }\end{array}$ & 694 \\
\hline $\begin{array}{l}\text { Palavras (sem artigos, preposições e } \\
\text { pontuações) do primeiro conjunto } \\
\text { experimental }\end{array}$ & 741 \\
\hline $\begin{array}{r}\text { Total de Palavras (sem artigos, } \\
\text { preposições e pontuações) }\end{array}$ & 1.023 \\
\hline
\end{tabular}

\section{TABELA 6 - QUANTIDADE TOTAL DE PALAVRAS NOS EXPERIMENTOS SEM ARTIGOS, PREPOSIÇÕES E PONTUAÇÕES}

Houve variação na ocorrência de palavras entre os valores do primeiro e segundo experimento de $6,77 \%$ a maior para o segundo conjunto experimentado.

Após a extração dos símbolos, artigos e preposições e identificação das palavras, a ocorrência das apresentações do rank foi alterada significantemente. Na Tabela 7 apresentam-se as dez (10) primeiras palavras do rank.

Algumas palavras carregam um conhecimento bastante específico da estrutura corpórea, como as palavras 'pulmonar' e 'aorta', por exemplo. 


\begin{tabular}{|c|c|c|c|c|c|c|}
\hline Rank & $\begin{array}{l}\text { Palavras do } \\
\text { primeiro } \\
\text { conjunto } \\
\text { experimental }\end{array}$ & $\begin{array}{l}\text { Quantidade } \\
\text { de palavras } \\
\text { do primeiro } \\
\text { conjunto } \\
\text { experimental }\end{array}$ & $\begin{array}{l}\text { Palavras do } \\
\text { segundo } \\
\text { conjunto } \\
\text { experimental }\end{array}$ & $\begin{array}{l}\text { Quantidade } \\
\text { de palavras } \\
\text { do segundo } \\
\text { conjunto } \\
\text { experimental }\end{array}$ & $\begin{array}{ll}\text { Palavras do } \\
\text { total } & \text { do } \\
\text { conjunto } & \\
\text { experimental }\end{array}$ & $\begin{array}{l}\text { Quantidade } \\
\text { de palavras } \\
\text { do total do } \\
\text { conjunto } \\
\text { experimental }\end{array}$ \\
\hline 1 & 'normal' & 3.959 & 'normal' & 3836 & 'normal' & 7795 \\
\hline 2 & 'tecnica' & 2.007 & 'tecnica' & 2.011 & 'tecnica' & 4.018 \\
\hline 3 & 'alta' & 1.997 & 'alta' & 2.001 & 'alta' & 3.998 \\
\hline 4 & 'contraste' & 1.997 & 'contraste' & 2.000 & 'contraste' & 3.997 \\
\hline 5 & 'pulmonar' & 1.841 & 'pulmonar' & 1.837 & 'pulmonar' & 3.678 \\
\hline 6 & 'laudo' & 1.010 & 'longa' & 1.013 & 'laudo' & 2.020 \\
\hline 7 & 'aorta' & 1.003 & 'laudo' & 1.010 & 'longa' & 2.012 \\
\hline 8 & 'longa' & 999 & 'exame' & 1.003 & 'exame' & 2.000 \\
\hline 9 & 'potencia' & 998 & 'realizado' & 1.001 & 'realizado' & 1.999 \\
\hline 10 & 'fornece' & 998 & 'equipamento' & 1.001 & 'equipamento' & 1.999 \\
\hline
\end{tabular}

TABELA 7 - AS 10 PALAVRAS MAIS FREQUENTES NOS EXPERIMENTOS, EXCLUÍNDO-SE ARTIGOS, PREPOSIÇÕES E PONTUAÇÕES 


\subsubsection{O Índice de Zipf}

A partir da lista de ocorrências e do ranking dos tokens foi calculado o índice de Zipf, com a finalidade de analisar a distribuição dos tokens.

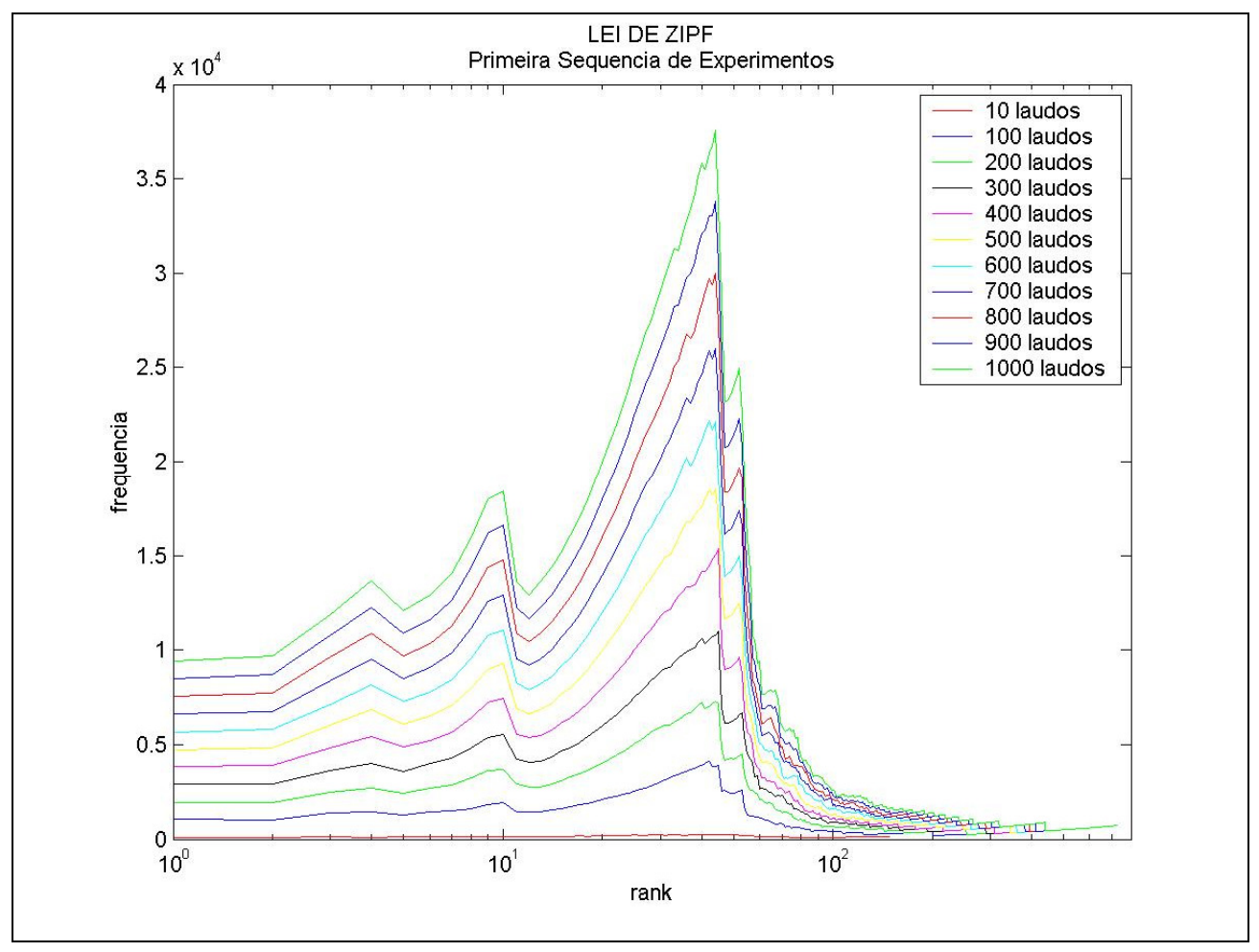

\section{FIGURA 18 - DISTRIBUIÇÃO DO ÍNDICE DE ZIPF NO PRIMEIRO CONJUNTO EXPERIMENTAL}

Nas Figuras 18 e 19 evidencia-se que as 100 palavras mais comuns são aquelas de maior representatividade dentro do espaço amostral. Verificamos nos dois experimentos um decaimento no valor do índice de Zipf por volta da palavra no rank 100 comprovando a lei de Zipf. 


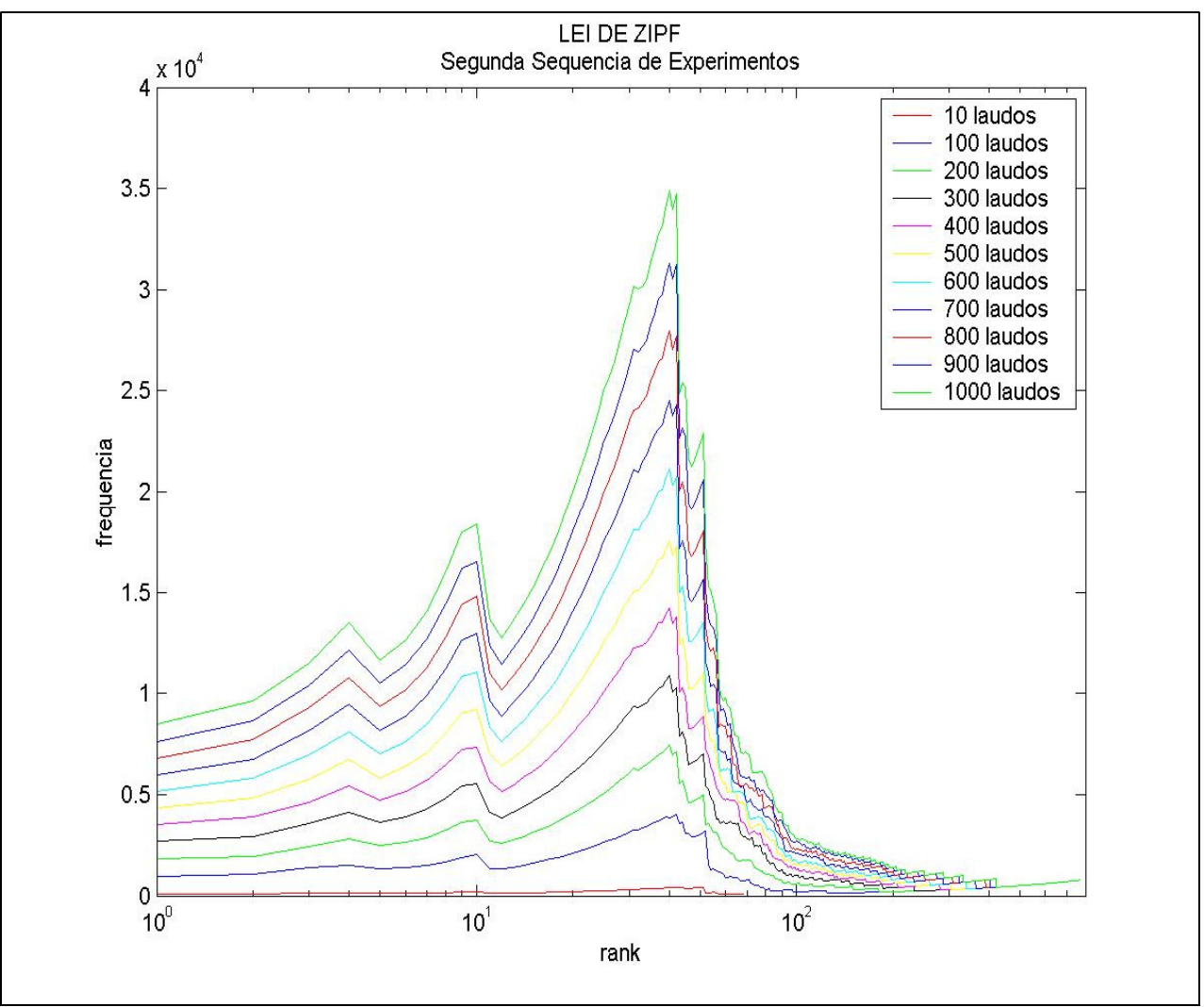

\section{FIGURA 19 - DISTRIBUIÇÃO DO ÍNDICE DA LEI DE ZIPF NO SEGUNDO CONJUNTO EXPERIMENTAL}

Na Figura 20 é demonstrado o resultado da aplicação do índice de Zipf nos 2000 laudos. Fica evidente que a tendência apontada nos dois segmentos experimentais de 1000 laudos permaneceu quando aplicado ao conjunto total.

O pico da curva está na palavra de rank quarenta (40) alcançando o valor máximo de 70.760, que é resultante do valor do rank (40) multiplicado pela freqüência da palavra (1.760). A palavra de número 40 no ranking é "transparência". 


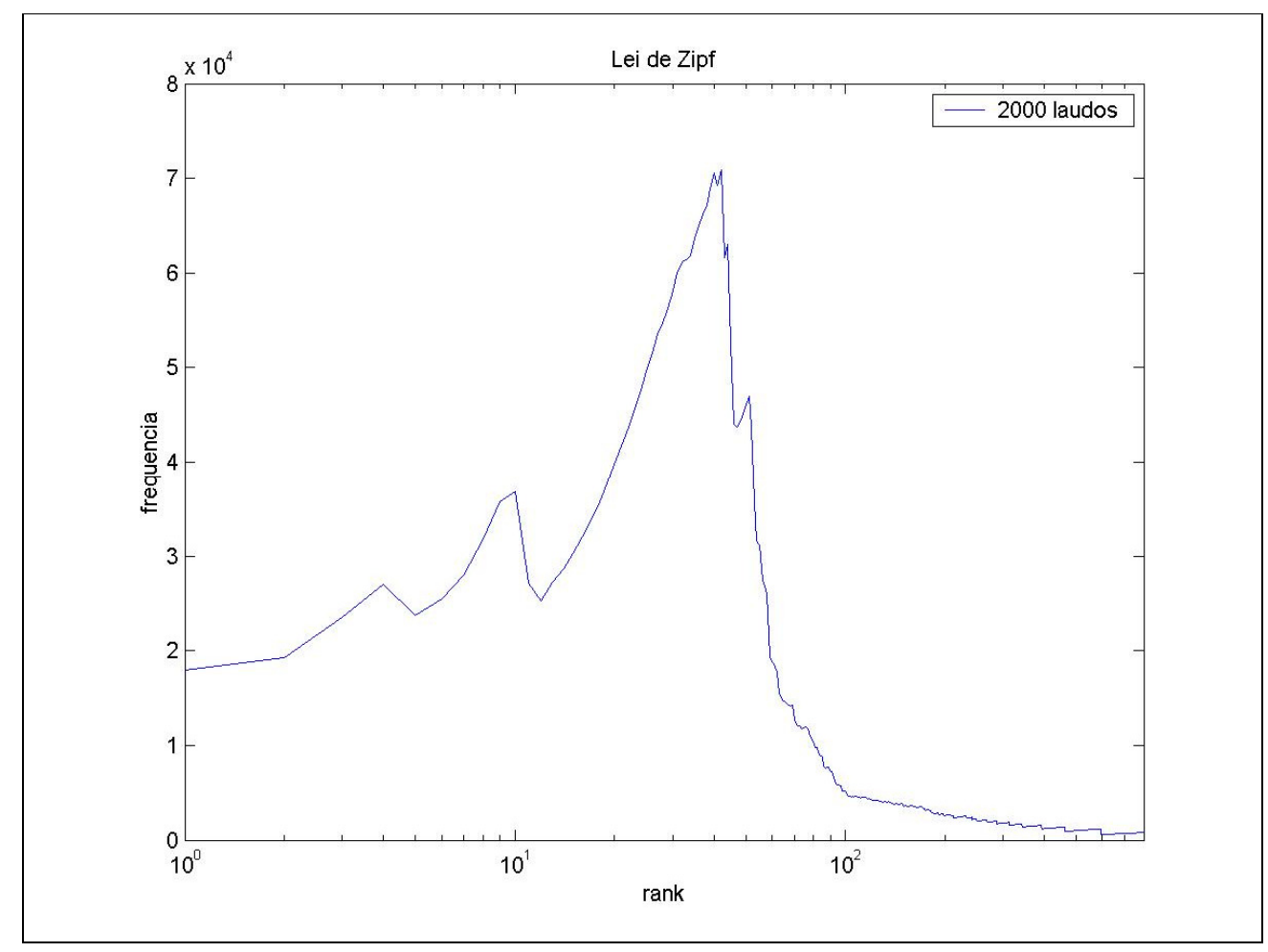

FIGURA 20 - O ÍNDICE DE ZIPF NOS 2000 LAUDOS

\subsubsection{0s n-gramas}

Com os laudos íntegros, compostos de todos os tokens, inclusive artigos e preposições e pontuações, foram segmentados os $n$-gramas com $n=2,3,4,5,6,7,8$ e 9 .

Em nossos experimentos, não houve ocorrências recorrentes de n-grams para $n>9$.

A quantidade de 2-gramas está demonstrada na Tabela 8.

\begin{tabular}{|c|c|}
\hline $\mathrm{N}$ & Quantidade de n-gramas do conjunto experimental \\
\hline $\mathrm{N}=2$ & 153.891 \\
\hline
\end{tabular}

TABELA 8 - QUANTIDADE DE 2-GRAMAS DO CONJUNTO EXPERIMENTAL 
Evidenciou-se que na análise do corpus, sob o aspecto dos n-gramas, a cada acréscimo no valor de $\mathrm{n}$, existe o decréscimo de uma unidade em cada n-grama, que é decorrente do algoritmo utilizado. Na tabela 9 exemplificamos este fato.

\begin{tabular}{|l|c|l|}
\hline TIPO & $\begin{array}{l}\text { QUANTIDADE } \\
\text { DE N-GRAMAS }\end{array}$ & SEPARAÇÃO \\
\hline FRASE & & parenquima pulmonar de transparencia normal. \\
\hline 2-grama & 4 & $\frac{\text { Parênquima pulmomar; pulmonar de; de transparência }}{\text { transparência normal }}$ \\
\hline 3 & 3 & $\frac{\text { Parênquima pulmonar de }}{\text { gransparência normal }}$ \\
\hline grama
\end{tabular}

\section{TABELA 9 - EXEMPLO DA REDUÇÃO DA QUANTIDADE DE N-GRAMAS QUANTO MAIOR O N}

Foram selecionados os n-gramas que se repetiram pelo menos uma vez. Aqueles que não apresentaram nenhuma recorrência no corpus foram descartados do conjunto da análise, pois não oferecem representatividade estatística.

$\mathrm{Na}$ tabela 10 são apresentados os n-gramas que tiveram maior ocorrência nesta fase do experimento para os primeiros dados experimentados. 


\begin{tabular}{|c|c|c|}
\hline $\mathbf{N}$ & n-gramas & $\begin{array}{c}\text { Quantidade de } \\
\text { ocorrências }\end{array}$ \\
\hline $\mathrm{N}=2$ & 'normal .' & 7.775 \\
\hline $\mathrm{N}=3$ & 'fornece escala de' & 1.998 \\
\hline $\mathrm{N}=4$ & 'fornece escala de contraste' & 1.998 \\
\hline $\mathrm{N}=5$ & 'que fornece escala de contraste' & 1.998 \\
\hline $\mathrm{N}=6$ & ', que fornece escala de contraste' & 1.998 \\
\hline $\mathrm{N}=7$ & 'kilovoltagem , que fornece escala de \\
& contraste' & 1.998 \\
\hline $\mathrm{N}=8$ & 'alta kilovoltagem , que fornece \\
& escala de contraste' & 1.998 \\
\hline
\end{tabular}

TABELA 10 - OS N-GRAMAS MAIS FREQUENTES NO CONJUNTO EXPERIMENTAL

Foram retirados do conjunto de n-gramas aqueles que continham símbolos em sua formação, exemplos como: “ “.”, “.”, “,”, “?” “!”, entre outros. Aqueles que iniciam ou terminam com preposições e artigos também foram retirados da amostra. Esta retirada não interfere no conhecimento expresso na linguagem, pois o cerne do n-grama ser repetirá em um ngrama com $n$ maior ou menor.

Em um processo manual, foram retirados os n-gramas que não faziam sentido em si.

llustramos este procedimento com o 5-grama 'normal . aorta normal $\therefore$. Este foi retirado da base de n-gramas pois além de conter um ponto final na sua formação, não faz sentido como língua portuguesa. 
Um outro exemplo de formação de 5-grama é 'exame realizado em equipamento de', que mesmo não contendo nenhuma pontuação, termina com a palavra "de" que não tem conteúdo semântico associado ao final de um termo.

Mais um exemplo de exclusão é o 5-grama 'dorsal com achatamento de corpos' que apesar de não conter pontuações, nem tampouco iniciar ou terminar com palavras de ligação, não faz sentido na língua portuguesa da forma que está expressa.

Um exemplo de 5-grama mantido na seleção é o termo 'tecidos moles da parede toracica', que não tem nenhum fator de exclusão e faz sentido na língua portuguesa.

No apêndice B se encontram todos os n-gramas resultantes deste método.

Na Tabela 11 demonstra-se a quantidade de n-gramas apresentado em cada $n$.

\begin{tabular}{|c|c|c|}
\hline N-grama & $\begin{array}{l}\text { Quantidade de } \\
\text { experimental }\end{array}$ & N-gramas do conjunto \\
\hline 2-grama & & 163 \\
\hline 3-grama & & 136 \\
\hline 4-grama & & 117 \\
\hline 5-grama & & 51 \\
\hline 6-grama & & 28 \\
\hline 7-grama & & 21 \\
\hline 8-grama & & 3 \\
\hline 9-grama & & 1 \\
\hline Total & & 520 \\
\hline
\end{tabular}

TABELA 11 - QUANTIDADE DE N-GRAMAS FINAL 
Os n-gramas foram analisados partindo das palavras até a formação de sentenças que façam sentido na língua portuguesa e que possam gerar conhecimento no contexto da análise de laudos de radiologia torácica.

Existe um decréscimo na quantidade de n-gramas quanto mais elevado seja o " $n$ ". Isto pode ser explicado pelo fato que uma sentença com várias palavras encadeadas tende a não se repetir nos laudos.

\subsubsection{As Frases}

Como descrito nos item Materiais, a edição dos laudos é feita pelos médicos, selecionandose algumas frases padrão que sofrem alterações pelos médicos e outros participantes que interfiram durante o processo de análise do exame.

Essa edição gera alterações significativas nas frases pré-estabelecidas, gerando um grande número de palavras, frases e setenças diferentes.

Com isso não é possível estabelecer um conjunto de frases comum e padronizado, o que poderia ser utilizado como base para a geração de termos de referência.

Nota-se também que se fosse utilizado um conjunto padronizado de frases termos, com referência a um vocabulário internacional, este sofreria alterações pelo processo de edição dos laudos. 


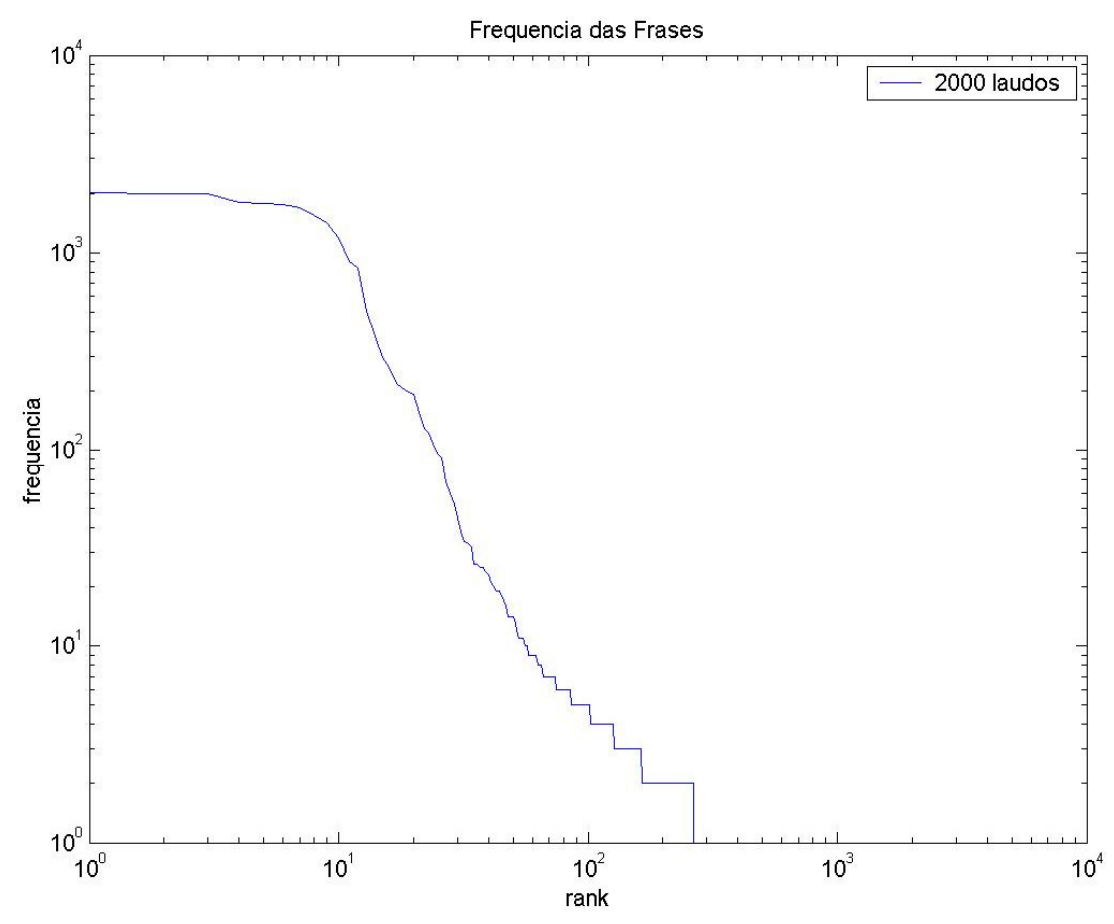

FIGURA 21 - FREQUÊNCIA DAS FRASES

Aplicando o método descrito no item 6.2, foram identificadas 1.156 frases diferentes na composição dos laudos. Da mesma forma que a distribuição de freqüência das palavras e dos n-gramas, as frases também contém o mesmo comportamento de poucas instâncias ter uma alta freqüência de incidência nos laudos e a grande maioria ter uma freqüência menor. As frases com maior freqüência são aquelas generalistas e que são estruturantes, e as frases mais específicas não ocorrem tantas vezes. A distribuição de freqüências das frases é demonstrada a Figura 21.

$\mathrm{Na}$ tabela 12 demonstramos as dez frases mais freqüentes encontradas no conjunto experimental. 


\begin{tabular}{|c|c|}
\hline Frases & $\begin{array}{c}\text { Quantidade de } \\
\text { ocorrências da } \\
\text { frase }\end{array}$ \\
\hline 'tecnica:' & 2.020 \\
\hline 'laudo:' & 1.992 \\
\hline 'exame realizado em equipamento de alta potencia, com tecnica de alta & 1.983 \\
\hline kilovoltagem, que fornece escala de contraste longa (baixo contraste).' & 1.800 \\
\hline 'seios e cupulas diafragmaticas livres.' & 1.772 \\
\hline 'vascularizacao pulmonar normal.' & 1.764 \\
\hline 'parenquima pulmonar de transparencia normal.' & 1.682 \\
\hline & \\
\hline
\end{tabular}

TABELA 12 - AS DEZ FRASES MAIS FREQUENTES DO CONJUNTO EXPERIMENTAL

\subsection{Geração de vocabulário padrão em Português}

Identificou-se que existe um grande número de termos das classes "estrutura corpórea" e da classe "valor qualificador", que é reflexo do conjunto experimental, visto que são identificadas partes do corpo e a elas associada um adjetivo qualificador. 
Algumas das classes do SNOMED-CT não foram identificadas no conjunto experimental, fato esse que ocorre por ser, o conjunto, restrito a um grupo de pessoas e a um tipo de laudo. Caso outros tipos de anotações médicas tivessem sido analisados, certamente a abrangência e cobertura de todas as classes do SNOMED-CT seriam demonstradas.

Por exemplo: o termo pulmão foi relacionado à classe "estrutura corpórea", porém a variação da palavra pulmonar (que compõe o termo parênquima pulmonar) foi identificada como valor qualificador e o termo parênquima foi identificado como estrutura corpórea.

$\mathrm{Na}$ Tabela 13 foi demonstrada a quantidade de termos referenciados por classe do SNOMED-CT.

\begin{tabular}{|l|c|}
\hline \multicolumn{1}{|c|}{ Classe SNOMED-CT } & Quantidade \\
\hline Achado Clínico & 38 \\
\hline Artefato de Armazenamento & 24 \\
\hline Conceito de Ligação & 1 \\
\hline Contexto Social & 3 \\
\hline Entidade de Observação & 81 \\
\hline Estrutura Corpórea & 1 \\
\hline Força Física & 22 \\
\hline Objeto Físico & 1 \\
\hline Organismo & 3 \\
\hline Procedimento & 2 \\
\hline Substância & 133 \\
\hline Valor Qualificador & 310 \\
\hline & Total \\
\hline
\end{tabular}

TABELA 13 - OS TERMOS REFERENCIADOS PELO SNOMED-CT 
De todos os termos extraídos dos laudos, 19,53\% puderam ser mapeados SNOMED-CT, composto de $26,4 \%$ de cobertura das palavras e $3,46 / \%$ de cobertura dos n-gramas, demonstrada na tabela 14.

Algumas palavras não referenciadas são os artigos, preposições e termos sem conteúdo semântico associado à área da saúde.

Nos n-gramas, 3,46\% compuseram a lista de termos referenciados. Esta baixa representatividade ocorre pois, aqueles n-gramas que não foram identificados na totalidade de representação do SNOMED-CT não fizeram parte do grupo de termos referenciados.

\begin{tabular}{|l|c|c|c|}
\hline & Quantidade Geral & Referenciados & \% Referenciado \\
\hline Palavras & 1.067 & 282 & $26,4 \%$ \\
\hline N-gramas & 520 & 18 & $3,46 \%$ \\
\hline & 1.587 & 310 & $19,53 \%$ \\
\hline
\end{tabular}

TABELA 14 - PERCENTUAL DE TERMOS REFERENCIADOS PELO SNOMED-CT

\subsection{Rotulador de Laudos}

Conforme descrito no item 6.2.3, os duzentos laudos experimentais foram comparados aos termos de referência em português para identificação da eficiência de rotulação.

Um dos resultados obtidos na rotulação dos laudos é apresentado abaixo.

Laudo:

tecnica:

exame realizado em equipamento de alta potencia, com tecnica de alta kilovoltagem, que fornece escala de contraste longa (baixo contraste).

laudo:

osteofitose dorsal.

esternorrafia.

obliteracao dos seios costo-frenicos.

vascularizacao pulmonar normal.

hilos de configuracao, topografia e dimensoes normais.

imagem cardiaca aumentada. 
aorta alongada.

arco medio normal.

estria densa no apice do hemitorax direito.

Rotulação:

[('tecnica', None), ('exame', 'ValQual_Qual / 302199004'), ('realizado', 'ValQual_Qual / 398166005'), ('em', None), ('equipamento', 'ConcLlg_Atr / 246137000'), ('de', None), ('alta', 'ValQual_Qual / 75540009'), ('potencia', None), ('com', None), ('tecnica', None), ('de', None), ('alta', 'ValQual_Qual / 75540009'), ('kilovoltagem', None), ('que', None), ('fornece', None), ('escala', 'ConcLlg_Atr / 278111002'), ('de', None), ('contraste', None), ('longa', 'ValQual_Qual / 255511005'), ('baixo', None), ('contraste', None), ('laudo', 'ArtArm /229059009'), ('osteofitose', 'EstCorp_AnormMorf / 88998003'), ('dorsal', None), ('esternorrafia', 'EstCorp / 302522007'), ('obliteracao', None), ('dos', None), ('seios', 'EstCorp / 181131000'), ('costo', None), ('frenicos', None), ('vascularizacao', 'ValQual_Qual / 255451006'), ('pulmonar', None), ('normal', 'ValQual / 17621005'), ('hilos', None), ('de', None), ('configuracao', 'ConcLlg_Atr / 103377007'), ('topografia', None), ('e', None), ('dimensoes', 'ValQual_Qual / 255506008'), ('normais', 'ValQual_Qual / 17621005'), ('imagem', 'ObjFis / 257445002'), ('cardiaca', None), ('aumentada', 'ValQual_Qual / 35105006'), ('aorta', 'EstCorp / 15825003'), ('alongada', None), ('arco', None), ('medio', 'ValQual_Qual / 260528009'), ('normal', 'ValQual / 17621005'), ('estria', None), ('densa', 'ValQual_Qual / 255596001'), ('no', None), ('apice', None), ('do', None), ('hemitorax', 'EstCorp / 422614002'), ('direito', None)].

As palavras que estão associadas ao rótulo None são aquelas que não foram rotuladas neste laudo

Identificou-se que os laudos contêm uma média de 57,85 palavras, sendo que 26,19 palavras em média foram rotuladas e outras 31,66 palavras não foram rotuladas.

Este resultado demonstra que apesar de 19,53 \% dos termos virarem referência, conseguiuse uma eficiência de $45,55 \%$ dos laudos serem referenciados, conforme demonstrado na Tabela 16.

É importante lembrar que existem muitos erros de digitação, abreviações e separações de palavras na edição, e que o rotulador não identifica tais situações.

Identificamos que os laudos que contém poucas palavras são aqueles para os quais se obtém um melhor índice de eficiência do rotulador, ao contrário dos laudos que contém muitas palavras.

Poucos laudos obtiveram uma quantidade de termos rotulados maior do que aqueles não rotulados como podemos verificar na Figura 22 e nas Tabelas 15 e 16. 

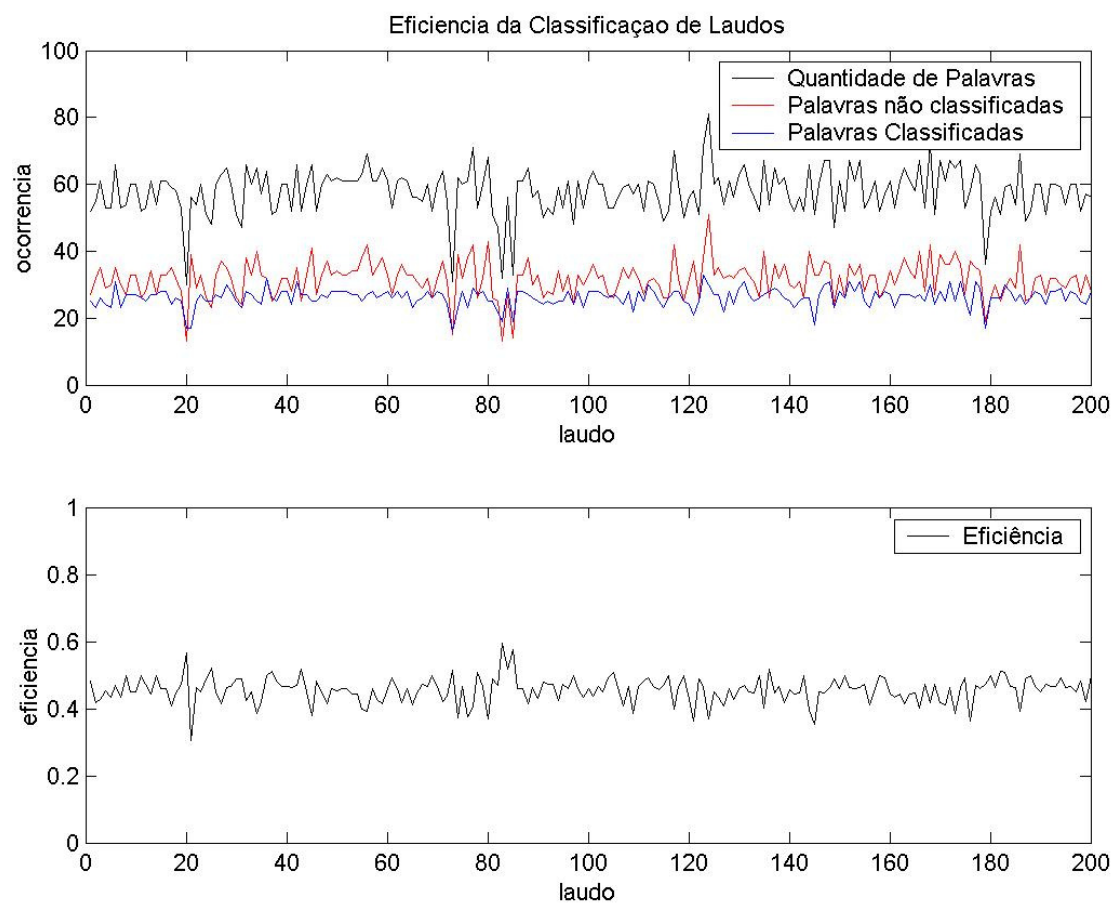

FIGURA 22 - EFICÁCIA NA ROTULAÇÃO DE LAUDOS

\begin{tabular}{|l|c|}
\hline & Média de palavras \\
\hline Por laudo & 57,85 \\
\hline Rotulados por laudo & 26,19 \\
\hline Não rotulados por laudo & 31,66 \\
\hline
\end{tabular}

TABELA 15 - MÉDIA DE PALAVRAS POR LAUDO, PALAVRAS ROTULADAS E NÃO ROTULADAS

\begin{tabular}{|l|c|}
\hline & Percentual \\
\hline Eficiência de rotulação & \\
\hline
\end{tabular}

TABELA 16 - EFICÁCIA DE ROTULAÇÃO DE LAUDOS 
Quando são inseridos no conjunto de termos referência alguns artigos, preposições ou conceito de ligação, a eficiência do rotulador tem uma expressiva melhora.

As palavras inseridas não estão associadas a um conceito do SNOMED-CT nem com o identificador único, porém também não trazem conhecimento incluso à sua semântica. Sua função é a de atribuir ou ligar conceitos dentro das frases.

As palavras inseridas como termos de referência em língua portuguesa foram 'a', 'com', 'da', 'de', 'do', 'dos', 'e', 'em', 'no', 'na', 'que', 'ao', 'as', 'nas', 'o' e 'os'.

A melhora obtida é um resultado direto da representação estatística que estas palavras têm dentro do conjunto experimental.

Com a inclusão de algumas palavras, a eficácia da rotulação tem uma expressiva melhora e em nenhum dos laudos do conjunto experimental a quantidade de palavras não rotuladas foi superior à quantidade de palavras rotuladas. Estes resultados estão expressos na Figura 23 e nas Tabelas 17 e 18. 

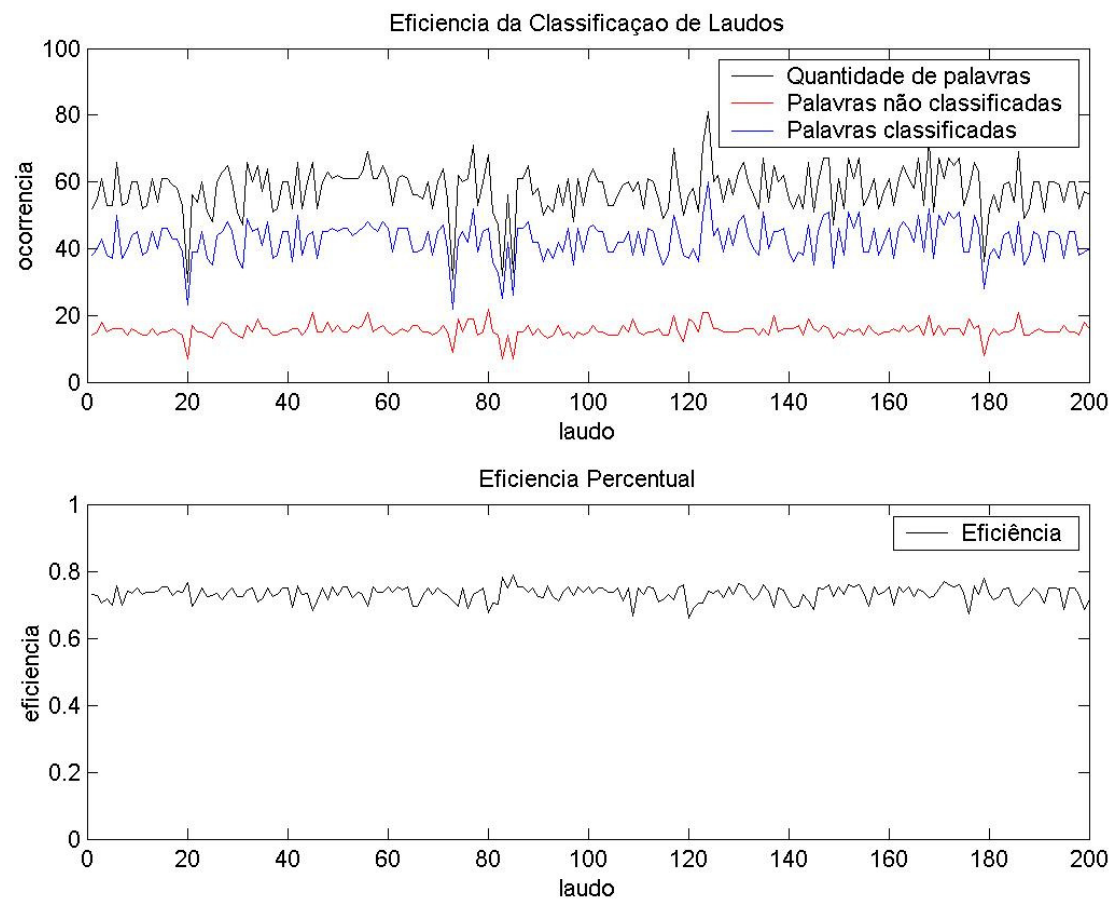

FIGURA 23 - EFICÁCIA NA ROTULAÇÃO DE LAUDOS COM REFERENCIAS COM ARTIGOS E PREPOSIÇÕES

\begin{tabular}{|l|c|}
\hline & Média de palavras \\
\hline Por laudo & 57,85 \\
\hline Rotulados por laudo & 42,39 \\
\hline Não rotulados por laudo & 15,46 \\
\hline
\end{tabular}

TABELA 17 - MÉDIA DE PALAVRAS POR LAUDO, PALAVRAS ROTULADAS E NÃO ROTULADAS COM ARTIGOS E PREPOSIÇÕES

\begin{tabular}{|l|c|}
\hline & Percentual \\
\hline Eficiência de rotulação & $73,26 \%$ \\
\hline
\end{tabular}

TABELA 18 - EFICÁCIA DE ROTULAÇÃO DE LAUDOS COM ARTIGOS E PREPOSIÇÕES 


\subsection{Precisão}

Como descrito no item 6.2.4, foi calculado o fator de precisão das palavras constantes nos 200 laudos do conjunto experimental rotulado, sem a incorporação dos artigos e preposições, e com a incorporação dos artigos e preposições, aplicando-se a equações 5.

Os resultados obtidos foram:

\begin{tabular}{|l|c|}
\hline Precisão (sem artigos e preposições) & 0,4527 \\
\hline Precisão (com artigos e preposições) & 0,7328 \\
\hline
\end{tabular}

\section{TABELA 19 - RESULTADOS DE PRECISÃO DO ROTULADOR}

Os resultados do fator de precisão são praticamente semelhantes ao fator de eficicácia aplicados ao conjunto de laudos. 


\section{O USO DOS LAUDOS EM VOCABULÁRIOS PADRONIZADOS PARA A INTEROPERABILIDADE ENTRE SISTEMAS.}

Um dos principais motivos da utilização de um vocabulário padrão é a possibilidade de realizar a interoperabilidade entre sistemas de informação.

Para haver a interoperabilidade entre dados, protocolos de comunicação são estabelecidos para que não haja perda durante a troca de informações entre sistemas.

Para operacionalizar a interoperabilidade semântica, tanto a origem da comunicação quanto o destino devem estar preparados para entender o significado das informações.

Quando a informação tem conteúdo semântico associado, e que faça sentido para o uso, seja para a recuperação de informação, seja para fins de estudos estatísticos da mesma base, ou outro fim, o conteúdo semântico deve ser estabelecido e as partes devem saber o significado do conteúdo.

Sabe-se que na área da saúde a falta de vocabulários padronizados dificulta a comunicação entre os sistemas, visto que os mesmos conceitos podem ser escritos de diversas formas, portanto, um vocabulário padrão com um identificador único pode auxiliar no estabelecimento dos conceitos, tanto pela origem como o destino da informação.

Hoje existem alguns modelos para se promover a interoperabilidade entre sistemas de informação em saúde, sendo que cada destes modelos tem características e necessidades distintas.

\subsection{Seleção do Modelo para Interoperabilidade semântica}

Três dos principais modelos utilizados para a representação da informação clínica, favorecendo a interoperabilidade semântica são as ontologias, o HL7/CDA e os arquétipos.

Para orientar o uso destes modelos, identificamos a forma de uso dos laudos rotulados para cada um deles.

tecnica:

exame realizado em equipamento de alta potencia, com tecnica de alta kilovoltagem, que fornece escala de contraste longa (baixo contraste).

laudo:

osteofitose dorsal. 
seios e cupulas diafragmaticas livres.

vascularizacao pulmonar normal.

hilos de configuracao, topografia e dimensoes normais.

imagem cardiaca normal.

aorta alongada.

arco medio normal.

parenquima pulmonar de transparencia normal.

Após o processo de rotulação do laudo o resultado obtido é:

[('tecnica', None), ('exame', 'ValQual_Qual / 302199004'), ('realizado', 'ValQual_Qual / 398166005'), ('em', None), ('equipamento', 'ConcLlg_Atr / 246137000'), ('de', None), ('alta', 'ValQual_Qual / 75540009'), ('potencia', None), ('com', None), ('tecnica', None), ('de', None), ('alta', 'ValQual Qual / 75540009'), ('kilovoltagem', None), ('que', None), ('fornece', None), ('escala', 'ConcLlg_Atr / 278111002'), ('de', None), ('contraste', None), ('longa', 'ValQual_Qual / 255511005'), ('baixo', None), ('contraste', None), ('laudo', 'ArtArm /229059009'), ('osteofitose', 'EstCorp_AnormMorf / 88998003'), ('dorsal', None), ('seios', 'EstCorp / 181131000'), ('e', None), ('cupulas', None), ('diafragmaticas', 'ValQual_Qual / 263734003'), ('livres', 'ConcLIg_Atr / 37837009'), ('vascularizacao', 'ValQual_Qual / 255451006'), ('pulmonar', None), ('normal', 'ValQual / 17621005'), ('hilos', None), ('de', None), ('configuracao', 'ConcLlg_Atr / 103377007'), ('topografia', None), ('e', None), ('dimensoes', 'ValQual_Qual / 255506008'), ('normais', 'ValQual_Qual / 17621005'), ('imagem', 'ObjFis / 257445002'), ('cardiaca', None), ('normal', 'ValQual / 17621005'), ('aorta', 'EstCorp / 15825003'), ('alongada', None), ('arco', None), ('medio', 'ValQual_Qual / 260528009'), ('normal', 'ValQual / 17621005'), ('parenquima', 'EstCorp / 113255004'), ('pulmonar', None), ('de', None), ('transparencia', 'ValQual_Qual / 261179002'), ('normal', 'ValQual / 17621005')]

As palavras que estão associadas ao rótulo None são aquelas que não foram rotuladas neste laudo.

Em seguida à classe com a qual a palavra foi rotulada, está descrito o identificador do conceito da palavra do SNOMED-CT. Por exemplo o resultado ('exame', 'ValQual_Qual / 302199004') indica que a palavra 'exame', está associada à classe valor qualificador, é um qualificador e tem um identificador de número 302199004.

Portanto as palavras rotuladas no exemplo são:

('exame', 'ValQual_Qual / 302199004'),

('realizado', 'ValQual_Qual / 398166005'),

('equipamento', 'ConcLlg_Atr / 246137000')

('alta', 'ValQual_Qual / 75540009'),

('alta', 'ValQual_Qual / 75540009')

('escala', 'ConcLIg_Atr / 278111002'

('longa', 'ValQual_Qual / 255511005')

('laudo', 'ArtArm /229059009'),

('osteofitose', 'EstCorp_AnormMorf / 88998003'),

('seios', 'EstCorp / 181131000')

('diafragmaticas', 'ValQual_Qual / 263734003')

('Iivres', 'ConcLlg_Atr / 37837009')

('vascularizacao', 'ValQual_Qual / 255451006')

('normal', 'ValQual / 17621005')

('configuracao', 'ConcLlg_Atr / 103377007') 
('dimensoes', 'ValQual_Qual / 255506008')

('normais', 'ValQual_Qual / 17621005')

('imagem', 'ObjFis / 257445002')

('normal', 'ValQual / 17621005')

('aorta', 'EstCorp / 15825003')

('medio', 'ValQual_Qual / 260528009'),

('normal', 'ValQual / 17621005')

('parenquima', 'EstCorp / 113255004')

('transparencia', 'ValQual_Qual/261179002')

('normal', 'ValQual / 17621005')]

Como exposto ao se discutir a eficiência do rotulador, algumas palavras do laudo não foram rotuladas, porém os pontos que contém termos clínicos foram classificados.

\subsubsection{Ontologias}

A ontologia utilizada foi a da classificação hierárquica do SNOMED-CT. Ela foi representada através do Protege baseada na linguagem OWL.

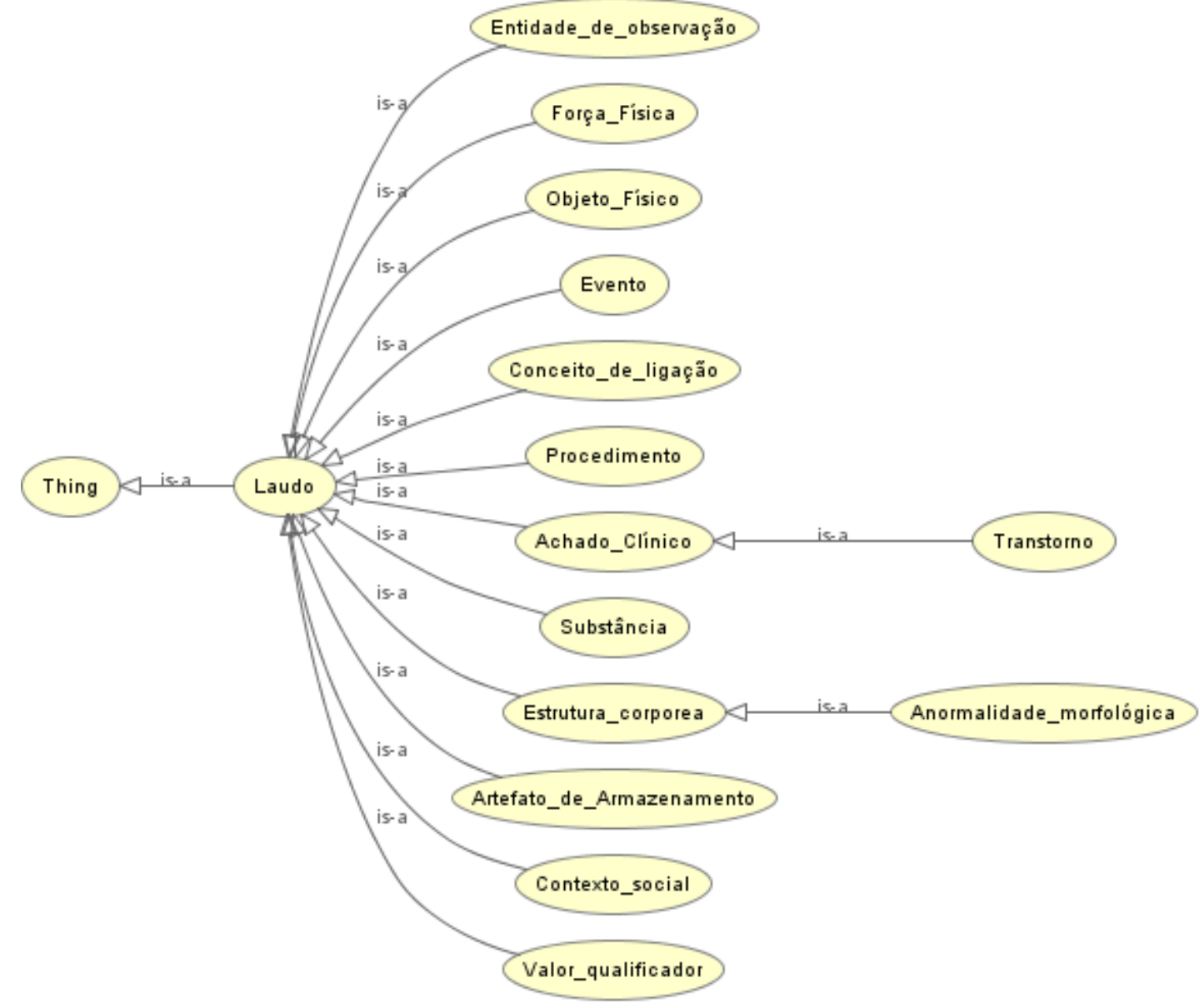

FIGURA 24 - ONTOLOGIA BASEADA NO SNOMED-CT E REPRESENTADA NO PROTĖGÈ 
Conceitualmente, quando um termo receber um rótulo da classe do SNOMED-CT este seria associado a esta classe e, no caso de necessitar de estabelecer comunicação com outros sistemas, seria utilizado o OWL com a semântica da estrutura hierárquica utilizada pelo SNOMED-CT.

Todas as palavras do grupo de referência foram inseridas na ontologia criada no Protégé como instâncias das classes hierárquicas do SNOMED-CT. As classes hierárquicas utilizadas estão descritas na Figura 24.

As classes Achado Clínico e Estrutura Corpórea possuem as subclasses Transtorno e Anormalidade Morfológica, respectivamente. Na Figura 25 representamos a estrutura hierárquica e as instâncias da classe Transtorno, representada no Protégé.

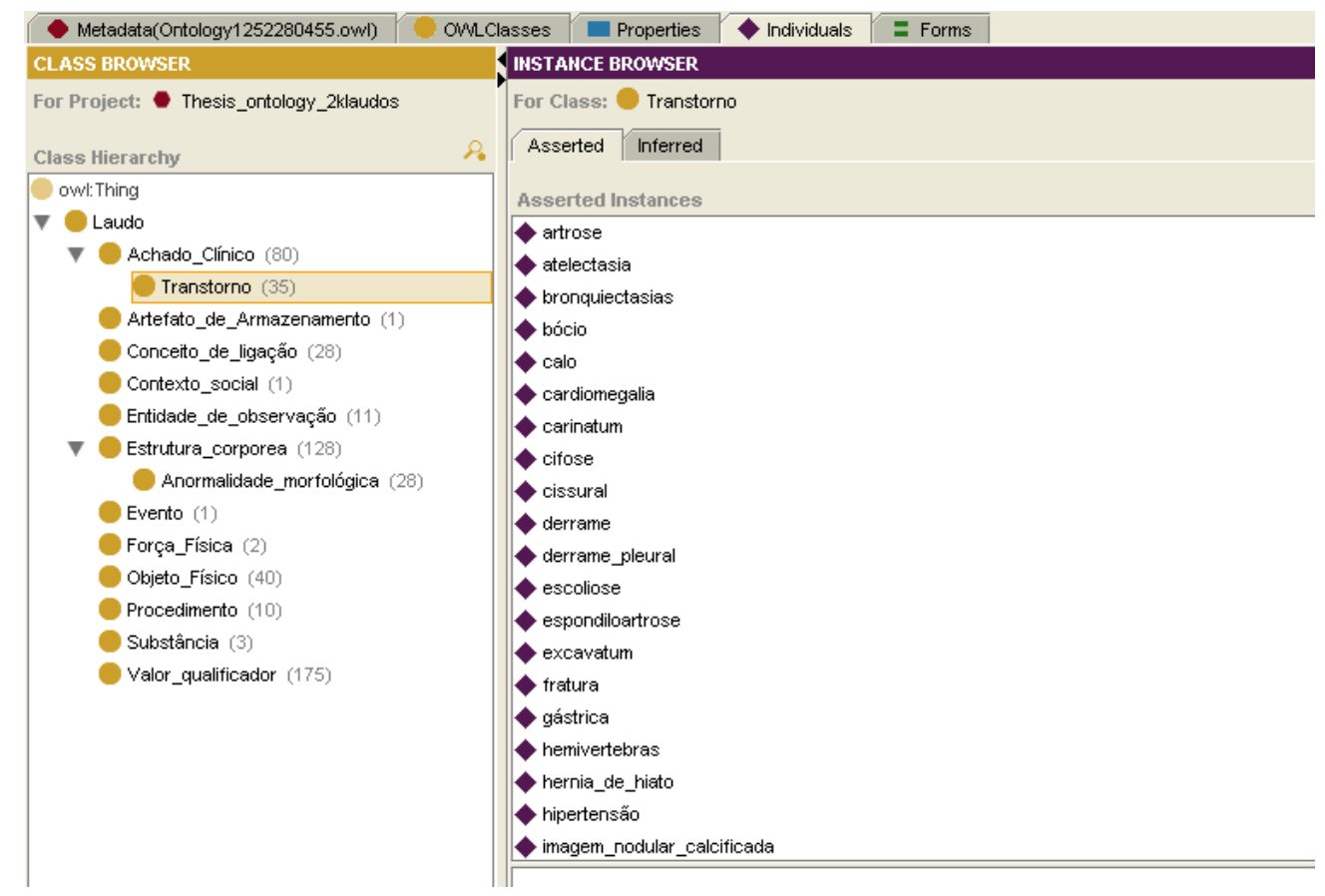

\section{FIGURA 25 - ONTOLOGIA BASEADA NO SNOMED-CT E REPRESENTADA NO PROTĖGÉ}

Conceitualmente, quando um termo recebe um rótulo da classe do SNOMED-CT este fica associado a esta classe e, no caso de necessitar de estabelecer comunicação com outros sistemas, seria utilizado o OWL com a semântica da estrutura hierárquica utilizada pelo SNOMED-CT. 
Dessa forma a representação do laudo que ilustrado nesse capítulo teria a representação ontológica demonstrada na Figura 26.

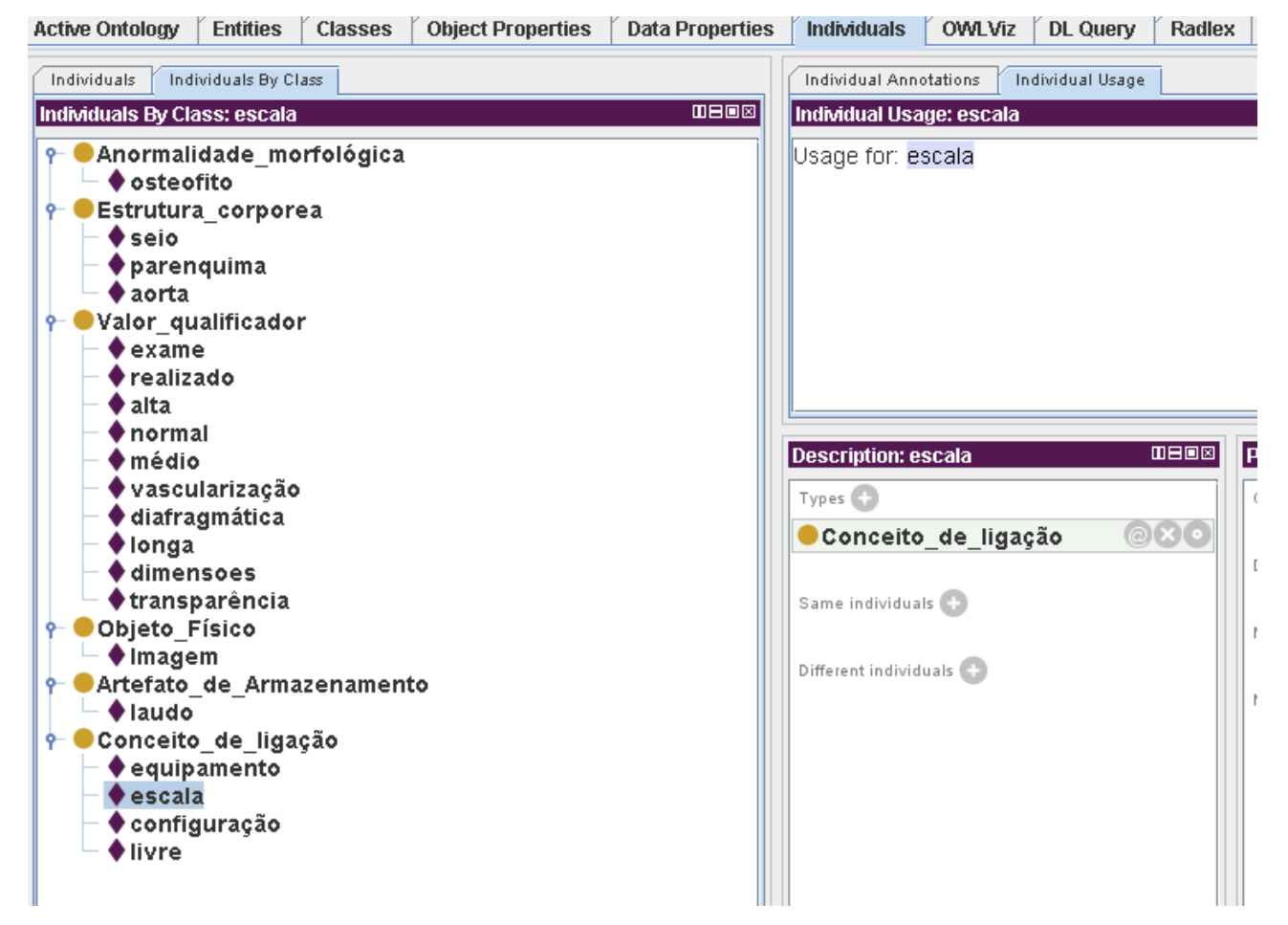

\section{FIGURA 26 - REPRESENTAÇÃO DAS INSTÂNCIAS DAS CLASSES DO LAUDO EXEMPLO}

Representada na Figura 26, a palavra "escala" é um conceito de ligação que é parte do laudo de radiologia torácica.

\subsubsection{HL7 / Clinical Document Architecture}

Visto que o HL7 Reference Information Model - RIM foi a referência para o desenvolvimento da Arquitetura de Documentos Clínicos, caso as informações dos laudos sejam utilizadas para incorporar este padrão, um modelo de dados deve basear a arquitetura do sistema para contemplar esta necessidade. 
As informações dos laudos devem ser mantidas de forma a não alterar sua integridade, e em outra estrutura do CDA deve ser identificada e estruturar o texto.

O cabeçalho, ou header, tem a função de identificar o paciente e as principais características sociais na qual ele se insere.

O corpo do CDA, ou body, tem a função de identificar o tipo de exame / procedimento ao qual o paciente foi submetido, bem como os resultados clínicos dessa atividade.

Os dados não estruturados, no nosso conjunto de laudos, são o laudo descrito em linguagem natural, já os dados estruturados devem conter a padronização de nomenclatura que utilizada, SNOMED-CT, e os identificadores dos termos clínicos encontrados no texto.

\subsubsection{Arquétipos}

Arquétipos são pedaços de conhecimento representado em uma árvore hierárquica, ou mapa mental, organizado e distribuído pelo OpenEHR. Os laudos de radiologia torácica eles são representados por conjuntos de arquétipos.

Existem "ramos" da árvore hierárquica que são diretamente relacionados com os resultados dos laudos.

No "ramo" Cluster existe um arquétipo para a discriminação do exame de tórax (examination of chest). No "ramo" Observation existe um arquétipo para o diagnóstico por imagens (diagnostic imaging) e para os achados do exame (examination findings).

Dessa forma, deve-se elaborar um mapeamento de dados no qual cada um dos tipos de informações descrita no laudo, seja por palavras, n-gramas ou frases, possa intergrar os templates definidos pelos arquétipos, reutilizando o conhecimento em várias fichas clínicas e mantendo o dado integro e único em um repositório. 


\section{DISCUSSÃO E ANÁLISE DOS RESULTADOS}

O material disponibilizado para a pesquisa foi um conjunto de laudos de radiologia em radiografia de tórax.

Deste conjunto selecionaram-se 2.000 laudos para serem analisados e, assim, fazerem parte do conjunto de referência e serem utilizados para rotulação dos laudos.

Foram selecionados 200 laudos para serem rotulados e serem submetidos à análise de eficiência dessa rotulação.

Para tanto, um conjunto de métodos foi aplicado com o objetivo de chegar à extração do conhecimento dos laudos.

O primeiro método aplicado foi a tokenização dos laudos.

Deste processo identificou-se que poucas palavras são responsáveis por grande representatividade estatística dos laudos. Por exemplo, o termo que teve maior ocorrência no texto foi o símbolo '.' e posteriormente a palavra 'de'.

Alguns artigos e preposições também têm grande representatividade estatística, o que foi comprovado quando tiramos os símbolos e a pontuação para identificação das palavras e fizemos a análise da distribuição estatística. Com a retirada de 44 palavras, ou pontuações, a redução do corpus foi de $37 \%$ de termos, demonstrando que poucas palavras e pontuações são responsáveis por grande parte do texto.

Com a retirada dos artigos e preposições, não foi alterado o gráfico da distribuição estatística. Isto comprova os estudos de George K. Zipf sobre o comportamento humano e o princípio do mínimo esforço, segundo o qual palavras que tem vários significados são as utilizadas com maior freqüência.

Outro ponto de nosso método é a análise dos n-gramas, que são termos formados por palavras consecutivas em que o $n$ se refere ao número de palavras que compõem o ngrama.

No intuito de analisar a semântica dos termos foram retirados do conjunto de n-gramas aqueles que não tinham recorrência, aqueles que tinham símbolos na sua formação, aqueles que se iniciam ou terminam com preposições e artigos, e aqueles que não fazem sentido em si. 
Dessa forma 520 n-gramas ou termos foram selecionados do corpus. O maior número de termos extraídos é aquele com o n menor, ou seja, foram 163 2-gramas extraídos e somente 19-grama extraído do conjunto de laudos para fazer parte do conjunto de referência.

Isto ocorre, pois quanto maior o $n$ menor a chance deste conjunto de termos ocorrer sem serem entrecortados por símbolos da linguagem e que tenha no início ou fim a composição de artigos e preposições além de fazer sentido em si.

Quando um n-grama é entrecortado por alguma pontuação, as partes separadas pelo símbolo obrigatoriamente farão parte de um n-grama com $n$ menor. Caso o n-grama não ocorra mais que uma vez, então ele não tem representatividade estatística.

Dessa forma além das 1.023 palavras que formam o conjunto para análise da composição do conjunto de referência, outros 520 termos também foram extraídos do texto para fazer parte deste conjunto, totalizando 1.543 palavras ou termos que foram comparados com um vocabulário de padrão internacional, na qual escolhemos o SNOMED-CT.

Outro estudo realizado no conjunto de laudos foi a extração das frases que compunham os 2.000 laudos. Foram identificadas 1.156 frases. Este experimento foi realizado para identificar qual o impacto da manipulação das frases selecionadas do sistema de digitação e elaboração de laudos.

Identificou-se que pequenas modificações são realizadas nas frases e que estas podem ter significados alterados com estas modificações.

O processo de manipulação dos laudos também é responsável pela geração de erros na grafia das palavras. Sabemos que esse processo é necessário para a adaptação das frases prontas para a real necessidade de escrita do laudo, porém, buscar uma forma de utilização de vocabulário padrão e livre de erros de grafia ajudaria no processo de análise, classificação e busca de resultados nos laudos.

As 1.543 palavras ou termos foram traduzidos e verificada a sua existência no SNOMEDCT. Como a tradução e análise dos termos não foram realizadas por um especialista médico, não foi realizada uma análise sobre sinonímia ou termos correlatos. Essa característica pode ter levado ao descarte de termos que existem no SNOMED-CT.

Da análise, foram encontrados 338 palavras ou termos com uma identificação expressa no vocabulário de referência SNOMED-CT. Destes termos foram identificados também a classe à qual ele pertence bem como o identificador do conceito.

Foram identificadas 12 classes de palavras de um total de 19 classes possíveis. A falta de cobertura para todas as classes é motivada pelo tipo do conjunto de laudos, que é restrito e 
especializado em radiologia torácica, não abrangendo todos os conhecimentos e vocabulário da área da saúde.

As 338 palavras expressas nas 12 classes formaram o conjunto de referência ao qual foi comparado um conjunto de 200 laudos.

Este conjunto de laudos se refere à média de um dia de procedimentos e geração de laudos de radiografias de tórax no InCor.

Cada palavra ou termo dos laudos foi comparado à existência de um termo de referência. Caso esse termo existisse, o termo ganharia um rótulo com a classe do termo e seu identificador único.

A eficiência de rotulação foi de $45,55 \%$ dos laudos. Identificamos este índice baixo, pois com esse processo não rotulamos $54,45 \%$ das palavras ou termos dos laudos.

Iniciamos então uma análise com o intuito de inserir no conjunto de palavras de referência, os artigos e preposições como parte do grupo de referência, na classe conceito de ligação. Esses termos fazem a ligação entre outros conceitos, não carregando uma semântica em sua estrutura.

Dessa forma refizemos o experimento de rotulação e o resultado obtido foi de $73,26 \%$, elevando substancialmente a eficiência do rotulador.

Obviamente, esse resultado é influenciado pela grande representatividade estatística que estes termos possuem, conforme discutido anteriormente.

Como a estrutura de geração de laudos ainda possui grande incidência de erros de grafia do português, um tradutor e rotulador automático também seriam passíveis de inserção de muitos erros.

A aplicação de técnicas de análise de palavras por radicais, como o stemmer necessita de uma análise criteriosa de especialistas da saúde, pois um termo pode ser um substantivo e se tornar um adjetivo somente pela sua terminação. Ex: pulmão e pulmonar, apesar de ter o mesmo radical "pulm" diferem seu sentido já que a palavra "pulmão" descreve o órgão e "pulmonar" descreve o local onde algo pode estar ocorrendo.

O resultado obtido não prejudica uma das funções do rotulador, que é a de possibilitar a interoperabilidade semântica entre sistemas.

A interoperabilidade ocorre quando originador e destinatário das informações trafegantes entre sistemas de comunicação entendem o conteúdo das informações gerando assim o conhecimento. 
Estudamos a interoperabilidade a partir ontologias, do HL7/CDA e dos arquétipos.

Para as ontologias utilizamos a classificação do SNOMED-CT e mapeamos, na ferramenta Protégé, em linguagem OWL, as classes e as instâncias dessas classes.

Caso um sistema não tenha qualquer preparação para a interoperabilidade, a iniciativa de ter uma referência semântica relacionada às classes SNOMED-CT poderia inicialmente ser uma boa alternativa.

O HL7/CDA é um padrão para interoperabilidade que tem com um dos preceitos que ele possa ser interpretado por humanos e por máquinas. Ele é expresso como um documento XML.

Por meio do HL7/CDA podem ser representados vários tipos de dados clínicos, como dados de identificação do paciente, endereço, procedimentos aplicados, e resultados obtidos, por exemplo.

Neste caso, o laudo de radiologia pode ser expresso na sua forma original, preservando as características e necessidades do profissional médico que o gerou, mas também de uma forma estruturada pela expressão de termos vinculados ao SNOMED-CT.

Outra forma de interoperabilidade que está aumentando sua expressão internacional é a representação através de arquétipos, que são pedaços de conhecimento reutilizáveis, usados como blocos para a composição de outros pedaços de conhecimento.

Como os laudos de radiografia torácica são uma técnica específica aplicada a uma parte restrita do corpo, os dados gerados podem compor partes de arquétipos, visto que não há um arquétipo específico para os resultados de laudos de radiografia torácica. 


\section{CONCLUSÃO}

O corpus utilizado é resultado da seleção de 2000 laudos, produto do processo da realização de exames de radiologia torácica do InCor nos quais médicos, descrevem a técnica utilizada, os achados obtidos e, circunstancialmente, a conclusão do laudo. Esse corpus é caracterizado pela falta sinais diacríticos e por erros de grafia.

Os laudos tem, em média, 57,85 palavras, sendo impossível identificar a distribuição de relatórios entre os médicos do corpo clínico do InCor.

O processo de tokenização permitiu identificar que, apesar do grande número de tokens que se apresentam no corpus (153.896), o número de palavras é muito menor (1.067). Ao retirarmos apenas 44 palavras como artigos e preposições entre outros (resultando em 1.023 palavras), existe uma grande diminuição da quantidade de tokens no corpus (96.798).

Essa redução de $37,10 \%$ demonstra que palavras que tem maior quantidade de significados associados, ou que oferecem a ligação entre termos, são muito representativas na formação do corpus.

Uma palavra é definida como sendo uma seqüência de caracateres que se localizam entre um espaço inicial e um espaço final. Um problema identificado é que as palavras de grafia incorreta não podem ser utilizadas nem para os termos de referência nem tampouco são possíveis de rotulação.

Foi comprovado o atendimento à lei de Zipf para o corpus utilizado. Esta lei oferece uma visão de que utilizamos poucas palavras para nos comunicar, e é baseada no princípio do mínimo esforço. Identificamos que pouco mais de 100 palavras são responsáveis pela grande maioria de palavras no corpus $(95,22 \%)$, sendo que as demais têm poucas ocorrências ou somente uma ocorrência.

A comprovação da lei de Zipf mostra que não podemos nos basear somente no processamento estatístico de linguagem natural para a seleção de palavras para compor os termos de referência. Algumas palavras da área médica, nem sempre ocorrem mais de uma vez, pois podem descrever alguma situação rara e podem não ser captadas, caso o processamento esteja baseado somente na distribuição estatística das palavras.

Para compor os termos de referência realizamos um estudo de identificação de n-gramas no corpus. Os $\mathrm{n}$-gramas foram identificados para atender $\mathrm{n}$ quando $2 \leq n \leq 9$. 
Os resultados obtidos demonstram que quanto maior o valor de "n", menor a quantidade de n-gramas identificados no corpus. Foram identificados 520 n-gramas sendo que 1632 gramas e apenas 1 9-grama. Isso confirma a percepção intuitiva de que quanto maior a quantidade de palavras no n-grama menor a chance de repetição do n-grama.

O conceito de n-grama está relacionado ao conceito de locução, em que uma sequência de palavras tem o significado de apenas uma, como em "dor de cabeça" que tem o significado de "cefaléia". Assim, se um n-grama é formado por muitas palavras, além da repetição da sua ocorrência ser menos provável, também há baixa probabilidade de se associar um conceito único àquele n-grama.

Foram identificadas as frases que compõem o corpus. Como 'frase' entendemos um conjunto de palavras que termine com um ponto final. Foram identificadas 1.156 frases diferentes no corpus.

Sabe-se que para a geração dos laudos fornecidos, é utilizado um sistema no qual o médico seleciona frases, a partir de um conjunto de frases, que frases são então editadas pelo próprio médico na busca de melhor representar o que deseja expressar. Uma vez que o texto final seja considerado correto ele é encaminhado para a assinatura do médico responsável e à entrega ao paciente.

A partir da quantidade de frases identificadas e do conhecimento do processo de digitação e correção das frases, concluímos que o conjunto de frases prontas remanescentes nos 2.000 laudos analisados é baixo. O processo de edição das frases prontas, incluindo acréscimo de palavras ao laudo, evidencia a insuficiência do sistema de conjunto de frases prontas .

Enquanto que a edição dos laudos como texto livre é a responsável pela inserção de erros de grafia, a ausência dos sinais diacríticos, ou acentos ortográficos, é uma característica intrínseca do sistema utilizado para a geração dos laudos.

As palavras e os $\mathrm{n}$-gramas foram traduzidos e comparados com o vocabulário de referência internacional SNOMED-CT. Dos 1.543 termos possíveis (1.023 palavras e 520 n-gramas) foram relacionados 338 termos que possuem uma identificação expressa diretamente no vocabulário de referência SNOMED-CT. Para cada um desses termos foram identificados a classe à qual ele pertence, bem como o identificador do conceito que o representa.

Com base nos termos de referência em português, foi rotulado um conjunto de 200 laudos de radiologia, o que corresponde ao número médio de laudos elaborados por dia no InCor.

Cada termo rotulado foi associado à classe ao qual o termo pertence bem como ao seu identificador único. A eficicácia de rotulação obtida foi de $45,55 \%$ que significa que $45,55 \%$ 
das palavras constantes nos 200 laudos foram rotuladas de acordo com os termos de referência.

Ao se acrescentarem 16 palavras entre artigos, preposições e outras palavras de ligação de conceitos, a eficicácia de rotulação passou a ser de 73,26\%.

Esse aumento na eficiência demonstra, de maneira similar aos resultados obtidos no estudo estatístico dos tokens e palavras, que algumas poucas palavras tem grande representatividade estatística e são responsáveis por grande parte da composição do corpus.

Já no calculo da precisão dos dados obtidos os resultados foram de 0,4527 para a rotulação e com a inserção dos artigos preposições e palavras de ligação dos conceitos a precisão foi de 0,7328 , que são resultados próximos aos obtidos no cálculo de eficiência do rotulador.

Com os termos de referência identificados houve a possibilidade de transformar texto livre em dados estruturados preparando-os para permitir interoperabilidade semântica.

Os padrões de representação de informação clínica utilizados, que viabilizam interoperabilidade semântica foram as ontologias, expressas em OWL, o HL7 / CDA e os arquétipos da OpenEHR Foundation.

Para a representação das ontologias foi utilizado o Protégé. As ontologias foram compostas pelas classes do SNOMED-CT que foram instanciadas pelos termos de referência.

Os arquétipos da Fundação OpenEHR foram analisados para identificar possíveis conjuntos através dos quais fosse possível utilizar e expressar os laudos de radiologia torácica, em todo seu conhecimento. Não foi encontrado um arquétipo que abrangesse todas as necessidades de expressão dos laudos porém identificou-se a existência de uma série de conjuntos de arquétipos que poderiam ser utilizados para formar um template para os laudos. Ex: "ramo" Cluster - examination of chest, "ramo" Observation - diagnostic imaging e examination findings.

No intuito de proporcionar a padronização de termos, melhorar a possibilidade de estruturação de texto livre e proporcionar a interoperabilidade de sistemas algumas evoluções devem ocorrer para que sejam utilizadas em trabalhos futuros que possam decorrer dessa tese.

A incorporação de um corretor ortográfico no momento que são gerados os laudos reduziria os problemas de erros de grafia e a ausência de sinais diacríticos, que se tornam problemáticos na aplicação de processos automáticos de identificação e rotulação de laudos. 
Sistemas de apoio à geração de laudos poderiam ser concebidos e desenvolvidos utilizando um conjunto de termos e frases que já tenham uma referência a um vocabulário de padrão internacional. Isto melhoraria o processo de rotulação e abrangeria um maior número de termos clínicos e específicos às síndromes e doenças raras. Os termos (rótulos) identificados neste trabalho podem ser utilizados como referência inicial para a construção de um sistema para este fim.

Um grupo de estudo formado por um corpo multidisciplinar poderia elaborar uma análise criteriosa dos termos em português que não fazem parte do vocabulário de referência SNOMED-CT, propondo à IHTSDO - International Health Terminology Standards Development Organization a incorporação desses termos.

Como última sugestão, entendemos que a criação de um template de arquétipos que atenda a necessidade de geração dos laudos do InCor, poderá ser um poderoso instrumento para o armazenamento, e reutilização do conhecimento das várias fichas clínicas e mantendo os dados semanticamente íntegros. 


\section{REFERÊNCIAS BIBLIOGRÁFICAS}

1. Almeida, Mauricio B. e Bax, Marcello P. 2003. Uma visão geral sobre ontologias: pesquisa sobre definições, tipos, aplicações, métodos de avaliação e de construção. Revista Ciência da Informação. Brasilia : s.n., set/dez de 2003.

2. Amaral, M Biczyk, Roberts, A e Rector, A. L. 2000. NLP Techiques associated with the OpenGalen Ontology for semi-automatic textual extraction of medical Knowledge: abstracting and mapping equivalent Linguistic and Logical constructs. s.I. : Journal of Medical Informatics Association, 2000.

3. ANS. 2008. SNOMED-CT. Agência National de Saúde Suplementar. 2008.

4. Arcoverde, João Marcelo. 2007. Indução de Filtros Linguisticamente Motivados na Recuperação da Informação. Dissertação de Mestrado ICMC-USP. São Carlos : s.n., 2007.

5. Bacic, Alice Shimada. 2007. Extração de Informação e Documentação de Laudos Médicos. Tese de Doutorado da Escola Politécnica da Universidade de São Paulo. São Paulo : s.n., 2007.

6. Baden, Andrew e Klein, Heinz K. 2008. New research directions for data and knowledge engineering: A philosophy of language approach. s.l. : Elsevier - Data \& Knowledge Engineering, 2008.

7. Banerjee, Satanjeev e Pedersen, Ted. 2002. The Design, Implementation and Use of the Ngram Statistics Package. s.I. : Carnegie Mellon University, 2002.

8. Baorto, David, Li, Li e Cimino, James J. 2009. Practical experience with the maintenance and auditing of a large medical ontology. New York : Elsevier - Jornal of Biomedical Informatics, 2009.

9. Bench-Capon, T.J.M. 1990. Knowledge Representation - An Approach to Artificial Intelligence. Department of Computer Science, University of Liverpool. Liverpool, England : Academic - Press, 1990.

10. Bird, Steven, Klein, Ewan e Loper, Edward. 2009. Natural Language Processing with Python. Sebastopol : O'Reilly, 2009. 978-0-596-51649.

11. - 2005. NLTK Tutorial: Introduction to Natural Language Processing. Creative Commons Attribution. Stanford, Califórnia, EUA : s.n., 2005. 
12. Borst, Pim, Akkermans, Hans e Top, Jan. 1997. Engineering ontologies. International Journal of Human-Computer Studies. s.I. : Academic Press, 1997. Vol. Volume 46.

13. Carvalheira, Luiz Carlos da Cruz. 2007. Método Semi-Automático de Construção de Ontologias Parciais de Domínio com Base em Textos. São Paulo : Dissertação de Mestrado pela Escola Politécnica da Universidade de São Paulo, 2007.

14. Casare, Sara Jane. 2005. Uma ontologia funcional de reputação para agentes. Dissertação de Mestrado da Escola Politécnica da USP. São Paulo : s.n., 2005.

15. Castilla, André Coutinho e Furuie, Sérgio Shiguemi. 2004. Avaliação da Tradução Automatizada de Relatórios de Radiografias de Tórax: Resultados Preliminares. Congresso Brasileiro de Informática em Saúde. 2004.

16. Castilla, André Coutinho. 2007. Instrumento de Investigação Clínico-Epidemiológica em Cardiologia Fundamentado no Processamento de Linguagem Natural. Tese de Doutorado. São Paulo, SP, Brasil : s.n., 2007.

17. Castro Jr., Amaury. 2008. Introdução à Radiologia. São Paulo : Editora Rideel, 2008.

18. Chang, Chia-Hui, et al. 2006. A Survey of Web Information Extraction Systems. IEEE TRANSACTIONS ON KNOWLEDGE AND DATA ENGINEERING. 2006.

19. Charniak, Eugene. 1993. Statistical Language Learning. s.I. : The MIT Press, 1993.

20. Chater, Nick e Manning, Christopher D. 2006. Probabilistic models of language processing and acquisition. TRENDS in Cognitive Sciences. s.I. : Elsevier, 2006.

21. Chaui, Marilena. 2003. Convite à Filosofia. São Paulo : Editora Ática, 2003.

22. Chomsky, Noam. 2006. Language and Mind. s.l. : Cambridge University Press, 2006.

23. Costa, Cláudio Giulliano Alves da. 2001. Desenvolvimento e avaliação tecnológica de um sistema de prontuário eletrônico do paciente, baseado nos paradigmas da World Wide Web e da engenharia de software. Dissertação de Mestrado. 2001.

24. Dang, Pragya A, et al. 2008. Natural Language Processing Using Online Analytic Processing for Assessing Recommendations in Radiology Reports. Massachussets : American College of Radiology, 2008.

25. Dolin, Robert H., et al. 2001. The HL7 Clinical Document Architecture. Journal of American Medical Informatics Association. 2001.

26. Ebisawa, M L.N., et al. 2008. Elaboração de um Modelo de Referência para o Processo de Radiologia. Congresso Brasileiro de Informática em Saúde. 2008. 
27. Engelbrecht, Rolf, Ingenerfz, Josef e Reiner, Jörg. 2006. Relevance of Terminological Standards and Services in Telemedicine. Springer. 2006.

28. Friedman, Carol e Hripcsak, George. 1999. Natural Language Processing and Its Future in Medicine: Can Computer Make Sense out of Natural Language Text. Academy of Medicine - 74:890-5. 1999.

29. Friedman, Carol, et al. 1994. A general natural-language text processor for clinical radiology. Journal of the American Medical Informatics Vol 1, 161-174. New York: JAMIA, 1994.

30. Friedman, Carol, et al. 2004. Automated encoding of clinical documents based on natural language processing. Journal of the American Medical Informatics Association. New York : s.n., 2004.

31. Garde, Sebastian, et al. 2007. Towards Semantic Interoperability for Electronic Health Records: Domain Knowledge Governance for openEHR Archetypes. Methods of Information in Medicine. 2007.

32. Gómez-Pérez, Asunción, Mariano, Fernandez-López e Oscar, Corcho. 2005. Ontological Engineering. Madrid : Springer, 2005.

33. Gough, Kevin John. 1988. Syntax analysis and software tools. s.I. : Addison-Wesley Publishing Company, 1988.

34. Harmelen, Frank van, Lifschitz, Vladimir e Porter, Bruce. 2007. HANDBOOK OF KNOWLEDGE REPRESENTATION, 1. s.I. : Elsevier, Dezembro de 2007.

35. Honorato, Daniel de Faveri. 2008. Metodologia para mapeamento de informações não estruturadas descritas em laudos médicos para uma representação atributovalor. Dissertação - ICM - USP. São Paulo, SP, Brasil : s.n., Março de 2008.

36. Hripcsak, George, et al. 2002. Use of Natural Language Processing to Translate Clinical Information from a Database of 889,921 Chest Radiographic Reports. New York: Departments of Medical Informatics and Radiology of Columbia University, 2002.

37. Huang, Yang, et al. 2005. Improved Identification of Noun Phrases in Clinical Radiology Reports Using a High-Performance Statistical Natual Language Parser Augmented with the UMLS Specialist Lexicon . American Medical Informatics. 2005. 
38. Huang, Yang, et al. 2005. Improved Identification of Noun Phrases in Clinical Radiology Reports Using a High-Performance Statistical Natural Language Parser Augmented with UMLS Specialist Lexicon. American Medical Informatics. 2005.

39. Huncher, Dale, et al. 2006. Representing Natural-Language Case Report Form Terminology Using Health Level 7 Common Document Architecture, LOINC, and SNOMED-CT. Lessons Learned. American Medical Informatics. 2006.

40. Hunscher, Dale, et al. 2006. Representing Natural-Language Case Report Form Terminology Using Health Level 7 Commom Document Architecture, LOINC, and SNOMED-CT: Lessons Learned. Americal Medical Informatics. 2006.

41. IHTSDO. 2008. SNOMED Clinical Terms User Guide. The International Health Terminology Standards Development Organization. 2008.

42. Kilic, Ozgur, Bicer, Veli e Asuman, Dogac. 2006. Mapping Archetypes to OWL. Middle East Techincal University. 2006.

43. Knowledge Sources for Natural Language Processing. Baud, Robert H., et al. 1996. Geneva : American Medical Informatics Association, 1996.

44. Malucelli, Andreia. 2006. Ontology-based Services for Agents Interoperability. Tese de Doutorado. Porto, Portugal : s.n., 2006.

45. Manine, Alain Pierre, Alphonse, Erick e Bessiéres, Philippe. 2009. Learning ontological rules to extract multiple relations of generic interactions from text. s.l. : International Journal of Medical Informatic, 2009.

46. Manning, Christopher D. e Schütze, Hinrich. 1999. Foundations of Statistical Natural Language Processing. s.I., EUA : The MIT Press, 1999.

47. Massad, Eduardo e Rocha, Armando Freitas. 2003. O Prontuário Eletrônico do Paciente na Assistência, Informação e Conhecimento Médico. São Paulo : s.n., 2003.

48. Meystre, Stephan e Haung, Peter J. 2003. Medical Problem and Document Model for Natural Language Understanding. American Medical Informatics. 2003.

49. Meystre, Stephane e Haung, Peter J. 2003. Medical Problem and Document Model for Natural Language Understanding. American Medical Informatics. 2003.

50. Minsky, Marvin. 2006. The Emotion Machine: commonsense thinking, artificial intelligence, and the future of the human mind. New York : Simon \& Schuster, 2006. 
51. Miranda, Elisangela Maschio. 2004. UMA FERRAMENTA DE APOIO AO PROCESSO DE APRENDIZAGEM DE ALGORITMOS. Dissertação de Mestrado. Florianópolis : Universidade Federal de Santa Catarina, 2004.

52. Mokva, Ana Maria, Comassetto, Leandro Ramires e Fontana, Nauria Inês. 2004. LINGÜÍSTICA DE CORPUS: COMO UTILIZÁ-LA PARA A COMPREENSÃO EM GRAMÁTICA. Revista Voz das Letras. Concórdia: Universidade do Contestado, 2004.

53. Moner, David, et al. 2006. Archetype-Based Semantic Integration and Standardization of Clinical Data. Proceedings of 28th IEEE EMBS Annual International Conference. 2006.

54. Nardon, Fabiane Bizinella. 2003. Compartilhamento de Conhecimento em Saúde Utilizando Ontologias e Banco de Dados Dedutivos. Tese de Doutorado pela Escola Politécnica da USP. 2003.

55. Nardon, Fabiane Bizinella, Fraça, Tony e Naves, Humberto. 2008. Construção de Aplicações em Saúde Baseadas em Arquétipos. XI Congresso Brasileiro de Informática em Saúde. 2008.

56. Neira, Ricardo Alfredo Quintano, et al. 2008. Como incorporar conhecimento aos sistemas de registro eletrônico em saúde? XI Congresso Brasileiro de Informática em Saúde. 2008.

57. Neurolinguistic approach to natural language processing with applications to medical text analysis. Duch, Wkidzuskaw, Matykiewicz, Pawel e Pestian, John. 2008. 2008, Neural Networks, pp. 1500-1510.

58. Névéol, Aurélie, et al. 2009. A recent advance in the automatic indexing of the biomedical literture. Journal of Biomedical Informatics. 2009.

59. Nishimoto, N., et al. 2008. Development of a medical-text parsing algorithm based on character adjacent probability distribuition for Japanese radiology reports. Methods of Information in Medicine. 6, 2008, Vol. 47, 513-521.

60. Novácek, Vít, et al. 2008. Infrastructure for dynamic knowledge integration Automated biomedical ontology extension using textual resources. s.I. : Elsevier Journal of Biomedical Informatics, 2008.

61. Pyrros, Ayis, et al. 2007. A Bayesian Approach for the Categorization of Radiology Reports. Academy of Radiology. 2007, pp. 426-430. 
62. Rich, Elaine e Knight, kevin. 1993. Inteliência Artificial. São Paulo : Makron Books, 1993.

63. Rocha, Marco. 1997. Supporting anaphor resolution in dialogues with a corpus-based probabilistic model. Techical Report . Brighton : University of Sussex, 1997.

64. Rubin, Daniel L., Noy, Natalya F. e Musen, Mark A. 2007. Protégé: A tool for Managing and Using Terminology in Radiology Applications. Stanford: Journal of Digital Imaging, 2007.

65. Russel, Stuart e Norvig, Peter. 2004. Inteligência Artificial. Rio de Janeiro : Elsevier, 2004.

66. Sahay, Saurav, et al. 2007. Domain Ontology Construction from Biomedical Text. Las Vegas : Intenational Conference on Artificial Intellingence (ICAI'07), 2007.

67. Santos, Diana. 2009. Caminhos percorridos no mapa da portuguesificação: $A$ Linguateca em perspectiva. s.I. : LinguaMÁTICA, 2009.

68. Schroeder, Paulo Roberto. 2009. Métodos de Apoio a Decisão Médica para Análise em Diabetes Mellitus Gestacional Utilizando a Probabilidade Pragmática na Lógica Paraconsistente Anotada de Dois Valores para Melhor Precisão de Resposta. São Paulo : Tese da Escola Politécnica da Universidade de São Paulo, 2009.

69. Shimakura, Silvia. 2008. Bioestatística - Notas de Aula. s.I. : Universidade Federal do Paraná, 2008.

70. Shortliffe, Edward H. e Cimino, James J. 2006. Biomedical Informatics: Computer Applications in Health Care and Biomedicine . JAMA - Journal of Americal Medical Association. New York, NY, EUA : Springer, 2006.

71. Spackman, Kent A. e Reynoso, Guillermo. 2002. Examining SNOMED from the Perspective of Formal Ontological Principles: Some Preliminary Analysis and Observations . 2002.

72. Spackman, Kent A., Campbell, Keith E. e Côté, Roger A. 1997. SNOMED RT: A reference Terminology for Health Care. New York: Journal of Medical Informatics Association, 1997.

73. Stefik, M. 1995. Introduction to Knowledge Systems. s.I., California, EUA : Morgan Koufmann Publishers, 1995.

74. Taira, Richy K e Soderland, Stephen G. 1999. A Statistical Natural Language Processor for Medical Reports. Journal of American Medical Informatics. 1999. 
75. Wang, Xiaoyan, et al. 2008. Automated Knowledge Acquisition from Clinical Narrative Reports. Symposium Proceeding Of AMIA - pg 783. New York : s.n., 2008.

76. Welty, Christopher e Guarino, Nicola. 2001. Supporting ontological analysis of taxonomic relationships. Data \& Knowledge Engineering . s.l. : Elsevier, Outubro de 2001.

77. World Health Organization. acessado em 23/09/2008. ePORTUGUESe. s.I. : http://www.who.int/eportuguese/en/, acessado em 23/09/2008.

78. Zhang, Wen, Yoshida, Taketoshi e Tang, Xijin. 2008. Using ontology to improve precision of terminology extraction from documents. s.l. : Elsevier - Expert Systems with Applications, 2008. 


\section{APÊNDICE A - PALAVRAS}

1. +

2. ++ .

3. + .

4. $+/++$.

5. 0

6. 02

7. 09

8. $0 \mathrm{~cm}$

9. 1

10. 10

11. 100

12. $1 \mathrm{a}$

13. 10

14. 2

15. 2003

16. $2 \mathrm{a}$

17. $2 \mathrm{~cm}$

18. 20

19. 3

20. 30

21. 3xame

22. 4

23. $4 \mathrm{~cm}$

24. $4 \mathrm{cn}$

25. 40

26. 5

27. $5 \mathrm{~cm}$

28. $5 \mathrm{~mm}$

29. 50

30. $5 \times 2 \times 2 \mathrm{~cm}$

31. 6

32. $6 \mathrm{~cm}$

33. 60

34. 7

35. 70

36. 8

37. 80

38. $80 a r c o$

39. 9

40. 90

41.

42. abaixadas

43. abaixo

44. abaulado

45. abaulamento

46. abdominal

47. abualado

48. ac

49. acentuacao

50. acentuacaop

51. acentuada

52. acentuado

53. achatamento

54. actinica
55. ad

56. adc

57. ade

58. aderencias

59. adf

60. adja

61. adjacente

62. adjacentes

63. ae

64. aereo

65. aerolar

66. afrco

67. agrupamento

68. alargado

69. alargamento

70. alca

71. alem

72. alongada

73. alongamento

74. alta

75. altas

76. alteracao

77. alteracoes

78. alto

79. altura

80. alturas

81. ambas

82. ambos

83. amplos

84. ana

85. analisado

86. analise

87. anatomica

88. andar

89. anel

90. aneurismatica

91. angulo

92. anterior

93. anteriores

94. anteriormente

95. antero

96. aorta

97. aortica

98. aortico

99. aparentemente

100.

101. apicais

$102 . \quad$ apical

103. apice

$104 . \quad$ apices

$105 . \quad$ apico

106. aproximadamente

107. aproximado

108. aprta 


\begin{tabular}{|c|c|c|c|}
\hline 109. & aqc & 168. & bronco \\
\hline 110. & ar & 169. & bronquiectasias \\
\hline 111. & arco & 170. & bronquios \\
\hline 112. & $\operatorname{arcos}$ & 171. & bt \\
\hline 113. & area & 172. & C \\
\hline 114. & areas & 173. & ca \\
\hline 115. & areolar & 174. & cabeca \\
\hline 116. & arizacao & 175. & cada \\
\hline 117. & arma & 176. & calcificacao \\
\hline 118. & arredondada & 177. & calcificacaos \\
\hline 119. & artefato & 178. & calcificacoa \\
\hline 120. & artefatos & 179. & calcificacoes \\
\hline 121. & artefatual & 180. & calcificacoesna \\
\hline 122. & arteria & 181. & calcificacoesparietaisna \\
\hline 123. & artrose & 182. & calcificada \\
\hline 124. & ascendente & 183. & calcificadas \\
\hline 125. & aspecto & 184. & calcificado \\
\hline 126. & assimetria & 185. & calcificados \\
\hline 127. & associadas & 186. & calcificalcoes \\
\hline 128. & associado & 187. & calibre \\
\hline 129. & ate & 188. & calibrosa \\
\hline 130. & atelectasia & 189. & calibrosos \\
\hline 131. & atelectasias & 190. & calo \\
\hline 132. & atenuacao & 191. & cama \\
\hline 133. & ateromatosa & 192. & camaras \\
\hline 134. & ateromatose & 193. & campo \\
\hline 135. & atrio & 194. & campos \\
\hline 136. & aumentada & 195. & cao \\
\hline 137. & aumentadas & 196. & caracterizada \\
\hline 138. & aumentado & 197. & caracterizadas \\
\hline 139. & aumentados & 198. & caracterizado \\
\hline 140. & aumento & 199. & cardiaca \\
\hline 141. & ausencia & 200. & cardiaco \\
\hline 142. & avaliacao & 201. & cardicaca \\
\hline 143. & avaliar & 202. & cardio \\
\hline 144. & avaliavel & 203. & cardiomegalia \\
\hline 145. & $\operatorname{axc}$ & 204. & carinatum \\
\hline 146. & axila & 205. & carinaturum \\
\hline 147. & azigos & 206. & cateter \\
\hline 148. & $\mathrm{~b}$ & 207. & cava \\
\hline 149. & baixa & 208. & cendente \\
\hline 150. & baixo & 209. & cente \\
\hline 151. & basal & 210. & central \\
\hline 152. & base & 211. & cerca \\
\hline 153. & bases & 212. & cervical \\
\hline 154. & bem & 213. & cifise \\
\hline 155. & bibasais & 214. & cifose \\
\hline 156. & bifidez & 215. & circulacao \\
\hline 157. & bilateral & 216. & circuscrita \\
\hline 158. & bilateralmente & 217. & cirurgica \\
\hline 159. & blalock & 218. & cissural \\
\hline 160. & boceladura & 219. & cisural \\
\hline 161. & boceladuras & 220. & clavicu \\
\hline 162. & bolha & 221. & clavicula \\
\hline 163. & borda & 222. & clavicular \\
\hline 164. & bordos & 223. & clinico \\
\hline 165. & borramento & 224. & clip \\
\hline 166. & borrando & 225. & clipe \\
\hline 167. & bra & 226. & clipes \\
\hline
\end{tabular}




\begin{tabular}{|c|c|c|c|}
\hline 227. & clips & 286. & d4 \\
\hline 228. & clis & 287. & d5 \\
\hline 229. & $\mathrm{~cm}$ & 288. & d6 \\
\hline 230. & colapso & 289. & $\mathrm{~d} 7$ \\
\hline 231. & colaterais & 290. & d8 \\
\hline 232. & colecao & 291. & d9 \\
\hline 233. & coluna & 292. & das \\
\hline 234. & compativeis & 293. & decimo \\
\hline 235. & compativel & 294. & decorrente \\
\hline 236. & compensatoria & 295. & defini \\
\hline 237. & complementar & 296. & definida \\
\hline 238. & compres & 297. & definidos \\
\hline 239. & compressao & 298. & deformidade \\
\hline 240. & concava & 299. & delas \\
\hline 241. & concavo & 300. & delgadas \\
\hline 242. & conclusao & 301. & delimitada \\
\hline 243. & condensacao & 302. & densa \\
\hline 244. & condicionando & 303. & densas \\
\hline 245. & configuracao & 304. & densidade \\
\hline 246. & consolidada & 305. & densificacao \\
\hline 247. & consolidadas & 306. & denso \\
\hline 248. & contorno & 307. & densos \\
\hline 249. & contornos & 308. & dentro \\
\hline 250. & contras & 309. & derra \\
\hline 251. & contraste & 310. & derrame \\
\hline 252. & controle & 311. & derrames \\
\hline 253. & convem & 312. & des \\
\hline 254. & conveniente & 313. & descendente \\
\hline 255. & convexa & 314. & desdobrado \\
\hline 256. & convexidade & 315. & desfribilador \\
\hline 257. & coracao & 316. & desproporcao \\
\hline 258. & coronaria & 317. & desse \\
\hline 259. & coronarias & 318. & desviada \\
\hline 260. & coronario & 319. & desviado \\
\hline 261. & corpo & 320. & desviados \\
\hline 262. & corpos & 321. & desvio \\
\hline 263. & corres & 322. & deve \\
\hline 264. & corresponder & 323. & dextro \\
\hline 265. & cortes & 324. & dextroconvexa \\
\hline 266. & costais & 325. & di \\
\hline 267. & costal & 326. & diafragmati \\
\hline 268. & costela & 327. & diafragmatica \\
\hline 269. & costo & 328. & diafragmaticas \\
\hline 270. & costofreicos & 329. & diafragmatico \\
\hline 271. & costofrenico & 330. & diafrgmatica \\
\hline 272. & costofrenicos & 331. & diametro \\
\hline 273. & costro & 332. & dificil \\
\hline 274. & criterio & 333. & difusa \\
\hline 275. & croca & 334. & difusamente \\
\hline 276. & cronico & 335. & difusas \\
\hline 277. & ct & 336. & difuso \\
\hline 278. & cular & 337. & difusos \\
\hline 279. & cupula & 338. & dilatacao \\
\hline 280. & cupulas & 339. & dilatada \\
\hline 281. & custas & 340. & dilatados \\
\hline 282. & d & 341. & dimensoes \\
\hline 283. & d10 & 342. & diminuida \\
\hline 284. & d11 & 343. & diminuido \\
\hline 285. & d12 & 344. & diminuta \\
\hline
\end{tabular}




\begin{tabular}{|c|c|c|c|}
\hline 345. & direcionado & 404. & esofagiano \\
\hline 346. & direi & 405. & esofago \\
\hline 347. & direita & 406. & esofagograma \\
\hline 348. & direitas & 407. & espaco \\
\hline 349. & direito & 408. & espacos \\
\hline 350. & diretia & 409. & esparsas \\
\hline 351. & diretito & 410. & especialmente \\
\hline 352. & discais & 411. & especifico \\
\hline 353. & discal & 412. & espes \\
\hline 354. & disco & 413. & espessa \\
\hline 355. & discopatias & 414. & espessadas \\
\hline 356. & discos & 415. & espessamen \\
\hline 357. & discreta & 416. & espessamento \\
\hline 358. & discretamente & 417. & espinhal \\
\hline 359. & discreto & 418. & espondiloartrose \\
\hline 360. & discretos & 419. & espondiloatrose \\
\hline 361. & disfibrilador & 420. & esquedo \\
\hline 362. & dispositivo & 421. & esquer \\
\hline 363. & distais & 422. & esquerda \\
\hline 364. & distal & 423. & esquerdas \\
\hline 365. & distensao & 424. & esquerdo \\
\hline 366. & distribuidas & 425. & estase \\
\hline 367. & distribuidos & 426. & esterenorrafia \\
\hline 368. & dorsais & 427. & esternais \\
\hline 369. & dorsal & 428. & esterno \\
\hline 370. & dreno & 429. & esternoorrafia \\
\hline 371. & dulos & 430. & esternorrafaia \\
\hline 372. & ec & 431. & esternorrafia \\
\hline 373. & ectasiada & 432. & estomago \\
\hline 374. & ele & 433. & estria \\
\hline 375. & eletrodo & 434. & estrias \\
\hline 376. & eletrodos & 435. & estrutura \\
\hline 377. & elevacao & 436. & estruturais \\
\hline 378. & elevada & 437. & estrutural \\
\hline 379. & elevadas & 438. & estruturas \\
\hline 380. & elevado & 439. & etaria \\
\hline 381. & elevads & 440. & evidente \\
\hline 382. & elevecao & 441. & exame \\
\hline 383. & elucidacao & 442. & excavatum \\
\hline 384. & encistado & 443. & expiracao \\
\hline 385. & encobertos & 444. & expirado \\
\hline 386. & endocavitario & 445. & extensoes \\
\hline 387. & endocavitarios & 446. & extremidade \\
\hline 388. & enf & 447. & extremidades \\
\hline 389. & enteral & 448. & faixa \\
\hline 390. & entre & 449. & faveolamento \\
\hline 391. & entregue & 450. & fazer \\
\hline 392. & entregues & 451. & fibroatelecta \\
\hline 393. & epicardico & 452. & fibrose \\
\hline 394. & epicardicos & 453. & fiisiologica \\
\hline 395. & epicaridicos & 454. & filme \\
\hline 396. & equipamento & 455. & filmes \\
\hline 397. & es & 456. & fina \\
\hline 398. & esbocando & 457. & finas \\
\hline 399. & escala & 458. & finos \\
\hline 400. & esclerose & 459. & fio \\
\hline 401. & esclerotica & 460. & fios \\
\hline 402. & escoliose & 461. & fisiologica \\
\hline 403. & esofa & 462. & fixacao \\
\hline
\end{tabular}




\begin{tabular}{|c|c|c|c|}
\hline $\begin{array}{l}463 . \\
464\end{array}$ & $\begin{array}{l}\text { flanco } \\
\text { focal }\end{array}$ & $\begin{array}{l}522 . \\
523 .\end{array}$ & $\begin{array}{l}\text { hipertransparentes } \\
\text { hipertrnapsrencia }\end{array}$ \\
\hline $\begin{array}{l}464 . \\
465 .\end{array}$ & foco & $\begin{array}{l}523 . \\
524 .\end{array}$ & $\begin{array}{l}\text { hipertrnapsrencia } \\
\text { hipertrofia }\end{array}$ \\
\hline 466. & fogo & 525. & hipertrofiado \\
\hline 467. & formacao & 526. & hipoatenuante \\
\hline 468. & formacoes & 527. & hipoplasia \\
\hline 469. & formando & 528. & hipotransparencia \\
\hline 470. & fornece & 529. & hipotransparentes \\
\hline 471. & fragmento & 530. & homogenea \\
\hline 472. & fratura & 531. & hp \\
\hline 473. & fraturas & 532. & htd \\
\hline 474. & frenica & 533. & hte \\
\hline 475. & frenicas & 534. & idade \\
\hline 476. & frenico & 535. & identificado \\
\hline 477. & frenicos & 536. & imagem \\
\hline 478. & frontal & 537. & imagens \\
\hline 479. & fusao & 538. & imensoes \\
\hline 480. & ganglio & 539. & imgem \\
\hline 481. & ganglionares & 540. & implantacao \\
\hline 482. & gastrica & 541. & importante \\
\hline 483. & gerador & 542. & imprecisa \\
\hline 484. & gle & 543. & imprecisas \\
\hline 485. & globosa & 544. & imprecisos \\
\hline 486. & gograma & 545. & inalterado \\
\hline 487. & gordu & 546. & incidencia \\
\hline 488. & grafia & 547. & incipiente \\
\hline 489. & grande & 548. & incipientes \\
\hline 490. & granuloma & 549. & infarto \\
\hline 491. & granulomas & 550. & infe \\
\hline 492. & grosseira & 551. & inferior \\
\hline 493. & gulares & 552. & inferiores \\
\hline 494. & hematoma & 553. & inferiormente \\
\hline 495. & hemi & 554. & infiltrado \\
\hline 496. & hemicupula & 555. & infiltrodo \\
\hline 497. & hemitorax & 556. & inflama \\
\hline 498. & hemivertebras & 557. & inflamatorio \\
\hline 499. & hernia & 558. & infra \\
\hline 500. & herniacao & 559. & infraclavicular \\
\hline 501. & heterogenea & 560. & infraclaviculares \\
\hline 502. & heterogeneas & 561. & infravertebral \\
\hline 503. & hi & 562. & inicipiente \\
\hline 504. & hiatal & 563. & ino \\
\hline 505. & hiato & 564. & insuflados \\
\hline 506. & hidro & 565. & integro \\
\hline 507. & hidroaereo & 566. & integros \\
\hline 508. & hilar & 567. & inter \\
\hline 509. & hilares & 568. & intercostais \\
\hline 510. & hilo & 569. & intercostal \\
\hline 511. & hilos & 570. & interfissural \\
\hline 512. & hipe & 571. & interna \\
\hline 513. & hiper & 572. & interposicao \\
\hline 514. & hiperinsuflacao & 573. & inters \\
\hline 515. & hiperinsufladas & 574. & intersticial \\
\hline 516. & hiperinsuflados & 575. & intersticio \\
\hline 517. & hipertensao & 576. & interstinal \\
\hline 518. & hipertranspa & 577. & intervertebrais \\
\hline 519. & hipertransparencia & 578. & intregros \\
\hline 520. & hipertransparencias & 579. & inversus \\
\hline 521. & hipertransparente & 580. & investigar \\
\hline
\end{tabular}




\begin{tabular}{|c|c|c|c|}
\hline 581. & ipsilateral & 640. & marginais \\
\hline 582. & irregular & 641. & marginal \\
\hline 583. & irregulares & 642. & massa \\
\hline 584. & irregularidade & 643. & mastectomia \\
\hline 585. & irregularidades & 644. & matalica \\
\hline 586. & jecao & 645. & matalicos \\
\hline 587. & junto & 646. & material \\
\hline 588. & kerley & 647. & maximos \\
\hline 589. & kilovoltagem & 648. & me \\
\hline 590. & kv & 649. & media \\
\hline 591. & la & 650. & medial \\
\hline 592. & laminar & 651. & mediastinais \\
\hline 593. & laminares & 652. & mediastinal \\
\hline 594. & lar & 653. & mediastino \\
\hline 595. & larga & 654. & mediatinais \\
\hline 596. & laudo & 655. & medindo \\
\hline 597. & lectasia & 656. & medio \\
\hline 598. & leito & 657. & medios \\
\hline 599. & lesao & 658. & melhor \\
\hline 600. & levemente & 659. & menor \\
\hline 601. & lie & 660. & menores \\
\hline 602. & ligamento & 661. & mente \\
\hline 603. & ligeira & 662. & mento \\
\hline 604. & ligeiramente & 663. & mes \\
\hline 605. & limite & 664. & metafise \\
\hline 606. & limites & 665. & metalica \\
\hline 607. & linear & 666. & metalicas \\
\hline 608. & lineares & 667. & metalico \\
\hline 609. & linfonodo & 668. & metalicos \\
\hline 610. & lingula & 669. & micronodular \\
\hline 611. & linha & 670. & micronodulares \\
\hline 612. & linhas & 671. & micronodulos \\
\hline 613. & lipoma & 672. & minando \\
\hline 614. & livre & 673. & mitral \\
\hline 615. & livres & 674. & mobilidade \\
\hline 616. & lobo & 675. & moles \\
\hline 617. & lobos & 676. & morfologia \\
\hline 618. & locado & 677. & morfologica \\
\hline 619. & localizada & 678. & $\mathrm{mp}$ \\
\hline 620. & localizadas & 679. & multiplas \\
\hline 621. & localizado & 680. & multiplos \\
\hline 622. & lombar & 681. & nados \\
\hline 623. & long & 682. & nao \\
\hline 624. & longa & 683. & nar \\
\hline 625. & longitudinal & 684. & naso \\
\hline 626. & longo & 685. & neoplasia \\
\hline 627. & lordose & 686. & nivel \\
\hline 628. & Isd & 687. & nodular \\
\hline 629. & maior & 688. & nodulares \\
\hline 630. & mais & 689. & nodulo \\
\hline 631. & mal & 690. & nodulos \\
\hline 632. & mama & 691. & noide \\
\hline 633. & mamaria & 692. & normais \\
\hline 634. & mamilar & 693. & normal \\
\hline 635. & mamilo & 694. & normalidade \\
\hline 636. & marca & 695. & nos \\
\hline 637. & marcacao & 696. & nota \\
\hline 638. & marcapaaso & 697. & notam \\
\hline 639. & marcapasso & 698. & novo \\
\hline
\end{tabular}




\begin{tabular}{|c|c|}
\hline 699. & obe \\
\hline 700. & obesidade \\
\hline 701. & obliteracao \\
\hline 702. & obliterado \\
\hline 703. & obliterados \\
\hline 704. & obs \\
\hline 705. & observada \\
\hline 706. & ol \\
\hline 707. & ombro \\
\hline 708. & ombros \\
\hline 709. & opacidade \\
\hline 710. & opacidades \\
\hline 711. & origem \\
\hline 712. & oseteofitose \\
\hline 713. & ossea \\
\hline 714. & osseas \\
\hline 715. & osseo \\
\hline 716. & osteoartrose \\
\hline 717. & osteofito \\
\hline 718. & osteofitos \\
\hline 719. & osteofitose \\
\hline 720. & osteofitse \\
\hline 721. & osteopenia \\
\hline 722. & osteopoenia \\
\hline 723. & ostetofitos \\
\hline 724. & ostetofitose \\
\hline 725. & ostiofitose \\
\hline 726. & ostios \\
\hline 727. & ovalada \\
\hline 728. & pa \\
\hline 729. & paciente \\
\hline 730. & padrao \\
\hline 731. & para \\
\hline 732. & parafuso \\
\hline 733. & paralisia \\
\hline 734. & parcial \\
\hline 735. & parcialmente \\
\hline 736. & parede \\
\hline 737. & paredes \\
\hline 738. & parenquima \\
\hline 739. & parese \\
\hline 740. & parietais \\
\hline 741. & parietal \\
\hline 742. & parietias \\
\hline 743. & parte \\
\hline 744. & partes \\
\hline 745. & passiva \\
\hline 746. & passivas \\
\hline 747. & passo \\
\hline 748. & patologica \\
\hline 749. & pctus \\
\hline 750. & pectius \\
\hline 751. & pectus \\
\hline 752. & pela \\
\hline 753. & pelo \\
\hline 754. & pelve \\
\hline 755. & pelvica \\
\hline 756. & pequena \\
\hline 757. & pequenas \\
\hline
\end{tabular}

\begin{tabular}{|c|c|}
\hline 758. & pequeno \\
\hline 759. & pequenos \\
\hline 760. & perfil \\
\hline 761. & peri \\
\hline 762. & peribronco \\
\hline 763. & periferia \\
\hline 764. & periferica \\
\hline 765. & perifericamente \\
\hline 766. & perifericase \\
\hline 767. & periferico \\
\hline 768. & perihilar \\
\hline 769. & pessamento \\
\hline 770. & pincamento \\
\hline 771. & placas \\
\hline 772. & plano \\
\hline 773. & plato \\
\hline 774. & pleu \\
\hline 775. & pleurais \\
\hline 776. & pleural \\
\hline 777. & pleuro \\
\hline 778. & plueral \\
\hline 779. & pneumectomia \\
\hline 780. & pneumonia \\
\hline 781. & pneumonite \\
\hline 782. & pneumopatia \\
\hline 783. & pneumoplasia \\
\hline 784. & pneumotorax \\
\hline 785. & pode \\
\hline 786. & podendo \\
\hline 787. & pografia \\
\hline 788. & pondente \\
\hline 789. & pontos \\
\hline 790. & por \\
\hline 791. & porcao \\
\hline 792. & porem \\
\hline 793. & portatil \\
\hline 794. & pos \\
\hline 795. & posicao \\
\hline 796. & posicio \\
\hline 797. & posicionado \\
\hline 798. & posicionados \\
\hline 799. & possivel \\
\hline 800. & poste \\
\hline 801. & posterior \\
\hline 802. & posteriores \\
\hline 803. & posteriormente \\
\hline 804. & postorior \\
\hline 805. & postural \\
\hline 806. & potencia \\
\hline 807. & pouco \\
\hline 808. & predominando \\
\hline 809. & predominante \\
\hline 810. & prejudicada \\
\hline 811. & presenca \\
\hline 812. & preservados \\
\hline 813. & primeiros \\
\hline 814. & principalmente \\
\hline 815. & pro \\
\hline 816. & processo \\
\hline
\end{tabular}




\begin{tabular}{|c|c|c|c|}
\hline 817. & proeminente & 876. & retroesternal \\
\hline 818. & proeminentes & 877. & rinsuflacao \\
\hline 819. & proje & 878. & rior \\
\hline 820. & projecao & 879. & riormente \\
\hline 821. & projetando & 880. & rotura \\
\hline 822. & projetil & 881. & $r x$ \\
\hline 823. & protese & 882. & samento \\
\hline 824. & proteses & 883. & schmorl \\
\hline 825. & provaveis & 884. & secundaria \\
\hline 826. & provavel & 885. & secundarios \\
\hline 827. & ptotese & 886. & segmento \\
\hline 828. & pulmao & 887. & segmentos \\
\hline 829. & pulmaoadjacente & 888. & seguelas \\
\hline 830. & pulmo & 889. & seio \\
\hline 831. & pulmoares & 890. & seios \\
\hline 832. & pulmoes & 891. & sem \\
\hline 833. & pulmonar & 892. & semisentada \\
\hline 834. & pulmonares & 893. & septais \\
\hline 835. & quelares & 894. & seque \\
\hline 836. & querdo & 895. & sequela \\
\hline 837. & ra & 896. & sequelar \\
\hline 838. & radiopaca & 897. & sequelares \\
\hline 839. & radiopada & 898. & seu \\
\hline 840. & ral & 899. & sia \\
\hline 841. & rarefacao & 900. & sidade \\
\hline 842. & ras & 901. & sieo \\
\hline 843. & raso & 902. & sigma \\
\hline 844. & re & 903. & silhueta \\
\hline 845. & reacao & 904. & silicose \\
\hline 846. & realizado & 905. & sinais \\
\hline 847. & realizar & 906. & sindermofitos \\
\hline 848. & reducao & 907. & sindesmofitos \\
\hline 849. & reduzida & 908. & sinequia \\
\hline 850. & reduzidos & 909. & sinias \\
\hline 851. & reestadiamento & 910. & situado \\
\hline 852. & regiao & 911. & situs \\
\hline 853. & regioes & 912. & siva \\
\hline 854. & regulares & 913. & sobre \\
\hline 855. & reita & 914. & som \\
\hline 856. & relacao & 915. & sombra \\
\hline 857. & rencia & 916. & sonda \\
\hline 858. & restantes & 917. & stent \\
\hline 859. & reticular & 918. & sua \\
\hline 860. & reticulo & 919. & sub \\
\hline 861. & retifica & 920. & subclavia \\
\hline 862. & retificacao & 921. & subclavio \\
\hline 863. & retificada & 922. & subpleurais \\
\hline 864. & retificadas & 923. & subpulmonares \\
\hline 865. & retificado & 924. & sugere \\
\hline 866. & retioficado & 925. & sugerindo \\
\hline 867. & retirado & 926. & sugeringo \\
\hline 868. & retirou & 927. & sugestiva \\
\hline 869. & reto & 928. & supe \\
\hline 870. & retracao & 929. & superficial \\
\hline 871. & retraidos & 930. & superiomente \\
\hline 872. & retrateis & 931. & superior \\
\hline 873. & retrocadiaca & 932. & superiores \\
\hline 874. & retrocardiaca & 933. & superiormente \\
\hline 875. & retrocardiaco & 934. & supra \\
\hline
\end{tabular}




\begin{tabular}{|c|c|}
\hline 935. & suturas \\
\hline 936. & $\mathrm{t} 10$ \\
\hline 937. & $\mathrm{t} 11$ \\
\hline 938. & t3 \\
\hline 939. & t5 \\
\hline 940. & t6 \\
\hline 941. & t7 \\
\hline 942. & t9 \\
\hline 943. & ta \\
\hline 944. & tbc \\
\hline 945. & tc \\
\hline 946. & te \\
\hline 947. & tecidos \\
\hline 948. & tecnic \\
\hline 949. & tecnica \\
\hline 950. & temus \\
\hline 951. & tendao \\
\hline 952. & tendo \\
\hline 953. & tenue \\
\hline 954. & tenues \\
\hline 955. & terceiro \\
\hline 956. & terco \\
\hline 957. & tercos \\
\hline 958. & terior \\
\hline 959. & ticial \\
\hline 960. & timo \\
\hline 961. & to \\
\hline 962. & topo \\
\hline 963. & topografia \\
\hline 964. & toracica \\
\hline 965. & toracicas \\
\hline 966. & toracicos \\
\hline 967. & toraco \\
\hline 968. & torax \\
\hline 969. & torio \\
\hline 970. & tortuosa \\
\hline 971. & trajeto \\
\hline 972. & transicao \\
\hline 973. & transparencia \\
\hline 974. & transparente \\
\hline 975. & transperencia \\
\hline 976. & traqueal \\
\hline 977. & traqueia \\
\hline 978. & trave \\
\hline 979. & traves \\
\hline 980. & trica \\
\hline 981. & triculo \\
\hline 982. & trodo \\
\hline 983. & tronco \\
\hline 984. & tubo \\
\hline 985. & tubular \\
\hline 986. & ultrassonografico \\
\hline 987. & um \\
\hline 988. & umeral \\
\hline 989. & V \\
\hline 990. & valva \\
\hline 991. & valvar \\
\hline 992. & valvares \\
\hline 993. & valvas \\
\hline
\end{tabular}

$\begin{array}{ll}994 . & \text { variante } \\ 995 . & \text { vas } \\ 996 . & \text { vascu } \\ 997 . & \text { vascul } \\ 998 . & \text { vascular } \\ 999 . & \text { vascularizaao } \\ 1000 . & \text { vascularizacao } \\ 1001 . & \text { vasos } \\ 1002 . & \text { vcs } \\ 1003 . & \text { vd } \\ 1004 . & \text { ve } \\ 1005 . & \text { veia } \\ 1006 . & \text { velado } \\ 1007 . & \text { velados } \\ 1008 . & \text { velamento } \\ 1009 . & \text { ven } \\ 1010 . & \text { venoso } \\ 1011 . & \text { ventricular } \\ 1012 . & \text { ventriculo } \\ 1013 . & \text { vertebra } \\ 1014 . & \text { vertebrais } \\ 1015 . & \text { vertebral } \\ 1016 . & \text { visualizada } \\ 1017 . & \text { voltada } \\ 1018 . & \text { volume } \\ 1019 . & \text { volumetrica } \\ 1020 . & \text { volumosa } \\ 1021 . & \text { volumoso } \\ 1022 . & \text { x } \\ 1023 . & \text { xame } \\ & \end{array}$




\section{APÊNDICE B - NGRAMAS}

\section{2-GRAMA}

1. alta kilovoltagem

2. alta potencia

3. alteracao estrutural

4. alteracoes estruturais

5. anel valvar

6. anterior direito

7. anterior esquerdo

8. aorta alongada

9. aorta longa

10. aorta normal

11. apical bilateral

12. apice direito

13. apice pulmonar

14. arco costal

15. arco medio

16. arcos costais

17. area cardiaca

18. atelectasia laminar

19. atelectasias passivas

20. baixo contraste

21. base direita

22. base esquerda

23. base pulmonar

24. bases pulmonares

25. borda cardiaca

26. calcificacoes laminares

27. calcificacoes parietais

28. calibre aumentado

29. camaras direitas

30. campo pulmonar

31. cardiomegalia discreta

32. cateter venoso

33. cifose dorsal

34. cifose toracica

35. clip metalico

36. clipes metalicos

37. clips metalicos

38. coluna dorsal

39. coracao aumentado

40. corpo vertebral

41. corpos vertebrais

42. costal posterior

43. costo frenico

44. costo frenicos

45. costofrenico direito

46. costofrenico esquerdo

47. cupula diafragmatica

48. cupula frenica

49. cupulas diafragmaticas

50. cupulas frenicas

51. derrame pleural
52. diafragmatica direita

53. dimensoes normais

54. discreta escoliose

55. discretamente aumentada

56. discreto aumento

57. discreto espessamento

58. dispositivo metalico

59. dorsais discretos

60. dorsais incipientes

61. dorsal dextro

62. dorsal dextroconvexa

63. dorsal marginal

64. eletrodo endocavitario

65. eletrodo epicardico

66. escoliose dextroconvexa

67. escoliose dorsal

68. escoliose toracica

69. espaco intercostal

70. espessamento cisural

71. espessamento pleural

72. esquerdo obliterado

73. estrias densas

74. estruturas osseas

75. exame realizado

76. filmes entregues

77. finas calcificacoes

78. finas traves

79. fio metalico

80. fratura consolidada

81. fraturas costais

82. frenica esquerda

83. frenico direito

84. frenico esquerda

85. hemitorax direito

86. hemitorax esquerdo

87. hernia hiatal

88. hilo direito

89. hilos aumentados

90. hilos proeminentes

91. hilos pulmonares

92. imagem cardiaca

93. imagem densa

94. imagem nodular

95. imagens nodulares

96. intercostal anterior

97. intercostal posterior

98. limites maximos

99. lobo azigos

100. lobo inferior

101. lobo medio

102. lobo superior

103. lobos inferiores

104. longitudinal anterior 
105. marcapasso cardiaco

106. morfologia compativel

107. nodular projetando

108. nodulo denso

109. opacidade heterogenea

110. opacidade nodular

111. opacidade tenue

112. opacidades heterogeneas

113. oseteofitose dorsal

114. osteofitos dorsais

115. osteofitos marginais

116. osteofitose dorsal

117. osteofitose marginal

118. padrao reticular

119. parede toracica

120. paredes espessadas

121. parenquima pulmonar

122. partes moles

123. pequena trave

124. pequeno nodulo

125. pleural apical

126. pleural bilateral

127. pneumopatia intersticia

128. pontos metalicos

129. possivel derrame

130. pouco aumentada

131. projecao evidente

132. protese metalica

133. protese valvar

134. pulmao adjacente

135. pulmao direito

136. pulmao esquerdo

137. pulmoes restantes

138. pulmonar direita

139. pulmonar esquerda

140. pulmonar esquerdo

141. reticular compativel

142. rx expirado

143. seio costofrenico

144. seios costofrenicos

145. sem alteracoes

146. silhueta cardiaca

147. sindesmofitos dorsais

148. stent cardiaco

149. superior esquerdo

150. suturas metalicas

151. tecidos moles

152. torax normal

153. transparencia diminuida

154. transparencia normal

155. trave densa

156. traves finas

157. valvar aortica

158. valvar mitral

159. valvas metalicas

160. vascularizacao pulmonar

161. velamento discreto

162. venoso central

163. vertebral toracica
3-GRAMA

1. 20 arco costal

2. 30 arco costal

3. 40 arco costal

4. 50 arco costal

5. 60 arco costal

6. 80 arco costal

7. 80 arcos costais

8. 80 espaco intercostal

9. 90 arco costal

10. acentuacao da cifose

11. alargamento do mediastino

12. altura do corpo

13. altura dos corpos

14. anterior a esquerda

15. anteriores a esquerda

16. aorta a direita

17. aorta com calcificacao

18. aorta com calcificacoes

19. aorta sem projecao

20. aparentemente a direita

21. apice pulmonar esquerdo

22. arco costal anterior

23. arco costal esquerdo

24. arco costal posterior

25. arco medio abaulado

26. arco medio desdobrado

27. arco medio normal

28. arco medio retificado

29. arcos costais anteriores

30. arcos costais posteriores

31. area cardiaca aumentada

32. area cardiaca globosa

33. atelectasia laminar basal

34. aumento da imagem

35. aumento da vascularizacao

36. base do hemitorax

37. base do pulmao

38. base pulmonar direita

39. base pulmonar esquerda

40. calcificacao do ligamento

41. calcificacao na croca

42. calcificacoes na croca

43. cateter venoso central

44. cifose e osteofitose

45. clipes metalicos mediastinais

46. clips metalicos mediastinais

47. clips no mediastino

48. compativel com aumento

49. corpo vertebral toracica

50. corpos vertebrais dorsais

51. costal anterior direito

52. costal posterior esquerdo

53. costo frenico direito

54. costo frenico esquerda

55. costo frenicos livres

56. costo frenicos obliterados 
57. costro frenico direito

58. croca da aorta

59. ct de torax

60. cupula diafragmatica direita

61. cupula frenica direita

62. cupula frenica elevada

63. cupula frenica esquerda

64. cupulas diafragmaticas livres

65. cupulas frenicas elevadas

66. densas em base

67. dentro dos limites

68. derrame pleural bilateral

69. desvio da traqueia

70. discreto espessamento pleural

71. eletrodos de marcapasso

72. elevacao da cupula

73. escoliose com convexidade

74. escoliose dextro convexa

75. escoliose dorsal dextro

76. escoliose dorsal dextroconvexa

77. escoliose e osteofitose

78. escoliose em sigma

79. escoliose toracica dextro

80. espessamento pleural apical

81. espessamento pleural bilateral

82. esquerda com eletrodo

83. extremidades em camaras

84. finas nas bases

85. frenico direito obliterado

86. frenico esquerdo obliterado

87. hilos pulmonares aumentados

88. hipoplasia dos 60

89. imagem cardiaca aumentada

90. imagem cardiaca normal

91. imagem nodular calcificada

92. imagem nodular retroesternal

93. intercostal anterior esquerdo

94. junto a borda

95. laminares na croca

96. limites da normalidade

97. lobo superior esquerdo

98. marca passo locado

99. marcapasso em camaras

100. marcapasso em hemitorax

101. mediastino a esquerda

102. medio do pulmao

103. metalica em valva

104. metalico no mediastino

105. osteofitos dorsais discretos

106. osteofitos dorsais incipientes

107. osteofitos marginais dorsais

108. osteofitose dorsal incipiente

109. osteofitose dorsal marginal

110. osteofitose marginal dorsal

111. padrao reticular compativel

112. pleural a direita

113. pleural apical bilateral

114. pontos metalicos esternais

115. posterior a esquerda
116. protese valvar mitral

117. retificacao da coluna

118. rx em expiracao

119. seio costo frenico

120. seio costofrenico direito

121. seio costofrenico esquerdo

122. seios costo frenicos

123. seios costofrenicos livres

124. seios costofrenicos obliterado

125. seios costro frenico

126. silhueta cardiaca aumentada

127. sinais de hiperinsuflacao

128. superior a direita

129. superior a esquerda

130. topografia de camaras

131. traves e nodulos

132. traves no terco

133. valvas metalicas aortica

134. vascularizacao pulmonar

normal

135. velamento do hemitorax

136. velamento do seio

4 - GRAMA

1. 50 arco costal anterior

2. 60 arco costal posterior

3. 80 arco costal posterior

4. 80 arcos costais anteriores

5. 9o arco costal posterior

6. acentuacao da cifose dorsal

7. alargamento do mediastino superior

8. altura do corpo vertebral

9. altura dos corpos vertebrais

10. aorta alongada com calcificacao

11. aorta alongada com calcificacoes

12. aorta com calcificacoes laminares

13. aorta com calcificacoes parietais

14. aorta com finas calcificacoes

15. arco costal anterior direito

16. arco costal posterior direito

17. arco costal posterior esquerdo

18. area cardiaca nos limites

19. atelectasias passivas em bases

20. aumento da imagem cardiaca

21. aumento da vascularizacao pulmonar

22. base do hemitorax direito

23. base do hemitorax esquerdo

24. base do pulmao direito

25. base do pulmao esquerdo

26. bronquios de paredes espessadas

27. calcificacao do ligamento longitudinal

28. calcificacoes laminares na croca

29. calcificacoes parietais na croca

30. cifose e osteofitose dorsal

31. clip metalico no mediastino 
32. clipes metalicos no mediastino

33. clips metalicos na projecao

34. clips metalicos no mediastino

35. conveniente ct de torax

36. convexidade para a direita

37. convexidade para a esquerda

38. coracao de dimensoes normais

39. corpo vertebral de t11

40. corpo vertebral de t9

41. costais anteriores a esquerda

42. costais posteriores a direita

43. costal anterior a esquerda

44. costal posterior a esquerda

45. costo frenico direito obliterado

46. costo frenico esquerda obliterado

47. costofrenicos obliterados e cupulas

48. costro frenico direito obliterado

49. cupula frenica direita elevada

50. cupula frenica esquerda elevada

51. discreto aumento da imagem

52. eletrodos de marcapasso posicionados

53. elevacao da cupula diafragmatica

54. elevacao da cupula frenica

55. equipamento de alta potencia

56. escala de contraste longa

57. escoliose dorsal com convexidade

58. escoliose e osteofitose marginal

59. escoliose toracica com convexidade

60. espaco intercostal anterior esquerdo

61. espessadas nos lobos inferiores

62. espessamento pleural a direita

63. espessamento pleural a esquerda

64. espessamento pleural apical bilateral

65. exame realizado em equipamento

66. extremidades em camaras direitas

67. filmes entregues ao paciente

68. finas calcificacoes na croca

69. finas traves na base

70. hilos e vascularizacao pulmonar

71. limites maximos da normalidade

72. marcapasso cardiaco a esquerda

73. marcapasso cardiaco com eletrodos

74. marcapasso em camaras direitas

75. mediastino e lobo superior

76. mediastino superior a direita

77. mediastino superior a esquerda

78. medio do hemitorax direito

79. morfologia compativel com aumento

80. nodulo denso na base

81. obliteracao do seio costo

82. obliteracao do seio costofrenico

83. obliteracao dos seios costo
84. opacidade heterogenea na base

85. paredes espessadas nos lobos

86. pleural apical a esquerda

87. posicionados em camaras direitas

88. presenca de dispositivo metalico

89. protese metalica em valva

90. retificacao da coluna dorsal

91. seio costo frenico direito

92. seio costo frenico esquerda

93. seios costo frenicos livres

94. seios costo frenicos obliterados

95. seios costro frenico direito

96. seios e cupulas diafragmaticas

97. sinais de hiperinsuflacao pulmonar

98. superior e abaulado inferiormente

99. suturas metalicas no esterno

100. tecnica de alta kilovoltagem

101. terco medio do hemitorax

102. terco medio do pulmao

103. topografia de camaras direitas

104. topografia e dimensoes normais

105. transparencia normal a esquerda

106. traqueia para a direita

107. trave densa na base

108. traves densas em base

109. traves densas na base

110. traves finas nas bases

111. traves no terco medio

112. vascularizacao e hilos pulmonares

113. vascularizacao peri - hilar

114. velamento discreto do seio

115. velamento do hemitorax esquerdo

116. velamento do seio costo

117. velamento dos seios costo

5 - GRAMA

1. acentuacao da cifose e osteofitose

2. aorta alongada com calcificacoes parietais

3. aorta alongada com finas calcificacoes

4. aorta com calcificacoes na croca

5. arco costal anterior a esquerda

6. arco costal posterior a esquerda

7. arcos costais anteriores a esquerda

8. arcos costais posteriores a direita

9. area cardiaca nos limites maximos

10. aumento da vascularizacao pulmonar periferica

11. calcificacao do ligamento longitudinal anterior

12. clips metalicos no mediastino superior 
13. com tecnica de alta kilovoltagem

14. cupula frenica elevada a esquerda

15. dimensoes normais e morfologia compativel

16. discreto aumento da imagem cardiaca

17. eletrodos de marcapasso em camaras

18. elevacao da cupula diafragmatica direita

19. elevacao da cupula frenica direita

20. escoliose e osteofitose marginal dorsal

21. espessamento pleural apical a esquerda

22. estrias densas na base direita

23. estruturas osseas e tecidos moles

24. fornece escala de contraste longa

25. hilos e vascularizacao pulmonar aumentada

26. hilos e vascularizacao pulmonar aumentados

27. imagem cardiaca de dimensoes normais

28. imagem cardiaca dentro dos limites

29. marcapasso posicionados em camaras direitas

30. mediastino e lobo superior esquerdo

31. morfologia compativel com aumento ae

32. obliteracao do seio costofrenico direito

33. obliteracao do seio costofrenico esquerdo

34. paredes espessadas nos lobos inferiores

35. parenquima pulmonar de transparencia normal

36. pequena trave no terco medio

37. reducao da altura do corpo

38. reducao da altura dos corpos

39. seio costo frenico direito obliterado

40. seio costo frenico esquerda obliterado

41. seios costofrenicos obliterados e cupulas

42. seios costro frenico direito obliterado

43. seios e cupulas diafragmaticas livres

44. tecidos moles da parede toracica

45. terco medio do hemitorax direito

46. traves densas na base pulmonar

47. traves na base do hemitorax

48. valvas metalicas aortica e mitral

49. vascularizacao e hilos pulmonares aumentados
50. velamento discreto do seio costo

51 . velamento do seio costo frênico

6 - GRAMA

1. acentuacao da cifose e osteofitose dorsal

2. alargamento do mediastino superior a direita

3. alongada com calcificacoes parietais na croca

4. aorta alongada com calcificacao na croca

5. aorta alongada com calcificacoes na croca

6. aorta com calcificacoes laminares na croca

7. aorta com calcificacoes parietais na croca

8. aorta com finas calcificacoes na croca

9. clipes metalicos no mediastino a esquerda

10. clips metalicos no mediastino a esquerda

11. desvio da traqueia para a direita

12. eletrodos de marcapasso em camaras direitas

13. escoliose com convexidade para a direita

14. escoliose com convexidade para a esquerda

15. hemitorax esquerdo de cerca de $5 \mathrm{~mm}$

16. marcapasso cardiaco a esquerda com eletrodo

17. marcapasso com extremidades em camaras direitas

18. nodulo denso na base do hemitorax

19. obliteracao dos seios costo frenicos

20. opacidade irregular em ambas as bases

21. reducao da altura do corpo vertebral

22. reducao da altura dos corpos vertebrais

23. trave no terco medio do hemitorax

24. traves densas na base do hemitorax

25. traves densas na base do pulmao

26. traves na base do hemitorax direito

27. traves no terco medio do hemitorax

28. velamento do seio costo frenico direito 
7 - GRAMA

1. aorta alongada com calcificacoes parietais na croca

2. aorta alongada com finas calcificacoes na croca

3. area cardiaca nos limites maximos da normalidade

4. bronquios de paredes espessadas nos lobos inferiores

5. clips metalicos no mediastino e lobo superior

6. clips metalicos no mediastino superior a esquerda

7. coracao de dimensoes normais e morfologia compativel

8. dimensoes normais e morfologia compativel com aumento

9. escoliose dorsal com convexidade para a esquerda

10. exame realizado em equipamento de alta potencia

11. marcapasso cardiaco a esquerda com eletrodo epicardico

12. nodulo denso na base do hemitorax esquerdo

13. nodulo denso na projecao do 50 arco

14. nodulo na projecao do 80 arco costal

15. parenquima pulmonar de transparencia normal a esquerda

16. pequena trave no terco medio do hemitorax

17. projecao do 20 arco costal anterior direito

18. projecao do 50 arco costal anterior direito

19. projecao do 80 arco costal posterior direito

20. traves densas na base do hemitorax direito

21. traves no terco medio do hemitorax direito

8 - GRAMA

1. clips metalicos no mediastino e lobo superior esquerdo

2. estruturas osseas e tecidos moles da parede toracica

3. pequena trave no terco medio do hemitorax direito

9 - GRAMA

1. coracao de dimensoes normais e morfologia compativel com aumento 


\section{APÊNDICE C - FRASES}

1. "stent" em projecao de coronarias.

2. (artefato ?).

3. (fibrose/atelectasias laminares).

4. *.

5. 1a costela a esquerda nao observada.

6. 2 filmes.

7. 3xame realizado em equipamento de alta potencia, com tecnica de alta kilovoltagem, que fornece escala de contraste longa (baixo contraste).

8. :exame realizado em equipamento de alta potencia, com tecnic ade alta kilovoltagem, que fornece escala de contraste long a(baixo contraste).

9.

10. ac.

11. a criterio clinico avaliar mobilidade frenica ao exame ultrassonografico.

12. a criterio clinico fazer $r x$ de ombro direito para elucidacao da area de esclerose.

13. a criterio clinico, perfil direito.

14. a criterio perfil direito com marcacao no mamilo.

15. ac ac.

16. ac.

17. acentuacao da cifose dorsal e escoliose dextro convexa.

18. acentuacao da cifose dorsal fisiologica.

19. acentuacao da cifose dorsal.

20. acentuacao da cifose e escoliose dextro-convexa.

21. acentuacao da cifose e espondiloartrose dorsal incipiente.

22. acentuacao da cifose e espondiloartrose dorsal.

23. acentuacao da cifose e osteofitose dorsal.

24. acentuacao da cifose fisiologica.

25. acentuacao da cifose toracica fisiologica.

26. acentuacao da cifose toracica.

27. acentuacao da cifose.

28. acentuacao da lordose lombar.

29. acentuacao do cifise e espondiloartrose dorsal.

30. acentuacao do intersticio pulmonar.

31. acentuacaop da cifose toracica fisiologica.

32. acentuada cifose fisiologica dorsal.

33. acentuada escoliose de convexidade a direita.

34. adc.

35. aderencias pleuro-diafragmaticas a esquerda.

36. aderencias pleuro-diafrgmatica direita.

37. adf.

38. afrco medio abaulado.

39. agrupamento vascular de projecao no lobo inferior, melhor identificado em perfil.

40. alargamento da 2a costela esquerda com bifidez de seu arco anterior.

41. alargamento do mediastino (timo).

42. alargamento do mediastino (vascular).

43. alargamento do mediastino a direita (vcs dilatada ?).

44. alargamento do mediastino superior (timo ?).

45. alargamento do mediastino superior a direita (tronco ino- minando + atelectasia?).

46. alargamento do mediastino superior a direita de provavel origem vascular.

47. alargamento do mediastino superior a direita.

48. alargamento do mediastino superior de provavel origem vas- cular.

49. alargamento do mediastino superior.

50. alargamento do mediastino.

51. alargamento mediastinal (timo).

52. alargamento mediastinal a esquerda pela presenca de formacao com atenuacao de partes moles, bem delimitada. 
53. alteracao estrutural com hipoplasia do 50 arco costal esquerdo.

54. alteracao estrutural do 40 arco costal a esquerda.

55. alteracao morfologica do 80 arco costal a direita.

56. alteracoes estruturais do 90 e 100 arcos costais posteriores a direita.

57. alteracoes estruturais em arco costal esquerdo.

58. alteracoes estruturais nos 40 e 50 arcos costais a esquerda (pos implantacao cirurgica).

59. ana, 80 andar.

60. analise do pulmao prejudicada secundaria a tecnica de alta kv.

61. anel metalico na topografia da valva mitral.

62. anel metalicos na topografia da valva mitral.

63. aorta a direita.

64. aorta a direita? arco medio abaulado.

65. aorta alongada a direita.

66. aorta alongada aparentemente a direita.

67. aorta alongada com calcificacao na croca.

68. aorta alongada com calcificacao parietais.

69. aorta alongada com calcificacao parietal na croca.

70. aorta alongada com calcificacao parietal.

71. aorta alongada com calcificacaos parietal na croca.

72. aorta alongada com calcificacoa na croca.

73. aorta alongada com calcificacoes croca.

74. aorta alongada com calcificacoes laminares na croca.

75. aorta alongada com calcificacoes na croca e anel valvar.

76. aorta alongada com calcificacoes na croca.

77. aorta alongada com calcificacoes parietais difusas.

78. aorta alongada com calcificacoes parietais finas.

79. aorta alongada com calcificacoes parietais na croca e des- cendente.

80. aorta alongada com calcificacoes parietais na croca e parte descendente.

81. aorta alongada com calcificacoes parietais na croca.

82. aorta alongada com calcificacoes parietais nas croca.

83. aorta alongada com calcificacoes parietais.

84. aorta alongada com calcificacoes, calibre aumentado.

85. aorta alongada com calcificacoes.

86. aorta alongada com finas calcificacoes na croca.

87. aorta alongada com finas calcificacoes.

88. aorta alongada com pequenas calcificacoes parietais.

89. aorta alongada com pequenas calcificalcoes parietais.

90. aorta alongada com temus calcificacoes parietais na croca.

91. aorta alongada com tenues calcificacoes na croca.

92. aorta alongada com tenues calcificacoes parietais na croca.

93. aorta alongada com tenues calcificacoes parietais.

94. aorta alongada com tenues calcificacoes parietias na croca.

95. aorta alongada discretamente.

96. aorta alongada e ateromatosa.

97. aorta alongada e calibrosa.

98. aorta alongada e densa com calcificacoes na croca.

99. aorta alongada e tortuosa com calcificacoes na croca.

100. aorta alongada e tortuosa com calcificacoes parietais na croca.

101. aorta alongada e tortuosa.

102. aorta alongada na sua porcao ascendente.

103. aorta alongada, ectasiada, com calcificacoes parietais.

104. aorta alongada, tortuosa com calcificacoes parietais na croca.

105. aorta alongada, tortuosa com calcificacoes parietais.

106. aorta alongada, tortuosa, com calcificacoes parietais na croca.

107. aorta alongada, tortuosa, com dilatacao na croca.

108. aorta alongada.

109. aorta aneurismatica ao nivel da croca com calcificacoes parietais.

110. aorta ascedente alongada.

111. aorta ascendente alongada com calcificacoes parietais na croca. 
112. aorta ascendente alongada.

113. aorta com calcificacao na croca.

114. aorta com calcificacao parietal na croca.

115. aorta com calcificacoes finas na croca.

116. aorta com calcificacoes laminares na croca.

117. aorta com calcificacoes laminares, alongada.

118. aorta com calcificacoes na croca.

119. aorta com calcificacoes parietais na croca, alongada.

120. aorta com calcificacoes parietais na croca.

121. aorta com calcificacoes parietais.

122. aorta com calcificacoes.

123. aorta com calcificacoesna croca.

124. aorta com finas calcificacoes na croca.

125. aorta com pequenas calcificacoes parietais.

126. aorta com tenues calcificacoes na croca.

127. aorta com tenues calcificacoes parietais na croca.

128. aorta de avaliacao prejudicada, aparentemente normal.

129. aorta de calcificacoes fina na croca.

130. aorta dilatada e com calcificacoes parietais.

131. aorta discretamente alongada com calcificacoes parietais na croca.

132.

133.

134.

aorta discretamente alongada com tenues calcificacoes parietais na croca.

aorta discretamente alongada.

aorta ectasiada e alongada com calcificacoes na croca.

135. aorta em projecao evidente em frontal, aparentemente a direita.

136. aorta longa com calcificacoes finas na croca.

137. aorta longa com calcificacoes na croca.

138. aorta longa com calcificacoes parietais.

139. aorta longa.

140. aorta nao caracterizada na incidencia em pa.

141. aorta nao visualizada.

142. aorta normal.

143. aorta pouco alongada com calcificacoes parietais na croca.

144. aorta pouco alongada.

145. aorta pouco evidente em pa.

146. aorta pouco evidente.

147. aorta proeminente para a faixa etaria.

148. aorta proeminente para a idade.

149. aorta sem projecao em frontal.

150. aorta sem projecao evidente em frontal.

151. aprta alongada.

152. aqc.

153. arco aortico a direita.

154. arco medio abaulado e denso.

155. arco medio abaulado e desdobrado inferiormente.

156. arco medio abaulado e desdobrado.

157. arco medio abaulado e longo.

158. arco medio abaulado inferiormente.

159. arco medio abaulado superiomente.

160. arco medio abaulado superiormente.

161. arco medio abaulado.

162. arco medio concavo.

163. arco medio desdobrado e abaulado inferiormente.

164. arco medio desdobrado e abaulado.

165. arco medio desdobrado e levemente abualado inferiormente.

166. arco medio desdobrado, retificado superior e abaulado inferiormente.

167. arco medio desdobrado, retificado, superior e abaulado inferiormente.

168. arco medio discretamente abaulado.

169. arco medio ligeiramente abaulado.

170. arco medio nao analisado. 


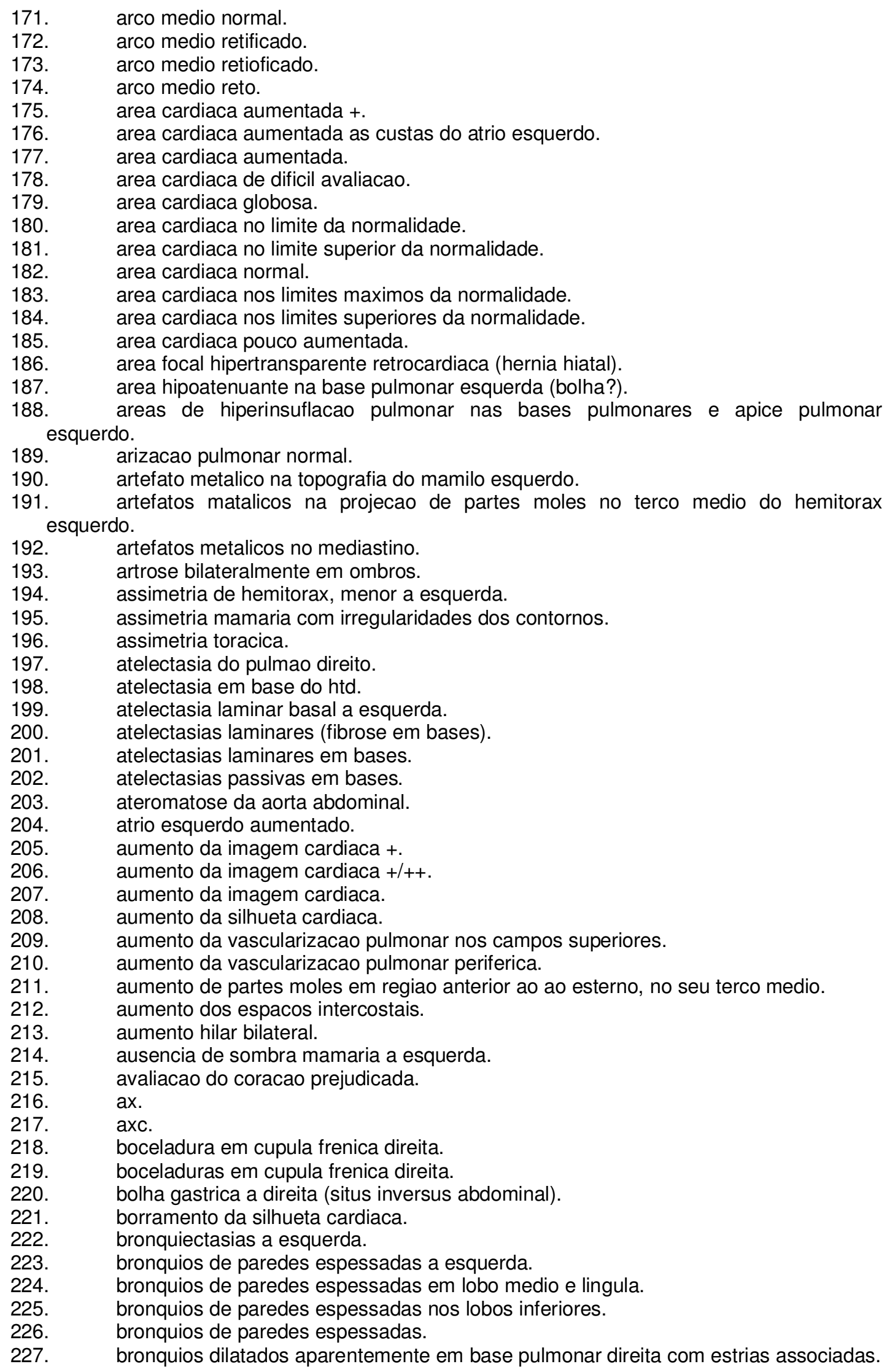


228. bt.

229. calcificacao do disco inter vertebral.

230. calcificacao do espaco discal t9-t10.

231. calcificacao do ligamento anterior.

232. calcificacao do ligamento longitudinal anterior.

233. calcificacao em partes moles localizada abaixo da clavicu- la a direita.

234. calcificacao grosseira em topografia pleural esquerda.

235. calcificacao laminar na croca da aorta.

236. calcificacao na croca da aorta.

237. calcificacao parietal na aorta.

238. calcificacoes de discos intervertebrais.

239. calcificacoes de partes moles na topografia do supra- espinhal a esquerda.

240. calcificacoes do anel valvar mitral.

241. calcificacoes ganglionares no mediastino.

242. calcificacoes laminares na croca da aorta.

243. calcificacoes na croca da aorta.

244. calcificacoes no hilo esquerdo.

245. calcificacoes parietais na aorta.

246. calcificacoes parietais na croca da aorta.

247. calcificacoesparietaisna croca da aorta.

248. cardiomegalia ++ .

249. cardiomegalia + .

250. cardiomegalia $+/++$.

251. cardiomegalia discreta.

252. cardiomegalia.

253. cateter com extremidade no ad.

254. cateter integro na vcs.

255. cateter na vcs.

256. cateter posicionado na topografia da veia cava superior.

257.

258.

cateter situado na projecao da veia cava superior.

cateter venoso central com a extremidade em ad.

259.

260.

cateter venoso central com extremidade na topografia vcs.

261. cg.

262. cifose acentuada.

263. cifose dorsal incipiente.

264. cifose dorsal.

265. cifose toracica.

266. clip metalico mediastinal.

267. clip metalico no mediastino.

268. clipe metalico no mediastino a direita.

269. clipe metalico no mediastino a esquerda.

270.

271.

clipe no apice pulmonar esquerdo e no mediastino.

clipes mediastinais.

272. clipes metalicos mediastinais.

273. clipes metalicos na projecao do trajeto de toracica interna.

274. clipes metalicos no mediastino a esquerda.

275. clipes metalicos no mediastino superior a direita.

276. clipes metalicos no mediastino.

277. clips metalicos e pontos metalicos esternais.

278. clips metalicos mediastinais a direita.

279. clips metalicos mediastinais a esquerda.

280. clips metalicos mediastinais.

281. clips metalicos mediastinal a esquerda.

282. clips metalicos mediatinais.

283. clips metalicos na projecao anterior do hemitorax esquerdo.

284. clips metalicos na projecao peri-hilar no hemitorax esquerdo.

285. clips metalicos no apice do hemitorax direito.

286. clips metalicos no mediastino a esquerda. 
287. clips metalicos no mediastino e lobo superior esquerdo.

288. clips metalicos no mediastino superior a esquerda.

289. clips metalicos no mediastino.

290. clips metalicos no terco superior do hemitorax esquerdo.

291. clips metalicos.

292. clips no mediastino.

293. clis metalicos no mediastino.

294. colapso de corpos vertebrais toracicos.

295. conclusao:

296. condensacao de limites imprecisos em apice de hemitorax esquerdo (pneumonite actinica sequelar?).

$297 . \quad$ controle ca de torax.

298. controle.

299. convem a criterio clinico realizar tc de torax com contras- te.

300. conveniente ct de torax.

301. conveniente esofagograma.

302. coracao aumentado.

303. coracao com morfologia de hipertrofia ventricular esquer- da).

304. coracao de dimensoes normais e morfologia compativel com aumento ae.

305. coracao discretamente aumentado.

306. costela cervical a esquerda.

307. cupula diafragmatica direita elevada.

308. cupula diafragmatica elevada a direita.

309. cupula diafragmatica elevada a esquerda.

310. cupula diafragmatica esquerda elevada.

311. cupula frenica direita elevada com interposicao de alca.

312. cupula frenica direita elevada.

313. cupula frenica elevada a direita.

314. cupula frenica elevada a esquerda.

315. cupula frenica esquerda elevada.

316. cupulas diafragmaticas livres.

317. cupulas frenicas abaixadas.

318. cupulas frenicas elevadas (obe- sidade).

319. cupulas frenicas elevadas ( $r x$ expirado ? obesidade ?).

320. cupulas frenicas elevadas (rx expirado? obesidade?) vascularizacao pulmonar normal.

321. cupulas frenicas elevadas.

322. cupulas frenicas elevads.

323. cupulas frenicas retificadas.

324. deformidade da cabeca umeral direita.

325. densas traves em hemitorax direito.

326. densificacao laminar na base esquerda com hiperinsuflacao do parenquima adjacente.

327. derrame interfissural.

328. derrame pleural bilateral com atelectasias passivas.

329. derrame pleural bilateral, maior a direita associado a ate- lectasia do pulmao adjacente.

330. derrame pleural bilateral.

331. derrame pleural volumoso a esquerda com atelectasia passiva do pulmao adjacente.

332. derrame sub-pulmonar a direita.

333. derrame/pleural bilateral com atelectasia do parenquima pulmonar adjacente.

334. desvio da traqueia e mediastino para a esquerda.

335. desvio da traqueia para a direita.

336. desvio da traqueia para a esquerda pela presenca de forma- cao de densidade de partes moles cervico-toracica-bocio.

337. desvio traqueal para direita por reducao de volume do Isd, de transperencia diminuida (fibrose? atelectasia?).

338. dextroversao com imagem cardiaca aumentada + .

339. diminuta imagem nodular com projecao do 40 arco costal posterior a direita. 
340. discopatias com osteofitose marginal e calcificacao do ligamento longitudinal anterior.

341. discopatias toracicas.

342. discreta elevacao da hemicupula diafragmatica esquerda em regiao posterior.

343. discreta elevacao da hemicupula diafragmatica esquerda.

344. discreta elevacao da hemicupula diafragmatica esquerdo.

345. discreta escoliose com convexidade para a direita.

346. discreta escoliose de convexidade a direita.

347. discreta escoliose dorsal de convexidade a direita.

348.

349.

350.

discreta escoliose dorsal dextro-convexa.

discreta escoliose dorsal dextroconvexa.

discreta escoliose em sigma.

351.

discreta escoliose toracica dextro-convexa.

352.

353.

354.

discreta hipotransparencia basal bilateral provavel mente decorrente de expiracao.

discreta obliteracao do seio costo-frenico direito.

discreta obliteracao do seio costo-frenico esquerdo (gordu- ra ?).

355.

356.

357.

discreta obliteracao do seio costo-frenico posterior direi- to.

discreta osteofitose dorsal.

discreta osteofitose marginal.

358. discreta reacao pleural apical a direita.

359. discreta reacao pleural apical bilateral.

360.

361.

362.

363.

364.

365.

366.

367.

368.

369.

370.

371.

discreta reducao da altura anterior do corpo vertebral na transicao toraco-lombar.

discreto alongamento da aorta ascendente.

discreto alongamento da croca.

discreto aumento da circulacao pulmonar.

discreto aumento da imagem cardiaca.

discreto aumento da vascularizacao pulmonar.

discreto espessamento pleural apical bilateral.

discreto espessamento pleural na base direita.

distensao gastrica.

dreno no hemitorax esquerdo.

e gerador em topografia pelvica a esquerda.

ec.

372.

373.

374.

eletrodo de marcapasso endocavitario posicionado no ventri- culo direito integro.

eletrodo endocavitario com extremidade no vd.

eletrodo endocavitario integro no vd.

eletrodos de marcapasso em camaras direitas.

376.

eletrodos de marcapasso posicionados em camaras direitas.

377.

378.

379.

380.

381.

382.

383.

384.

385.

386.

387.

388.

389.

elevacao da base do hemitorax direito.

elevacao da cupula diafragmatica a direita.

elevacao da cupula diafragmatica direita.

elevacao da cupula frenica direita.

elevacao da cupula frenica esquerda.

elevacao da hemi-cupula diafragmatica esquerda.

elevacao da hemicupula diafragmatica direita.

elevacao da hemicupula diafragmatica esquerda.

elevacao da hemicupula diafragmatica.

elevacao da hemicupula diafrgmatica esquerda (paralisia).

elevacao da hemicupula direita.

elevacao de cupula diafragmatica direita.

elevacao dos hilos pulmonares.

390.

391.

392.

393.

394.

395.

396.

397.

elevecao da hemicupula diafragmatica direita, lobulada.

es.

escoliose com convexidade para a direita.

escoliose com convexidade para a esquerda.

escoliose com convexidade voltada para esquerda.

escoliose de convexidade a direita.

escoliose dextro convexa.

escoliose dextro-convexa. 
399. escoliose dorsal com achatamento de corpos vertebrais.

400. escoliose dorsal com convexidade para a esquerda.

401. escoliose dorsal de convexidade a direita.

402. escoliose dorsal dextro convexa.

403. escoliose dorsal dextro-concava.

404. escoliose dorsal dextro-convexa.

405. escoliose dorsal dextroconvexa.

406. escoliose dorsal em sigma.

407. escoliose dorsal.

408. escoliose e osteofitose dorsal.

409. escoliose e osteofitose marginal dorsal.

410. escoliose em sigma.

411. escoliose para direita.

412. escoliose toracica com convexidade para a direita.

413. escoliose toracica com convexidade voltada para direita.

414. escoliose toracica de convexidade a esquerda.

415. escoliose toracica dextro-convexa com mal formacoes de corpos vertebrais.

416. escoliose toracica dextro-convexa.

417. escoliose toraco-lombar de convexidade a esquerda.

418. escoliose toraco-lombar em sigma.

419. eslevacao da cupula frenica direita com obliteracao do seio costofrenico posterior (condensacao?).

420. espacos discais reduzidos difusamente.

421. espessamento cissural.

422. espessamento cisural a esquerda.

423. espessamento peribronco-vascular difuso.

424. espessamento pleural a direita com seio costo-frenico velado vascularizacao pulmonar normal.

425. espessamento pleural a direita, calcificado.

426. espessamento pleural a direita.

427. espessamento pleural a esquerda, calcificado, com reducao volumetrica desse pulmao.

428. espessamento pleural a esquerda.

429. espessamento pleural apical a direita com traves densas e desvio da traqueia para a direita com elevecao do hilo ipsilateral.

430. espessamento pleural apical a esquerda.

431. espessamento pleural apical bilateral associado a opacidades heterogeneas nos apices associado a areas de hipertranspa- rencia pulmonares.

432. espessamento pleural apical bilateral.

433. espessamento pleural apical.

434. espessamento pleural bilateral.

435. espessamento pleural com irregularidade do parenquima adja- cente, apice direito (sequelar?).

436. espessamento pleural direito com fixacao alta da cupula frenica.

437. espessamento plueral a esquerda.

438. espondiloartrose dorsal.

439. espondiloatrose dorsal.

440. estase do pulmaoadjacente e do hte.

441. estase pulmonar (linhas b de kerley).

442. estase pulmonar.

443. esterenorrafia.

444. esternoorrafia.

445. esternorrafaia.

446. esternorrafia.

447. esternorrafia/clips metalicos.

448. estria densa em base pulmonar a direita.

449. estria densa no apice pulmonar direito.

450. estria densa no lobo superior direito.

451. estria em base pulmonar esquerda. 
452. estria no terco medio do hemitorax esquerdo.

453. estrias densas na base direita.

454. estrias densas na base do hemitorax direito.

455. estrias densas na base pulmonar direita.

456. estrias densas nas bases pulmonares (atelectasias).

457. estrias densas nas bases pulmonares.

458. estrias densas no apice a direita e base esquerda.

459. estrias densas no terco medio do hemitorax direito.

460. estrias densas no terco medio/inferior do hemitorax esquerdo ol.

461. estrias densas nos lobos superiores.

462. estrias em Isd e bases.

463. estrias finas em base pulmonar a direita.

464. estrias na base do hemitorax esquerdo.

465. estrutura metalica na projecao do mediastino a esquerda.

466. estrutura metalica na projecao do tronco pulmonar.

467. estruturas osseas e tecidos moles da parede toracica, sem alteracoes.

468. estruturas osseas e tecidos moles da parese toracica, sem alteracoes.

469. exame direcionado para avaliacao de marcapasso.

470. exame realizado com equipamento portatil, com o paciente no leito, em posicao semisentada.

471. exame realizado em equipamento de alta potencia, com tecnica de alta kilovoltagem, que fornece escala de contraste longa (baixo contraste).

472. extremidades de marcapasso em camaras direitas.

473. fazer $r x$ de torax com contraste de esofago.

474. filme entregue ao paciente.

475. filme retirado pela enf.

476. filmes entregues ao paciente.

477. filmes entregues laudo: esternorrafia.

478. filmes entregues para paciente.

479. filmes entregues.

480. fina estria em base pulmonar esquerda.

481. fina trave em base esquerda.

482. finas estrias em bases pulmonares.

483. finas estrias esparsas em ambos hemitorax.

484. finas traves densas em base esquerda e lsd.

485. finas traves densas em bases pulmonares.

486. finas traves densas nas bases.

487. finas traves densas no terco medio do pulmao direito.

488. finas traves na base direita.

489. finas traves nas bases pulmonares.

490. fio metalico na projecao do ad.

491. fio metalico na topografia de atrio direito.

492. fios metalicos no mediastino.

493. fragmento de eletrodo de marcapasso na vcs.

494. fragmento de eletrodo epicardico.

495. fratura compressao no nivel d7.

496. fratura consolidada de arcos costais a direita.

497. fratura consolidada do 60 arco costal posterior a esquerda.

498. fratura do 40 arco costal anterior esquerdo.

499. fratura no 8 arco costal posterior a esquerda (patologica?).

500. fraturas consolidadas em arcos costais posteriores a direita.

501. fraturas costais consolidadas.

502. fraturas costais multiplas a direita.

503. fusao parcial dos 30 e 40 arcos costais.

504. grande area hipertransparente anterior no pulmao direito sugerindo bolha.

505. hemicupula diafragmatica direita elevada.

506. hemicupula direita elevada.

507. hilo direito aumentado, hilo esquerdo diminuido.

$508 . \quad$ hilo direito aumentado. 
509. hilo direito discretamente aumentado.

$510 . \quad$ hilo direito elevado.

$511 . \quad$ hilo direito proeminente.

512. hilo esquerdo elevado.

513. hilo pulmonar direito proeminente.

$514 . \quad$ hilo pulmonar esquerdo aumentado.

515. hilo pulmonar esquerdo elevado e aumentado.

516. hilos amplos.

$517 . \quad$ hilos aumentados.

$518 . \quad$ hilos calibrosos.

519. hilos de configuracao, topografia e d aorta normal.

520. hilos de configuracao, topografia e dimensoes normais.

521. hilos e vascularizacao peri-hilar aumentados.

522. hilos e vascularizacao peri-hilar proeminentes.

523. hilos e vascularizacao perihilar aumentados.

524. hilos e vascularizacao pulmonar aumentada +/++.

525. hilos e vascularizacao pulmonar aumentada.

526. hilos e vascularizacao pulmonar aumentadas.

527. hilos e vascularizacao pulmonar aumentado.

528. hilos e vascularizacao pulmonar aumentados a direita.

529. hilos e vascularizacao pulmonar aumentados.

530. hilos e vascularizacao pulmonar discretamente aumentadas.

531. hilos e vascularizacao pulmonar peri-hilar aumentados.

532. hilos e vascularizacao pulmonar peri-hilar proeminentes.

533. hilos e vascularizacao pulmonar periferica aumentada.

534. hilos e vascularizacao pulmonar preservados a direita.

535. hilos encobertos.

536. hilos proeminentes, mais evidente a direita

$537 . \quad$ hilos proeminentes.

538. hilos pulmonar esquerdo elevado.

539. hilos pulmonares aumentados maior a esquerda.

540. hilos pulmonares aumentados.

541. hilos pulmonares e vascularizacao peri-hilar proeminentes.

542. hilos pulmonares proeminentes.

543. hilos pulmonares retraidos.

544. hilos/vascularizacao aumentados.

545. hilos/vascularizacao pulmonar aumentada.

546. hilos/vascularizacao pulmonar aumentados.

547. hilos/vascularizacao pulmonares aumentados, com desproporcao hilo/periferia.

548. hiperinsuflacao compensatoria dos apices.

549. hiperinsuflacao do pulmao direito com herniacao para a esquerda pelo mediastino anterior.

550. hiperinsuflacao pulmonar.

551. hipertransparencia a esquerda secundaria a mastectomia.

552. hipertransparencia pulmonar a direita.

553. hipertransparencia pulmonar do terco-superior do hemitorax esquerdo.

554. hipertransparencia pulmonar na base esquerda (bolha de ar?).

$555 . \quad$ hipertransparencia pulmonar.

556. hipertransparencia retroesternal, nivel hidro-aereo peri- cardiaco a esquerda.

557. hipertransparencias pulmonar em apices.

558. hipoplasia do 10 arco costal e.

559. hipoplasia dos 60,70 e 80 arcos costais anteriores a esquerda.

560. hipoplasia dos primeiros arcos costais.

561. hipotransparencia basal bilateral.

562. hipotransparencia de padrao intersticial com areas de faveolamento, mais evidente em pulmao esquerdo.

563. hipotransparencia de padrao intersticial mais evidente nas bases.

564. hipotransparencia heterogenea apico-infravertebral a direi- ta.

565. hipotransparencia heterogenea na base pulmonar direita. 
566. hipotransparencia heterogenea sobre cupulas frenicas na pro- jecao de lobos inferiores.

$567 . \quad$ hipotransparencia pulmonar.

568. hte de transparencia diminuida.

569. imagem aerolar nas bases (bronquiectasias ?).

570. imagem arredondada heterogenea com cerca de $0.9 \mathrm{~cm}$ peri-hi- lar a esquerda (ganglio calcificado).

571. imagem arredondada hipertransparente na base pulmonar direi- ta.

572. imagem arredondada radiopaca entre os espacos discais de d9 e d10.

573. imagem arredondada radiopaca junto a borda inferior da gle- noide direita.

574. imagem arredondada radiopaca medindo cerca de $0.3 \mathrm{~cm}$ na projecao do 70 arco costal anterior esquerdo.

575. imagem cardiaca aumentada ++ .

576. imagem cardiaca aumentada + .

577. imagem cardiaca aumentada $+/++$.

578. imagem cardiaca aumentada aparentemente ( $r x$ expirado).

579. imagem cardiaca aumentada com abaulamento na silhueta infe- riormente.

580. imagem cardiaca aumentada com calcificacao em anel valvar mitral.

581. imagem cardiaca aumentada, aorta normal.

582. imagem cardiaca aumentada, globosa.

583. imagem cardiaca aumentada.

584. imagem cardiaca cardiaca.

585. imagem cardiaca com provavel aumento (avaliacao prejudicada).

586. imagem cardiaca de dimensoes normais.

587. imagem cardiaca dentro dos limites da normalidade.

588. imagem cardiaca discretamente aumentada + .

589. imagem cardiaca discretamente aumentada.

590. imagem cardiaca e mediastino desviados para a esquerda.

591. imagem cardiaca normal.

592. imagem cardiaca normal/ aumentada + .

593. imagem cardiaca normal/aumentada + .

594. imagem cardiaca pouco aumentada + .

595. imagem cardiaca pouco aumentada.

596. imagem cardicaca aumentada.

597. imagem com nivel hidroaereo no espaco retrocardiaco corres- pondente a hernia diafragmatica.

598. imagem densa no terco medio da clavicula esquerda (calo osseo).

599. imagem densa superficial projetando-se em partes moles a direita.

600. imagem heterogenea, de limites mal definidos no terco supe- rior do hemitorax esquerdo compativel com processo inflama- torio.

601. imagem hipertransparente arredondada com limites bem defini- dos medindo $10.0 \mathrm{x}$

$8.5 \mathrm{~cm}$ localizada no terco medio anterior do pulmao esquerdo (bolha).

602. imagem linear densa (metalica?) na base pulmonar esquerda.

603. imagem nodular calcificada na base pulmonar esquerda.

604. imagem nodular calcificada na projecao do 40 arco costal posterior.

605. imagem nodular calcificada no 50 arco costal anterior direi- to.

606. imagem nodular de $0.5 \mathrm{~cm}$ projetando-se sobre o decimo arco costal posterior esquerdo podendo corresponder a imagem mamilar.

607. imagem nodular de aproximadamente $0.5 \mathrm{~cm}$, projetando-se sobre o novo arco costal posterior direito.

608. imagem nodular densa na projecao do 60 espaco posterior a direita medindo $0.4 \mathrm{cn}$.

609. imagem nodular medindo $0.7 \mathrm{~cm}$ com area hipertransparente central localizada na base do hemitorax direito.

610. imagem nodular na base pulmonar direita medindo $0.5 \mathrm{~cm}$ (som- bra que pode corresponder a mamilo).

611. imagem nodular na projecao do 60 arco costal anterior direi- to que pode corresponder a projecao do mamilo.

612. imagem nodular na projecao do 60 arco costal posterior a direita (ossea? pulmonar?).

613. imagem nodular na projecao do 60 arco costal posterior a esquerda com $0.4 \mathrm{~cm}$. 
614. imagem nodular na projecao do 90 arco costal posterior esquerdo (mamilo ?) mediastino sem alteracoes.

615. imagem nodular no 90 espaco intercostal posterior direito.

616. imagem nodular no campo pulmonar medio a esquerda (vascu- lar ?).

617. imagem nodular projetando-se no 80 espaco intercostal pos- terior a direita.

618. imagem nodular projetando-se no 80 espaco intercostal poste- rior a direita.

619. imagem nodular projetando-se sobre o 30 arco costal anterior a esquerda.

620. imagem nodular radiopaca a esquerda de contornos regulares medindo $1.5 \mathrm{~cm}$ na projecao do 50 arco costal anterior.

621. imagem nodular radiopaca com cerca de $0.3 \mathrm{~cm}$ na projecao do 30 arco costal anterior esquerdo.

622. imagem nodular radiopaca com cerca de $0.5 \mathrm{~cm}$ na base pulmo- nar visualizada na incidencia de perfil.

623. imagem nodular radiopaca com cerca de $0.6 \mathrm{~cm}$ entre 60 e 70 arcos costais anteriores (vascular?).

624. imagem nodular radiopaca medindo cerca de $0.4 \mathrm{~cm}$ na base do hemitorax esquerdo (vascular?).

625. imagem nodular radiopaca medindo cerca de $0.4 \mathrm{~cm}$ na proje- cao do 70 arco costal anterior direito.

626. imagem nodular radiopaca medindo cerca de $0.4 \mathrm{~cm}$, na topo- grafia do corpo vertebral no terco medio do torax.

627. imagem nodular radiopada com cerca de $0.2 \mathrm{~cm}$ na projecao do 90 arco costal posterior esquerdo (vascular?).

628. imagem nodular retroesternal anterior, aparentemente a direita com $0.5 \mathrm{~cm}$.

629. imagem nodular retroesternal de cerca de $0.5 \mathrm{~cm}$, identificado em perfil (vascular).

630. imagem ovalada, radiopaca com cerca de $0.4 \mathrm{~cm}$, na topografia do 20 arco costal posterior direito.

631. imagem radiopaca medindo $1.0 \mathrm{~cm}$ localizada na projecao do 70 arco costal posterior a direita (aparentemente artefatual).

632. imagem radiopaca medindo cerca de $0.4 \mathrm{~cm}$ na topografia do 30 arco costal posterior esquerdo (vascular-colaterais ?).

633. imagem radiopaca medindo cerca de $1.0 \mathrm{~cm}$ na projecao do 100 arco costal posterior.

634. imagem retrocardiaca com nivel hidro aereo compativel com hernia de hiato a criterio clinico complementar com esofa- gograma.

635. imagem sugestiva de hernia de hiato esofagiano.

636. imagem transparente retrocadiaca (hernia hiatal?).

637. imagem tubular em projecao de subclavio direita.

638. imagens cardiaca aumentada.

639. imagens de densidade metalica projetando-se na regiao da parede toracica posterior na altura de $\mathrm{d} 12$.

640. imagens hipertransparente retrocardiaca (hernia diafragmati- ca?).

641. imagens nodulares calcificadas de ate $1.0 \mathrm{~cm}$ localizadas na base do hemitorax direito.

642. imagens nodulares calcificadas medindo a maior delas cerca de $0.5 \mathrm{~cm}$ na base pulmonar direita.

643. imagens nodulares em projecao da base do hemitorax direito (partes moles?).

644. imagens nodulares em terco medio do pulmao direito e esquer- do com $0.4 \mathrm{~cm}$ cada.

645. imagens nodulares hipotransparentes no lobo inferior esquer- do e sem posicao de rotura.

646. imensoes normais.

647. imgem cardiaca aumentada.

648. importante pneumotorax a direita com atelectasia do pulmao ipsilateral.

649. inalterado com relacao ao exame anterior de 02/09/2003.

650. infiltrado intersticial bilateral difuso micronodular.

651. infiltrado intersticial de padrao reticulo-nodular, mais evidente em apices.

652. infiltrado intersticial nas bases pulmonares.

653. infiltrado intersticial peribronco-vascular difuso mais acentuado na base do hemitorax direito.

654. infiltrado interstinal na base e terco medio do hemitorax direito. 
655. infiltrado na base pulmonar direita.

656. infiltrado padrao reticular compativel com pneumopatia intersticial a esquerda.

657. infiltrado tenue na base do pulmao direito.

658. infiltrado tenue no apice do pulmao esquerdo.

659. infiltrodo intersticial nos $2 / 3$ inferiores pulmonares, alem de multiplos nodulos.

660. investigar tbc.

661. laudo:

662. laudo: escoliose com convexidade a direita.

663. laudo: escoliose dorsal.

664. laudo: esternorrafia.

665. laudo: estruturas osseas e tecidos moles da parede toracica, sem alteracoes.

666. laudo: fratura no 80 e 90 arco costal posterior a esquerda.

667. laudo: osteofitose dorsal incipiente.

668. laudo: osteofitose dorsal.

669. laudo: suturas metalicas no esterno.

670. lesao esclerotica irregular na metafise umeral esquerda (infarto ?).

671. ligeira escoliose dorsal.

672. linha densa na base do pulmao direito.

673. linha densa na base do pulmao esquerdo.

674. linha densa na base pulmonar esquerda.

675. linha densa no terco inferior do hemitorax esquerdo.

676. linhas $b$ de kerley bibasais.

677. linhas b de kerley na base direita.

678. linhas b de kerley na base do hemitorax.

679. linhas b de kerley nas bases.

680. linhas $b$ de kerley.

681. linhas densas em base do htd.

682. linhas densas na base direita.

683. linhas densas na base do hemitorax esquerdo.

684. linhas densas na base do pulmao direito.

685. linhas densas na base pulmonar esquerda.

686. linhas densas no hemitorax direito.

687. linhas densas septais nas bases pulmonares.

688. lobo azigos (variante do normal).

689. lobo azigos (variante o normal).

690. lobo azigos.

691. lobos azigos (variante anatomica).

692. lordose da transicao toraco-lombar.

693. mal formacao vertebral dorsal (d4. d5 e d6) com provaveis hemivertebras condicionando escoliose dextroconvexa.

694. mama direita nao visualizada (mastectomia a direita?).

695. marca passo com eletrodo em ad/ad.

696. marca passo locado em hemitorax direito com eletrodo tendo sua extremidade em topografia de vd.

697. marca passo locado em projecao do terceiro arco costal anterior esquerdo com eletrodo posicionado na topografia de vd.

698. marca-passo com eletrodo endocavitario integro no vd.

699. marca-passo com eletrodo endocavitario integro.

700. marca-passo com eletrodo endocavitario, integro no vd.

701. marca-passo com eletrodo epicardico.

702. marca-passo com eletrodos ad/vd.

703. marca-passo com eletrodos em camaras direitas.

704. marca-passo com eletrodos endocavitarios no ad e vd e ele- trodo epicardico no vd.

705. marca-passo com eletrodos endocavitarios, integros nas cama- ras direitas.

706. marca-passo com eletrodos endocavitarios, integros, em ad e vd.

707. marca-passo com eletrodos endocavitarios, integros, posicio- nados na topografia de camaras direitas.

708. marca-passo com extremidade distal em camaras direitas.

709. marca-passo endocavitario com eletrodos integros. 
710. marca-passo/desfribilador em extremidades distais em ad/vd.

711. marcapaaso com eletrodo integro.

712. marcapasso cardiaco a esquerda com eletrodo epicardico.

713. marcapasso cardiaco a esquerda com eletrodos epicardicos.

714. marcapasso cardiaco a esquerda.

715. marcapasso cardiaco com eletrodos em topografia de camaras direitas.

716. marcapasso cardiaco com eletrodos na projecao de camaras direitas e fio epicardico.

717. marcapasso cardiaco com eletrodos na topografia de camaras direitas.

718. marcapasso cardiaco.

719. marcapasso com eletrodo endocavitario com extremidade na projecao da parede toracica anterior no nivel do vd.

720. marcapasso com eletrodo integro em ventriculo direito.

721. marcapasso com eletrodo integro endocavitario em vd.

722. marcapasso com eletrodo integro.

723. marcapasso com eletrodos endocavitarios integros nas cama- ras direitas.

724. marcapasso com eletrodos endocavitarios integros nas camaras direitas.

725. marcapasso com eletrodos endocavitarios integros nas camaras esquerdas.

726. marcapasso com eletrodos endocavitarios integros no vd.

727. marcapasso com eletrodos endocavitarios nas camaras direitas e epicardicos.

728. marcapasso com eletrodos endocavitarios posicionados em to- pografia de camaras direitas.

729. marcapasso com eletrodos endocavitarios, integros, posicio- nados na topografia de camaras direitas e ve.

730. marcapasso com eletrodos epicaridicos a esquerda.

731. marcapasso com eletrodos intregros posicionados na topo- grafia de vd e ve.

732. marcapasso com extremidades em camaras direitas.

733. marcapasso em flanco esquerdo com eletrodo na projecao do vd.

734. marcapasso em hemitorax direito, com extremidade em veia subclavia direita.

735. marcapasso/disfibrilador com eletrodos integros.

736. massa mediastinal postorior a esquerda bem circuscrita, com paredes calcificadas medindo $2.5 \times 2 \times 2 \mathrm{~cm}$ - calcificacao do tubo do blalock? hematoma? ac.

737. massa medindo $3.5 \times 3.0 \mathrm{~cm}$ localizada no terco medio do hemitorax direito.

738. mastectomia a esquerda.

739. material de fixacao interna na clavicula direita.

740. mediastino alargado (timo ?).

741. mediastino alargado (timo).

742. mediastino desviado para a direita.

743. mediastino sem alteracoes.

744. micronodulos calcificados em regiao hilar direita e lsd (se quelares ).

745. micronodulos difusos.

746. micronodulos medindo $0.4 \mathrm{~cm}$ localizado na base do hemitorax esquerdo.

747. micronodulos medindo $0.4 \mathrm{~cm}$ localizado na projecao no 90 arco costal posterior a direita.

748. micronodulos nos tercos medio e inferior do pulmao direito.

749. $\mathrm{mp}$ com eletrodo em $\mathrm{v}$.

750. $\quad \mathrm{mp}$ com eletrodo endocavitario.

751. multiplas imagens hipertransparentes de aspecto areolar nos apices sugeringo bronquiectasias, alem de delgadas estrias densas - sequela de processo especifico? ac.

752. multiplas imagens micronodulares difusas predominando nos $2 / 3$ superiores pulmonares e na periferia.

753. nodulo calcificado perihilar a esquerda (linfonodo).

754. nodulo com cerca de $1.5 \mathrm{~cm}$ projetando-se na base do hte (mamilo).

755. nodulo de baixa densidade na projecao do 100 arco costal posterior.

756. nodulo denso na base do hemitorax esquerdo de cerca de $5 \mathrm{~mm}$.

757. nodulo denso na base do hemitorax esquerdo medindo $0.5 \mathrm{~cm}$.

758. nodulo denso na projecao do 20 arco costal anterior direito.

759. nodulo denso na projecao do 30 espaco intercostal anterior esquerdo.

760. nodulo denso na projecao do 40 espaco intercostal anterior esquerdo medindo 0.4 $\mathrm{cm}$. 
761. nodulo denso na projecao do 50 arco costal anterior direito.

762. nodulo denso no terco medio do pulmao direito com $0.5 \mathrm{~cm}$.

763. nodulo distribuidos difusamente em aorta no hemitorax, re- gulares, o maior no terco inferior do hemitorax esquerdo, medindo $1.0 \mathrm{~cm}$.

764. nodulo irregular em lobo superior esquerdo e em campo pulmo- nar medio a direita com traves adjacentes.

765. nodulo medindo $0.4 \mathrm{~cm}$ localizado no terco superior do hemi- torax direito.

766. nodulo medindo $0.5 \mathrm{~cm}$ projetando-se perifericamente no 70 arco costal esquerdo.

767. nodulo medindo $0.6 \mathrm{~cm}$ na projecao do 80 arco costal anterior a esquerda.

768. nodulo medindo $0.6 \mathrm{~cm}$ localizado na base do hemitorax direi- to.

769. nodulo medindo $0.7 \mathrm{~cm}$ projetando-se sobre 060 arco costal posterior direito.

770. nodulo medindo $0.9 \mathrm{~cm}$ projetando-se no 90 arco costal poste- rior direito (mamilo ?) linhas $b$ de kerley.

771. nodulo na base do hemitorax esquerdo que deve corresponder a projecao de mamilo.

772. nodulo na projecao do 40 espaco costal posterior a esquerda de $0.4 \mathrm{~cm}$.

773. nodulo periferico no campo medio do pulmao direito.

774. nodulo projetando-se sobre o 60 arco costal posterior direi- to.

775. nodulos calcificados apicais bilateralmente.

776. nodulos densos, menores que $1.0 \mathrm{~cm}$ em Isd e lie.

777. nodulos menor que $1.0 \mathrm{~cm}$ em projecao do $1 / 3$ medio do htd.

778. nodulos no apice do htd.

779. nodulos pulmonares (granulomas ? secundarios ?).

780. nota-se pequenas imagens no apice pulmonar direito (seque- lar ?).

781. notam-se nodulos de schmorl.

$782 . \quad 0$.

783. obliteracao do seio cardio frenico direito (lipoma?).

784. obliteracao do seio costo-frenico direito (espessamento pleural?).

785. obliteracao do seio costo-frenico direito.

786. obliteracao do seio costo-frenico esquerdo (espessamento pleural).

787. obliteracao do seio costo-frenico esquerdo.

788. obliteracao do seio costo-frenico.

789. obliteracao do seio costofrenico direito.

790. obliteracao do seio costofrenico esquerdo.

791. obliteracao do sieo costofrenico direito.

792. obliteracao dos seios costo-frenicos por possivel derrame pleural com opacidade e traves em bases pulmonares.

793. obliteracao dos seios costo-frenicos posteriormente maior a esquerda (espessamento/derrame).

794. obliteracao dos seios costo-frenicos.

795. obliteracao dos seios costofrenicos posteriores.

796. obs:

$797 . \quad$ ol.

798. opacidade arredondada no segmento basal medial do lie.

799. opacidade com finas traves na base pulmonar direita.

800. opacidade de ate $1.0 \mathrm{~cm}$ localizadas no terco superior do hemitorax direito (sequelares).

801. opacidade heterogenea da projecao da lingula com base pleural larga (colecao pleural encistado?).

802. opacidade heterogenea em base do hemitorax esquerdo.

803. opacidade heterogenea em lobo inferior.

804. opacidade heterogenea na apice pulmonar direito (espessa- mento pleural a direita).

805. opacidade heterogenea na base direita borrando o contorno cardiaco.

806. opacidade heterogenea na base do hemitorax direito.

807. opacidade heterogenea na base do hemitorax esquerdo (derra- me pleural bilateral maior a esquerda + atelectasias.

808. opacidade heterogenea na base do hemitorax esquerdo (derrame pleural + atelectasias).

809. opacidade heterogenea na base do hemitorax esquerdo.

810. opacidade heterogenea na base do pulmao esquerdo. 


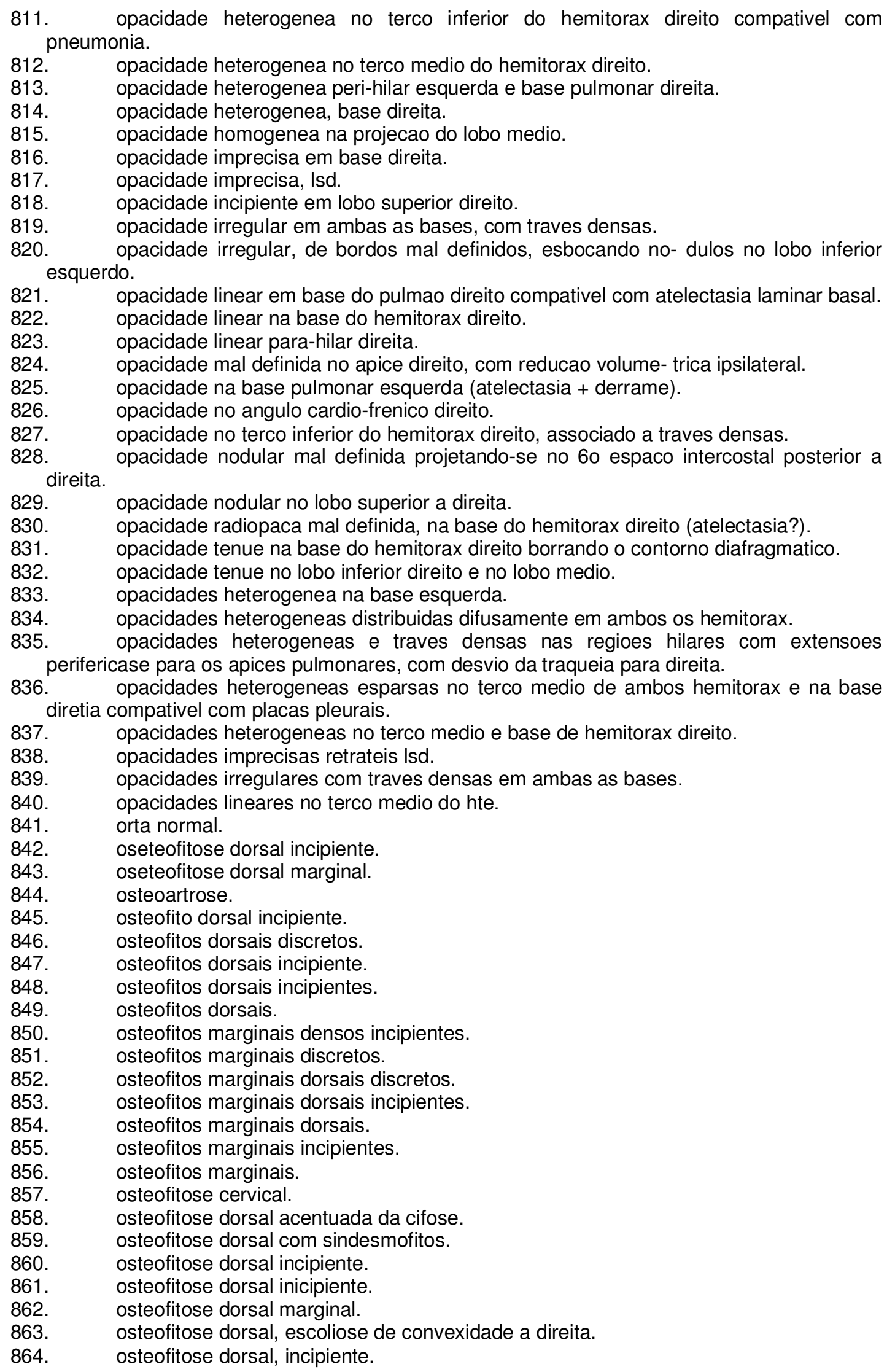


865. osteofitose dorsal.

866. osteofitose e acentuacao da cifose dorsal.

867. osteofitose marginal dorsal formando sindesmofitos.

868. osteofitose marginal dorsal incipiente.

869. osteofitose marginal dorsal.

870. osteofitose marginal incipiente.

$871 . \quad$ osteofitose marginal toracica.

872. osteofitose marginal.

873. osteofitose toracica.

874. osteofitose.

875. osteofitse dorsal.

876. osteopenia difusa.

877. osteopenia.

878. osteopoenia difusa.

879. ostetofitos dorsais.

880. ostetofitose dorsal.

$881 . \quad$ ostiofitose dorsal.

882. ostios metalicos na projecao do mediastino a direita.

883. paciente retirou imagens.

884. padrao intersticial em base direita.

885. padrao intersticial em bases.

886. padrao intersticial peri-bronco vascular.

887. padrao intersticial reticular mais acentuado nas bases.

888. padrao reticular predominante nas bases pulmonares.

889. parafuso metalico no ombro esquerdo.

890. parenquima pulmonar de transparencia normal a direita, a esquerda de analise prejudicada.

891. parenquima pulmonar de transparencia normal a esquerda.

892. parenquima pulmonar de transparencia normal, a direita.

893. parenquima pulmonar de transparencia normal.

894. pctus carinaturum.

895. pectius carinatum.

896. pectus carinatum.

897. pectus excavatum.

898. pequena imagem nodular medindo $0.5 \mathrm{~cm}$ na base pulmonar direita, visualizada apenas na incidencia em perfil, em regiao posterior.

899. pequena trave no terco medio do hemitorax direito.

900. pequenas imagens nodulares em projecao da base do hemitorax esquerdo.

901. pequenas imagens nodulares na projecao do 80 arco costal posterior a esquerda (vasos? nodulos?).

902. pequeno foco de condensacao na regiao infra-clavicular direita.

903. pequeno nodulo na projecao do 80 arco costal posterior direito (vascular? granuloma?).

904. pincamento da hemicupula diafragmatica direita.

905. pincamento de cupula diafragmatica esquerda e opacidades imprecisas.

906. pincamento pleuro-diafragmatico da cupula esquerda.

907. pincamento pleuro-diafragmatico.

908. pneumonia a direita.

909. pneumopatia intersticial difusa a direita, caracterizada por padrao reticular.

910. pontos metalicos esternais.

911. pontos metalicos no esterno.

912. pontos metalicos no mediastino anterior a direita.

913. possivel calcificacao em projecao do tendao supra-espinhal a direita.

914. possivel hernia gastrica hiatal.

915. presenca de dispositivo metalico projetando-se posterior- mente junto a borda cardiaca.

916. presenca de fragmento de eletrodo de marca-passo.

917. presenca de linhas b de kerley.

918. presenca de lobo azigos. 
919. presenca de marca passo na pelve com sua extremidade no ven- triculo direito.

920. processo inflamatorio cronico (tbc + silicose ?).

921. processo intersticial difuso no pulmao direito caracterizado por padrao reticular.

922. projetil de arma de fogo na axila direita.

923. protese mamaria bilateral.

924. protese matalica valvar aortica.

925. protese metalica aortica.

926. protese metalica em valva aortica.

927. protese metalica em valva mitral.

928. protese metalica na topografia da valva aortica.

929. protese metalica na topografia da valva mitral.

930. protese metalica valvar aortica.

931. protese mitral.

932. protese valvar aortica.

933. protese valvar metalica aortica.

934. protese valvar metalica mitral.

935. protese valvar mitral.

936. proteses valvares metalicas mitral e aortica.

937. proteses valvares mitral e aortica.

938. ptotese valvar mitral.

939. pulmoes hiperinsuflados principalmente nas bases.

940. pulmoes hiperinsuflados.

941. pulmoes hipertransparentes nas bases.

942. pulmoes hipertransparentes.

943. pulmoes restantes hiper-insuflados.

944. pulmoes restantes hiperinsufladas.

945. pulmoes restantes hipertransparentes.

946. rarefacao ossea difusa.

947. rarefacao ossea.

948. reacao pleural anterior ipsilateral.

949. reducao da altura anterior do corpo vertebral d11 (fratura por compressao).

950. reducao da altura de corpo vertebral toracica medio.

951. reducao da altura de corpos vertebrais toracicos medios.

952. reducao da altura de corpos vertebrais toracicos superiores e de um corpo vertebral lombar alto.

953. reducao da altura de corpos vertebrais.

954. reducao da altura de d8 (fratura compressao).

955. reducao da altura do corpo da vertebra dorsal inferior.

956. reducao da altura do corpo vertebral de d9. com achatamento do seu plato superior.

957. reducao da altura do corpo vertebral de t11.

958. reducao da altura do corpo vertebral de t9 (fratura compres- siva).

959. reducao da altura do corpo vertebral de t9.

960. reducao da altura do corpo vertebral no nivel aproximado de $t 7$.

961. reducao da altura do corpo vertebral toracica media.

962. reducao da altura dos corpos vertebrais de 13 . t5 e t6.

963. reducao da altura dos corpos vertebrais dorsais medios.

964. reducao das alturas dos corpos vertebrais dorsais.

965. reducao difusa da altura dos corpos vertebrais toracicos.

966. reducao do volume do htd, de transparencia diminuida (pleural?).

967. reducao dos espacos discais difusamente.

968. reducao dos espacos discais na porcao media e inferior da coluna toracica.

969. reestadiamento de neoplasia mamaria.

970. retificacao da cifose dorsal fisiologica.

971. retificacao da cifose toracica fiisiologica.

972. retificacao da cifose toracica fisiologica.

973. retificacao da coluna dorsal (postural?).

974. retificacao da coluna dorsal fisiologica.

975. retificacao da coluna dorsal.

976. retificacao da coluna toracica. 
977. retificacao da cupula diafragmatica direita.

978. retracao do hilo direito.

979. rx em expiracao.

980. rx expirado.

981. segmentos posteriores.

982. seio costo frenico direito obliterado.

983. seio costo frenico esquerda obliterado posteriormente.

984. seio costo frenico esquerdo obliterado.

985. seio costo frenicos obliterados.

986. seio costo-frenico direito livre e esquerdo nao avaliavel.

987. seio costo-frenico direito obliterado (derrame pleural).

988. seio costo-frenico direito obliterado (espessamento pleu- ral ?).

989. seio costo-frenico direito obliterado (espessamento pleural a direita).

990. seio costo-frenico direito obliterado (espessamento pleural) vascularizacao pulmonar normal.

991. Seio costo-frenico direito obliterado e cupula frenica direita elevada.

992. seio costo-frenico direito obliterado por espessamento pleu- ral possivel derrame.

993. seio costo-frenico direito obliterado posteriormente (espes- samento pleural ?).

994. seio costo-frenico direito obliterado posteriormente.

995. seio costo-frenico direito obliterado, com espessamento pleural/derrames subpleurais.

996. seio costo-frenico direito obliterado.

997. seio costo-frenico direito raso com cupula retificada.

998. seio costo-frenico direito velado posteriormente.

999. seio costo-frenico diretito velado.

1000. seio costo-frenico esquedo obliterado.

1001. seio costo-frenico esquerdo obliterado (derrame pleural es- querdo).

1002. seio costo-frenico esquerdo obliterado (derrame pleural).

1003. seio costo-frenico esquerdo obliterado com elevacao da hemi- cupula diafragmatica.

1004. seio costo-frenico esquerdo obliterado posteriormente.

1005. seio costo-frenico esquerdo obliterado.

1006. seio costo-frenico esquerdo velado anteriormente.

1007. seio costo-frenico esquerdo velado posteriormente (espessa- mento pleural?).

1008. seio costo-frenico esquerdo velado posteriormente.

1009. seio costo-frenico esquerdo velado.

1010. seio costo-frenico obliterado (derrames pleurais).

1011. seio costo-frenico obliterado a direita.

1012. seio costo-frenico obliterado posteriormente a direita (espessamento pleural).

1013. seio costo-frenico obliterado posteriormente a direita.

1014. seio costo-frenico velado a direita.

1015. seio costofrenico direito obliterado.

1016. seio costofrenico direito velado.

1017. seio costofrenico esquerdo obliterado (derrame).

1018. seio costofrenico esquerdo obliterado, elevacao da cupula ipsilateral.

1019. seio costofrenico esquerdo obliterado.

1020. seios costo frenicos livres.

1021. seios costo frenicos obliterados (derrames).

1022. seios costo frenicos obliterados posteriormente.

1023. seios costo-frenico direito obliterado.

1024. seios costo-frenicos livres, cupula frenica elevada a direi- ta.

1025. seios costo-frenicos livres.

1026. seios costo-frenicos obliterados (derrame pleural).

1027. seios costo-frenicos obliterados (derrame subpulmonares?).

1028. seios costo-frenicos obliterados bilateralmente.

1029. seios costo-frenicos obliterados posteriormente (espessamen- to pleural).

1030. seios costo-frenicos obliterados posteriormente.

1031. seios costo-frenicos obliterados, elevacao da base esquerda.

1032. seios costo-frenicos obliterados.

1033. seios costo-frenicos velados (espessamento/pequenos derra- mes).

1034. seios costo-frenicos velados bilateralmente. 
1035. seios costo-frenicos velados posteriormente.

1036. seios costo-frenicos velados.

1037. seios costofrenico esquerdo obliterado.

1038. seios costofrenicos livres.

1039. seios costofrenicos obliterados e cupulas frenicas retifica- das.

1040. seios costofrenicos obliterados especialmente a direita.

1041. seios costofrenicos obliterados.

1042. seios costofrenicos parcialmente obliterados.

1043. seios costofrenicos posteriores obliterados.

1044. seios costofrenicos velados.

1045. seios costro frenico direito obliterado.

1046. seios e cupulas diafragmaticas livres, porem altas ( $r x$ expirado? obesidade?).

1047. seios e cupulas diafragmaticas livres.

1048. silhueta cardiaca aumentada + .

1049. Silhueta cardiaca aumentada $+/++$.

1050. silhueta cardiaca aumentada.

1051. silhueta cardiaca discretamente aumentada.

1052. silhueta cardicaca normal/aumentada.

1053. sinais compativeis com pneumectomia esquerda.

1054. sinais de fratura com reducao da altura do corpo vertebral de d8.

1055. sinais de hiperinsuflacao pulmonar associado a opacidade mal definida no terco medio do htd.

1056. sinais de hiperinsuflacao pulmonar caracterizadas por hipertrnapsrencia pulmonar aumento do diametro antero- posterior e retificacao das cupulas frenicas.

1057. sinais de hiperinsuflacao pulmonar.

1058. sinais de hipertensao pulmonar.

1059. sinais de hp.

1060. sindermofitos marginais dorsais.

1061. sindesmofitos dorsais.

1062. sinequia pleuro-diafragmatica a direita.

1063. sinias de hiperinsuflacao pulmonar.

1064. situs solitus.

1065. sombra mamaria direita nao visualizada (mastectomia a di - reita).

1066. sonda naso enteral com extremidade no estomago.

1067. stent cardiaco.

$1068 . \quad$ stent coronario.

1069. stent em arteria coronaria.

1070. stent metalico em topografia de coronaria direita.

1071. sugere ct com cortes finos.

1072. suturas metalicas no esterno.

1073. suturas metalicas.

1074. tecnica:

1075. tenue opacidade e traves densas na base do pulmao direito.

1076. tenue padrao reticular compativel com pneumoplasia inters- ticial.

1077. tenues calcificacoes na croca da aorta.

1078. tenues calcificacoes parietais na croca da aorta.

1079. tenues calcificacoes parietais na croca.

1080. torax normal.

1081. torax plano.

1082. traqueia desviada para a direita.

1083. trave densa na base direita.

1084. trave densa na base do hemitorax direito.

1085. trave densa na base do hemitorax esquerdo.

1086. trave densa na base do htd e no terco superior do hte.

1087. trave densa na base do hte.

1088. trave densa no campo pulmonar medio do hemitorax esquerdo.

1089. trave densa no terco medio do hemitorax esquerdo.

1090. trave densa no terco medio do pulmao direito.

1091. traves densas ambas as bases. 
1092. traves densas difusas.

1093. traves densas em apice e base pulmonar esquerda.

1094. traves densas em base e 1/3 medio do hemitorax direito.

1095. traves densas em bases pulmonares.

1096. traves densas infraclaviculares a direita.

1097. traves densas na base direita.

1098. traves densas na base do hemitorax direito.

1099. traves densas na base do hemitorax esquerdo (fibroatelecta- sia).

1100. traves densas na base do hemitorax esquerdo e terco medio do hemitorax direito.

1101. traves densas na base do hemitorax esquerdo.

1102. traves densas na base do pulmao direito com sinais de hipe- rinsuflacao pulmonar.

1103. traves densas na base do pulmao esquerdo.

1104. traves densas na base pulmonar direita.

1105. traves densas na base pulmonar esquerda.

1106. traves densas nas bases.

1107. traves densas no campo pulmonar medio direito e multiplos nodulos densos na base pulmonar direita.

1108. traves densas no Isd.

1109. traves densas no terco medio do hemitorax direito.

1110. traves densas no terco superior do hemitorax direito.

1111. traves densas no terco superior do hemitorax esquerdo.

1112. traves densas nos apices na incidencia de perfil.

1113. traves densas nos apices pulmonares.

1114. traves densas peri-hilar a esquerda e na base do hemitorax direito.

1115. traves e estrias densas no Isd.

1116. traves e nodulos apico-infraclavicular a esquerda.

1117. traves e nodulos densas no Isd (seguelas de tbc).

1118. traves finas em bases.

1119. traves finas na base esquerda.

1120. traves finas nas bases.

1121. traves na base do hemitorax direito.

1122. traves no terco medio do hemitorax direito.

1123. valvas metalicas aortica e mitral.

1124. vascul imagem cardiaca normal.

1125. vascularizaao pulmonar aumentada.

1126. vascularizacao aumentada.

1127. vascularizacao e hilos pulmonares aumentados.

1128. vascularizacao hilos pulmonares aumentados.

1129. vascularizacao peri-hilar aumentada.

1130. vascularizacao peri-hilar e hilos pulmoares aumentados.

1131. vascularizacao pulmonar aumentada nos campos superiores.

1132. vascularizacao pulmonar aumentada superiormente.

1133. vascularizacao pulmonar aumentada.

1134. vascularizacao pulmonar e hilar aumentados.

1135. vascularizacao pulmonar e hilos aumentados.

1136. vascularizacao pulmonar normal.

1137. vascularizacao pulmonar reduzida.

1138. velamento da base direita (atelectasias laminares).

1139. velamento de lid, segmento posterior.

1140. velamento discreto do seio costo-frenico esquerdo.

1141. velamento do hemitorax esquerdo.

1142. velamento do seio cardiofrenico direito.

1143. velamento do seio costo frenico direito.

1144. velamento do seio costo frenico posterior direito.

1145. velamento do seio costo-frenico direito.

1146. velamento do seio costo-frenico esquerdo (derrame) hilos e vascularizacao aumentadas.

1147. velamento do seio costo-frenico posterior direito.

1148. velamento dos seios costo-frenicos bilateralmente (derrame pleural). 
1149. velamento dos seios costo-frenicos bilateralmente (es - pessamento pleural).

1150. velamento dos seios costo-frenicos.

1151. velamento dos seios costofreicos posteriores.

1152. velamento dos seios costofrenicos.

1153. ventriculo direito hipertrofiado.

1154. ventriculo esquerdo hipertrofiado.

1155. volumosa hernia hiatal.

1156. xame realizado em equipamento de alta potencia, com tecnica de alta kilovoltagem, que fornece escala de contraste longa (baixo contraste). 


\section{APÊNDICE D - TERMOS EM PORTUGUÊS COM CLASSES SNOMED E IDENTIFICADORES}

ACHADO CLÍNICO

\begin{tabular}{|c|c|c|c|}
\hline ITEM & TERMO & CLASSE & ID \\
\hline 1 & artrose & AchCli_Trans & 399269003 \\
\hline 2 & atelectasia & AchCli_Trans & 46621007 \\
\hline 3 & bocio & AchCli_Trans & 3716002 \\
\hline 4 & bronquiectasias & AchCli_Trans & 12295008 \\
\hline 5 & calibre aumentado & AchCli_Trans & 51381009 \\
\hline 6 & calo & AchCli_Trans & 201040000 \\
\hline 7 & cardiomegalia & AchCli_Trans & 8186001 \\
\hline 8 & carinatum & AchCli_Trans & 38774000 \\
\hline 9 & cifose & AchCli_Trans & 268040001 \\
\hline 10 & cifose dorsal & AchCli_Trans & 298493002 \\
\hline 11 & cifose toracica & AchCli_Trans & 298493002 \\
\hline 12 & coracao aumentado & AchCli_Trans & 287272002 \\
\hline 13 & derrame & AchCli_Trans & 230690007 \\
\hline 14 & dimensoes normais & AchCli_Trans & 53461003 \\
\hline 15 & escoliose & AchCli_Trans & 111266001 \\
\hline 16 & escoliose dorsal & AchCli_Trans & 298494008 \\
\hline 17 & escoliose toracica & AchCli_Trans & 298494008 \\
\hline 18 & espessamento pleural & AchCli_Trans & 73725006 \\
\hline 19 & excavatum & AchCli_Trans & 391987005 \\
\hline 20 & fratura & AchCli_Trans & 125605004 \\
\hline 21 & hernia hiatal & AchCli_Trans & 84089009 \\
\hline 22 & hipertensao & AchCli_Trans & 38341003 \\
\hline 23 & lordose & AchCli_Trans & 249712000 \\
\hline 24 & neoplasia & AchCli_Trans & 55342001 \\
\hline 25 & obesidade & AchCli_Trans & 414916001 \\
\hline 26 & osteoartrose & AchCli_Trans & 396275006 \\
\hline 27 & osteopenia & AchCli_Trans & 312894000 \\
\hline 28 & parenquima pulmonar & AchCli_Trans & 370063005 \\
\hline 29 & pectus & AchCli_Trans & 38774000 \\
\hline 30 & pleural bilateral & AchCli_Trans & 425802001 \\
\hline 31 & pneumonia & AchCli_Trans & 233604007 \\
\hline 32 & pneumonite & AchCli_Trans & 205237003 \\
\hline 33 & pneumopatia intersticia & AchCli_Trans & 64667001 \\
\hline 34 & pneumotorax & AchCli_Trans & 36118008 \\
\hline 35 & schmorl & AchCli_Trans & 45181002 \\
\hline 36 & sequela & AchCli_Trans & 362977000 \\
\hline
\end{tabular}




\begin{tabular}{|c|l|c|c|}
37 & silicose & AchCli_Trans & 805002 \\
\hline 38 & torax normal & AchCli_Trans & 168733007 \\
\hline
\end{tabular}

ARTEFATO DE ARMAZENAMENTO

\begin{tabular}{|c|c|c|c|}
\hline ITEM & TERMO & CLASSE & ID \\
\hline 1 & laudo & ArtArm & 229059009 \\
\hline
\end{tabular}

CONCEITO DE LIGAÇÃO

\begin{tabular}{|c|c|c|c|}
\hline ITEM & TERMO & CLASSE & ID \\
\hline 1 & associadas & ConcLlg_Atr & 47429007 \\
\hline 2 & avaliacao & ConcLIg_Atr & 246228008 \\
\hline 3 & compativeis & ConcLIg_Atr & 7883008 \\
\hline 4 & configuracao & ConcLIg_Atr & 103377007 \\
\hline 5 & controle & ConcLIg_Atr & 246106000 \\
\hline 6 & decorrente & ConcLIg_Atr & 42752001 \\
\hline 7 & delimitada & ConcLIg_Atr & 75958009 \\
\hline 8 & escala & ConcLlg_Atr & 278111002 \\
\hline 9 & forma & ConcLIg_Atr & 300842002 \\
\hline 10 & investigar & ConcLIg_Atr & 116698004 \\
\hline 11 & livre & ConcLIg_Atr & 37837009 \\
\hline 12 & localizada & ConcLIg_Atr & 18720000 \\
\hline 13 & morfologia & ConcLlg_Atr & 116676008 \\
\hline 14 & nivel & ConcLIg_Atr & 276625007 \\
\hline 15 & origem & ConcLIg_Atr & 246062003 \\
\hline 16 & padrao & ConcLIg_Atr & 255711007 \\
\hline 17 & parte & ConcLlg_Atr & 260726005 \\
\hline 18 & posicao & ConcLIg_Atr & 246268007 \\
\hline 19 & regiao & ConcLlg_Atr & 410673009 \\
\hline 20 & relacao & ConcLIg_Atr & 263498003 \\
\hline 21 & situado & ConcLlg_Atr & 18720000 \\
\hline 22 & vasos & ConcLIg_Atr & 272735005 \\
\hline 23 & velamento & ConcLIg_Atr & 263506008 \\
\hline 24 & equipamento & ConcLlg_Atr & 246137000 \\
\hline
\end{tabular}

CONTEXTO SOCIAL

\begin{tabular}{|r|c|c|c|}
\hline \multicolumn{1}{|c|}{ ITEM } & TERMO & CLASSE & ID \\
\hline 1 & paciente & ConSoc_Pes & 116154003 \\
\hline
\end{tabular}

\section{ENTIDADE DE OBSERVAÇÃO}




\begin{tabular}{|r|l|c|c|}
\hline \multicolumn{1}{|c|}{ ITEM } & \multicolumn{1}{|c|}{ TERMO } & CLASSE & ID \\
\hline 1 & expiracao & EntObs & 58322009 \\
\hline 2 & mobilidade & EntObs & 246197003 \\
\hline 3 & processo & EntObs & 415178003 \\
\hline
\end{tabular}

\section{ESTRUTURA CORPÓREA}

\begin{tabular}{|c|c|c|c|}
\hline ITEM & TERMO & CLASSE & ID \\
\hline 1 & abaulado & EstCorp_AnormMorf & 413269001 \\
\hline 2 & achatamento & EstCorp_AnormMorf & 20601007 \\
\hline 3 & ateromatose & EstCorp_AnormMorf & 48434008 \\
\hline 4 & colapso & EstCorp_AnormMorf & 16277007 \\
\hline 5 & compressao & EstCorp_AnormMorf & 71173004 \\
\hline 6 & consolidada & EstCorp_AnormMorf & 9656002 \\
\hline 7 & deformidade & EstCorp_AnormMorf & 6081001 \\
\hline 8 & distensao & EstCorp_AnormMorf & 25322007 \\
\hline 9 & esclerose & EstCorp_AnormMorf & 43846000 \\
\hline 10 & estase & EstCorp_AnormMorf & 19685008 \\
\hline 11 & fibrose & EstCorp_AnormMorf & 112674009 \\
\hline 12 & fusao & EstCorp_AnormMorf & 31883006 \\
\hline 13 & ganglio & EstCorp_AnormMorf & 71307009 \\
\hline 14 & granuloma & EstCorp_AnormMorf & 45647009 \\
\hline 15 & hematoma & EstCorp_AnormMorf & 35566002 \\
\hline 16 & hernia & EstCorp_AnormMorf & 414403008 \\
\hline 17 & hiperinsuflacao & EstCorp_AnormMorf & 73578008 \\
\hline 18 & hipertrofia & EstCorp_AnormMorf & 56246009 \\
\hline 19 & hipoplasia & EstCorp_AnormMorf & 55199003 \\
\hline 20 & infarto & EstCorp_AnormMorf & 55641003 \\
\hline 21 & infiltrado & EstCorp_AnormMorf & 47351003 \\
\hline 22 & lesao & EstCorp_AnormMorf & 49755003 \\
\hline 23 & lipoma & EstCorp_AnormMorf & 46720004 \\
\hline 24 & opacidade & EstCorp_AnormMorf & 128305008 \\
\hline 25 & osteofito & EstCorp_AnormMorf & 88998003 \\
\hline 26 & rotura & EstCorp_AnormMorf & 125671007 \\
\hline 27 & sinequia & EstCorp_AnormMorf & 5242004 \\
\hline 28 & aorta & EstCorp & 15825003 \\
\hline 29 & arteria & EstCorp & 51114001 \\
\hline 30 & azigos & EstCorp & 244407004 \\
\hline 31 & bronquios & EstCorp & 19568000 \\
\hline 32 & cabeca & EstCorp & 302548004 \\
\hline 33 & cava & EstCorp & 244405007 \\
\hline 34 & coluna & EstCorp & 243930007 \\
\hline 35 & coracao & EstCorp & 302509004 \\
\hline
\end{tabular}




\begin{tabular}{|c|c|c|c|}
\hline 36 & coronaria & EstCorp & 41801008 \\
\hline 37 & costais & EstCorp & 24256007 \\
\hline 38 & costela & EstCorp & 113197003 \\
\hline 39 & costofrenico & EstCorp & 46297007 \\
\hline 40 & esofago & EstCorp & 181245004 \\
\hline 41 & espinhal & EstCorp & 243930007 \\
\hline 42 & esternais & EstCorp & 244107007 \\
\hline 43 & esternorrafia & EstCorp & 302522007 \\
\hline 44 & estomago & EstCorp & 181246003 \\
\hline 45 & flanco & EstCorp & 58602004 \\
\hline 46 & hemitorax & EstCorp & 422614002 \\
\hline 47 & infraclavicular & EstCorp & 181036008 \\
\hline 48 & intercostais & EstCorp & 93615001 \\
\hline 49 & ligamento & EstCorp & 182358004 \\
\hline 50 & linfonodo & EstCorp & 59441001 \\
\hline 51 & mama & EstCorp & 181131000 \\
\hline 52 & mamilo & EstCorp & 24142002 \\
\hline 53 & mediastino & EstCorp & 181217005 \\
\hline 54 & metafise & EstCorp & 33251002 \\
\hline 55 & mitral & EstCorp & 204586005 \\
\hline 56 & ombro & EstCorp & 16982005 \\
\hline 57 & parenquima & EstCorp & 113255004 \\
\hline 58 & pelve & EstCorp & 12921003 \\
\hline 59 & pelvica & EstCorp & 277113001 \\
\hline 60 & perihilar & EstCorp & 277113001 \\
\hline 61 & pulmao & EstCorp & 181216001 \\
\hline 62 & seio & EstCorp & 181131000 \\
\hline 63 & subpulmonares & EstCorp & 244380000 \\
\hline 64 & $\mathrm{t} 10$ & EstCorp & 181838008 \\
\hline 65 & $\mathrm{t} 11$ & EstCorp & 181839000 \\
\hline 66 & t3 & EstCorp & 181830001 \\
\hline 67 & $\mathrm{t} 5$ & EstCorp & 181832009 \\
\hline 68 & t6 & EstCorp & 181834005 \\
\hline 69 & t7 & EstCorp & 181835006 \\
\hline 70 & t9 & EstCorp & 181837003 \\
\hline 71 & tecidos & EstCorp & 85756007 \\
\hline 72 & tendao & EstCorp & 13024002 \\
\hline 73 & torax & EstCorp & 51185008 \\
\hline 74 & traqueia & EstCorp & 181213009 \\
\hline 75 & triculo & EstCorp & 21814001 \\
\hline 76 & tronco & EstCorp & 22943007 \\
\hline 77 & umeral & EstCorp & 181923006 \\
\hline 78 & valva & EstCorp & 181285005 \\
\hline 79 & veia & EstCorp & 181367001 \\
\hline
\end{tabular}




\begin{tabular}{|c|l|l|c|}
80 & ventriculo & EstCorp & 21814001 \\
\hline 81 & vertebra & EstCorp & 181817002 \\
\hline
\end{tabular}

FORÇA FÍSICA

\begin{tabular}{|c|l|c|c|}
\hline ITEM & TERMO & CLASSE & ID \\
\hline 1 & fogo & ForFis & 80032004 \\
\hline
\end{tabular}

OBJETO FÍsICO

\begin{tabular}{|c|c|c|c|}
\hline ITEM & TERMO & CLASSE & ID \\
\hline 1 & anel & ObjFis & 72070000 \\
\hline 2 & cama & ObjFis & 229772003 \\
\hline 3 & cateter & ObjFis & 19923001 \\
\hline 4 & cateter venoso & ObjFis & 303728004 \\
\hline 5 & clip & ObjFis & 77720000 \\
\hline 6 & desfribilador & ObjFis & 19257004 \\
\hline 7 & dispositivo & ObjFis & 49062001 \\
\hline 8 & dreno & ObjFis & 32712000 \\
\hline 9 & eletrodo & ObjFis & 16470007 \\
\hline 10 & eletrodo endocavitario & ObjFis & 360144005 \\
\hline 11 & eletrodo epicardico & ObjFis & 360071008 \\
\hline 12 & imagem & ObjFis & 257445002 \\
\hline 13 & leito & ObjFis & 229772003 \\
\hline 14 & marcapasso & ObjFis & 233184008 \\
\hline 15 & parafuso & ObjFis & 68183006 \\
\hline 16 & projetil & ObjFis & 86122002 \\
\hline 17 & protese & ObjFis & 53350007 \\
\hline 18 & protese valvar & ObjFis & 17107009 \\
\hline 19 & sonda & ObjFis & 7402007 \\
\hline 20 & stent & ObjFis & 65818007 \\
\hline 21 & stent cardiaco & ObjFis & 65818007 \\
\hline 22 & tubo & ObjFis & 83059008 \\
\hline
\end{tabular}

\section{ORGANISMO}

\begin{tabular}{|c|l|c|c|}
\hline ITEM & \multicolumn{1}{|c|}{ TERMO } & CLASSE & ID \\
\hline 1 & globosa & Org & 54326003 \\
\hline
\end{tabular}

PROCEDIMENTO

\begin{tabular}{|c|l|c|c|}
\hline ITEM & \multicolumn{1}{|c|}{ TERMO } & CLASSE & ID \\
\hline 1 & mastectomia & Proc & 172043006 \\
\hline
\end{tabular}




\begin{tabular}{|l|l|l|l|}
2 & pneumectomia & Proc & 49795001 \\
\hline 3 & ultrassonografico & Proc & 16310003 \\
\hline
\end{tabular}

\section{SUBSTÂNCIA}

\begin{tabular}{|c|l|c|c|}
\hline ITEM & \multicolumn{1}{|c|}{ TERMO } & CLASSE & ID \\
\hline 1 & metalica & Subs & 425620007 \\
\hline 2 & radiopaca & Subs & 385420005 \\
\hline
\end{tabular}

VALOR QUALIFICADOR

\begin{tabular}{|c|c|c|c|}
\hline ITEM & TERMO & CLASSE & ID \\
\hline 1 & anterior & ValQual_Qual & 9130008 \\
\hline 2 & massa & ValQual_Prop & 118538004 \\
\hline 3 & abaixo & ValQual_Qual & 255518004 \\
\hline 4 & abdominal & ValQual_Qual & 277112006 \\
\hline 5 & acentuada & ValQual_Qual & 46998006 \\
\hline 6 & adjacente & ValQual_Qual & 18769003 \\
\hline 7 & alargado & ValQual_Qual & 288467006 \\
\hline 8 & alta & ValQual_Qual & 75540009 \\
\hline 9 & amplos & ValQual_Qual & 255509001 \\
\hline 10 & analise & ValQual_Qual & 272389005 \\
\hline 11 & aneurismatica & ValQual_Qual & 255378009 \\
\hline 12 & angulo & ValQual_Qual & 1483009 \\
\hline 13 & apicais & ValQual_Qual & 43674008 \\
\hline 14 & aproximadamente & ValQual_Qual & 26175008 \\
\hline 15 & area & ValQual_Qual & 42798000 \\
\hline 16 & assimetria & ValQual_Qual & 4128009 \\
\hline 17 & aumentada & ValQual_Qual & 35105006 \\
\hline 18 & baixa & ValQual_Qual & 62482003 \\
\hline 19 & basal & ValQual_Qual & 57195005 \\
\hline 20 & bem & ValQual_Qual & 20572008 \\
\hline 21 & bilateral & ValQual_Qual & 51440002 \\
\hline 22 & borda & ValQual_Qual & 57183005 \\
\hline 23 & cada & ValQual_Qual & 419473009 \\
\hline 24 & calibre & ValQual_Qual & 81827009 \\
\hline 25 & central & ValQual_Qual & 26216008 \\
\hline 26 & cervical & ValQual_Qual & 261064006 \\
\hline 27 & cirurgica & ValQual_Qual & 83578000 \\
\hline 28 & clinico & ValQual_Qual & 58147004 \\
\hline 29 & cronico & ValQual_Qual & 90734009 \\
\hline 30 & decimo & ValQual_Qual & 28226006 \\
\hline 31 & delgadas & ValQual_Qual & 18043004 \\
\hline
\end{tabular}




\begin{tabular}{|c|c|c|c|}
\hline 32 & densa & ValQual_Qual & 255596001 \\
\hline 33 & descendente & ValQual_Qual & 255518004 \\
\hline 34 & dextro & ValQual_Qual & 24028007 \\
\hline 35 & diafragmatica & ValQual_Qual & 263734003 \\
\hline 36 & diametro & ValQual_Qual & 81827009 \\
\hline 37 & dificil & ValQual_Qual & 52925006 \\
\hline 38 & difusa & ValQual_Qual & 19648000 \\
\hline 39 & dimensoes & ValQual_Qual & 255506008 \\
\hline 40 & diminuida & ValQual_Qual & 1250004 \\
\hline 41 & direita & ValQual_Qual & 24028007 \\
\hline 42 & discais & ValQual_Qual & 427678004 \\
\hline 43 & distais & ValQual_Qual & 46053002 \\
\hline 44 & dorsais & ValQual_Qual & 255554000 \\
\hline 45 & ectasiada & ValQual_Qual & 255381004 \\
\hline 46 & elevacao & ValQual_Qual & 103720008 \\
\hline 47 & encistado & ValQual_Qual & 255283003 \\
\hline 48 & enteral & ValQual_Qual & 225770002 \\
\hline 49 & epicardico & ValQual_Qual & 261073003 \\
\hline 50 & espessa & ValQual_Qual & 246703001 \\
\hline 51 & esquerda & ValQual_Qual & 7771000 \\
\hline 52 & etaria & ValQual_Qual & 397669002 \\
\hline 53 & exame & ValQual_Qual & 302199004 \\
\hline 54 & extremidade & ValQual_Qual & 261782000 \\
\hline 55 & fina & ValQual_Qual & 18043004 \\
\hline 56 & focal & ValQual_Qual & 87017008 \\
\hline 57 & formando & ValQual_Qual & 35810008 \\
\hline 58 & fragmento & ValQual_Qual & 29140007 \\
\hline 59 & frontal & ValQual_Qual & 255549009 \\
\hline 60 & grande & ValQual_Qual & 255509001 \\
\hline 61 & grosseira & ValQual_Qual & 255344003 \\
\hline 62 & hemi & ValQual_Qual & 363665002 \\
\hline 63 & hilar & ValQual_Qual & 32381004 \\
\hline 64 & idade & ValQual_Qual & 397669002 \\
\hline 65 & identificado & ValQual_Qual & 7882003 \\
\hline 66 & implantacao & ValQual_Qual & 71861002 \\
\hline 67 & inalterado & ValQual_Qual & 260388006 \\
\hline 68 & incipiente & ValQual_Qual & 25721003 \\
\hline 69 & inferior & ValQual_Qual & 261122009 \\
\hline 70 & interna & ValQual_Qual & 260521003 \\
\hline 71 & intervertebrais & ValQual_Qual & 264042003 \\
\hline 72 & ipsilateral & ValQual_Qual & 255208005 \\
\hline 73 & irregular & ValQual_Qual & 49608001 \\
\hline 74 & laminar & ValQual_Qual & 88446008 \\
\hline 75 & levemente & ValQual_Qual & 425404009 \\
\hline
\end{tabular}




\begin{tabular}{|c|c|c|c|}
\hline 76 & ligeira & ValQual_Qual & 255510006 \\
\hline 77 & linear & ValQual_Qual & 50009006 \\
\hline 78 & linha & ValQual_Qual & 50009006 \\
\hline 79 & lombar & ValQual_Qual & 264082005 \\
\hline 80 & longa & ValQual_Qual & 255511005 \\
\hline 81 & longitudinal & ValQual_Qual & 38717003 \\
\hline 82 & longo & ValQual_Qual & 255511005 \\
\hline 83 & maior & ValQual_Qual & 263768009 \\
\hline 84 & marginais & ValQual_Qual & 112233002 \\
\hline 85 & media & ValQual_Qual & 228654009 \\
\hline 86 & medial & ValQual_Qual & 255561001 \\
\hline 87 & medio & ValQual_Qual & 260528009 \\
\hline 88 & melhor & ValQual_Qual & 3442003 \\
\hline 89 & menor & ValQual_Qual & 263796003 \\
\hline 90 & moles & ValQual_Qual & 37378003 \\
\hline 91 & multiplas & ValQual_Qual & 255204007 \\
\hline 92 & nodular & ValQual_Qual & 255288007 \\
\hline 93 & normais & ValQual_Qual & 17621005 \\
\hline 94 & novo & ValQual_Qual & 7147002 \\
\hline 95 & parcial & ValQual_Qual & 255609007 \\
\hline 96 & parietais & ValQual_Qual & 263832009 \\
\hline 97 & passo & ValQual_Qual & 398298007 \\
\hline 98 & pequena & ValQual_Qual & 255507004 \\
\hline 99 & pleurais & ValQual_Qual & 264148002 \\
\hline 100 & pode & ValQual_Qual & 429308001 \\
\hline 101 & possivel & ValQual_Qual & 371930009 \\
\hline 102 & postural & ValQual_Qual & 35799003 \\
\hline 103 & pouco & ValQual_Qual & 255507004 \\
\hline 104 & prejudicada & ValQual_Qual & 260379002 \\
\hline 105 & presenca & ValQual_Qual & 386397008 \\
\hline 106 & primeiros & ValQual_Qual & 255216001 \\
\hline 107 & proeminente & ValQual_Qual & 4657009 \\
\hline 108 & projecao & ValQual_Qual & 260419006 \\
\hline 109 & provaveis & ValQual_Qual & 2931005 \\
\hline 110 & reacao & ValQual_Qual & 263851003 \\
\hline 111 & realizado & ValQual_Qual & 398166005 \\
\hline 112 & reducao & ValQual_Qual & 289928003 \\
\hline 113 & regulares & ValQual_Qual & 17854005 \\
\hline 114 & restantes & ValQual_Qual & 74964007 \\
\hline 115 & reticular & ValQual_Qual & 255442003 \\
\hline 116 & retroesternal & ValQual_Qual & 255568007 \\
\hline 117 & secundaria & ValQual_Qual & 2603003 \\
\hline 118 & segmento & ValQual_Qual & 264193005 \\
\hline 119 & septais & ValQual_Qual & 255584008 \\
\hline
\end{tabular}




\begin{tabular}{|c|l|c|c|}
120 & sigma & ValQual_Qual & 421269006 \\
\hline 121 & subclavia & ValQual_Qual & 303578004 \\
\hline 122 & superficial & ValQual_Qual & 26283006 \\
\hline 123 & supra & ValQual_Qual & 352730000 \\
\hline 124 & terceiro & ValQual_Qual & 70905002 \\
\hline 125 & toracica & ValQual_Qual & 261179002 \\
\hline 126 & transparencia & ValQual_Qual & 261179002 \\
\hline 127 & traqueal & ValQual_Qual & 261180004 \\
\hline 128 & um & ValQual_Qual & 261180004 \\
\hline 129 & variante & ValQual_Qual & 40885006 \\
\hline 130 & vascularizacao & ValQual_Qual & 255451006 \\
\hline 131 & venoso & ValQual_Qual & 263925004 \\
\hline 132 & volumetrica & ValQual_Qual & 262266004 \\
\hline 133 & gastrica & ValQual_Qual & 264010009 \\
\hline
\end{tabular}

